Universidad NACIONAL DE LA PLATA

FACULTAD DE HUMANIDADES Y CIENCIAS DE LA EDUCACIÓN SECRETARÍA DE Posgrado

\title{
EL APRENDIZAJE MOTOR: UNA INVESTIGACIÓN DESDE LAS PRÁCTICAS
}

\section{Prof. Ángela Liliana Rocha Bidegain}

Tesis para optar por el grado de Magíster en Educación Corporal Director Dr. Ricardo Luis Crisorio, UNLP

La Plata, 14 de septiembre de 2012 


\section{Para Marcelo, Nahir y Sol, mis grandes amores.}




\section{AgRAdeCIMIENTOS}

Casi como un sueño, soñado durante tanto tiempo, hoy hay una tesis. Una tesis que no me pertenece enteramente, porque si este trabajo puede ser presentado es porque hubo otros, hay otros... siempre hay otros. Otros que impulsaron, que alentaron, que creyeron que era posible y acompañaron; otros que me plantearon preguntas, leyeron, sugirieron bibliografía, cuestionaron, esperaron y volvieron a preguntar. Otros que son contemporáneos y otros con los que discutí a pesar de no ser de esta época. A todos va mi agradecimiento: sin ellos esta tesis no hubiese sido posible.

En primer lugar, quiero agradecer al maestro Ricardo Crisorio, que me dirigió con la misma generosidad con la que siempre guía en dirección al saber; a Agustín Lescano, mi compañero y amigo, que siempre trabajó a la par, leyendo cada página, sugiriendo bibliografía y poniendo el hombro cuando hizo falta para que yo pudiera escribir; a María Eugenia Villa y Marcelo Giles, por sus lecturas, aportes y comentarios; a mis compañeros del GEEC (Grupo de Estudios en Educación Corporal) con quienes en este tiempo he compartido y discutido algunas de las ideas que hoy toman forma; a mis compañeros del equipo de gestión, porque mate de por medio escucharon mis monotemáticas conversaciones; a Gabriela Bravo de Laguna que dispuso de su tiempo para trabajar conmigo y a Claudia Capello que hizo posible que esta Tesis al fin se escribiera.

Vaya también mi reconocimiento a los alumnos del Profesorado y la Licenciatura que en todos estos años escucharon, plantearon preguntas y pensaron conmigo, y a Bruno Crisorio por su laboriosa paciencia.

Este trabajo va especialmente dedicado a mi familia por el amor con el que acompañan este largo viaje.

Á. Liliana Rocha Bidegain

La Plata, septiembre de 2012 


\section{ÍNDICE}

- INTRODUCCIÓN 6

- CAPÍTULO 1:ESTADO DE LA CUESTIÓN 13

1.1 La configuración de un campo de estudio en torno al aprendizaje motor: el Siglo XX y la preocupación por el Aprendizaje $\quad 13$

1.2 El Aprendizaje Motor 13

1.3 Principales teorías y perspectiva: las explicaciones sobre el Aprendizaje Motor 16

1.4 Fases del Aprendizaje Motor $\quad 24$

1.5 El Desarrollo Motor $\quad 29$

- $\quad$ CAPÍtULO 2:EN LA TEORÍA ESTÁ EL MÉTODO 37

2.1 La investigación del Aprendizaje Motor. El Siglo XX y las metáforas de la Naturaleza

2.2 Del Conductismo a la Teoría de los Sistemas Dinámicos: tres modelos, un paradigma

2.2.1 El método experimental en el estudio del Aprendizaje y del Desarrollo: la conducta observable como unidad de análisis

2.2.2 Las investigaciones cognitivistas y la analogía del ser humano con un procesador de información: la mente como unidad de análisis

2.2.3 Las investigaciones ecológicas y las teorías de los sistemas dinámicos: el ser humano como autorregulador de sus conductas motrices

- CAPÍTULO 3: NUESTRA OPCIÓN TEÓRICA Y METODOLÓGICA

3.1 Seguir la propia sombra $\quad 65$

3.2 Las Ciencias del Hombre y la Educación 71

$\begin{array}{ll}3.3 \text { Cauciones Metodológicas } & 77\end{array}$

3.4 Arqueología y Genealogía: presente, pasado y futuro del Aprendizaje Motor 80 
- $\quad$ CAPÍTULO 4: BIOPOLÍTICA Y EDUCACIÓN 84

4.1 De la enseñanza del Siglo XIX al aprendizaje del Siglo XX 84

4.2 El "modelo organicista": el individuo, la conciencia, la unidad y el problema de la $\begin{array}{ll}\text { gubernamentalidad } & 90\end{array}$

4.3 Del maestro al docente: de la asimetría del Siglo XIX al falso empoderamiento del alumno en el Siglo XX $\quad 99$

4.4 Del "modelo evolutivo" a la era del genoma 103

- CAPÍtulo 5 Reflexiones paRA la ELABORACión de UNA teORIA DE LA ENSEÑANZA. HACIA UNA BIOPOLÍTICA POSITIVA 109

5.1 El Aprendizaje Motor como dispositivo biopolítico 109

5.2 El esquema del Uno $\quad 111$

5.3 La Educación Corporal: hacia una biopolítica positiva 115

5.4 El esquema del "al menos tres" $\quad 124$

- CONCLUSIONES 129

- BIBLIOGRAFÍA 133 


\section{INTRODUCCIÓN}

1. La Matanza, Buenos Aires, marzo de 2012. Carlitos es un poco petiso y retacón, de piel trigueña y con algunos dientes picados por no haber visitado en sus 10 años de vida al odontólogo. Tiene algunos kilitos extra por una alimentación a base de harinas, es que "el viejo labura de changarín" y a veces "no hay para parar la olla". En el barrio donde vive Carlitos, como en tantos otros de la Argentina el "fulbo" manda, y él está justo en esa edad en que las cosas empiezan a definirse y ser guapo entre los guapos no es poca cosa. Hace unos días que se lo nota un poco preocupado, cabizbajo y meditabundo; es que el profe de la escuela le ha dicho que "para eso no sirve", que a lo sumo "el gordo al arco", que "el que nace para pito nunca será matraca", y otras cosas que no me quiere contar. Como madre me preocupa verlo así, los días pasan y su cara no mejora. Los otros días lo espié por la ventana cuando salió contento pa' el potrero de la esquina, y ahí se quedó sentado, mirando cómo los otros jugaban. Cuando volvió la ropa estaba intacta, le dije: "gordo que te pasa", "nada, qué querés que haga, gordo como estoy no puedo jugar a nada".

La Plata, diciembre de 1995. Soledad se acerca a su clase del último ciclo de jardín de infantes, lleva consigo 30 bolsitas de arena que con esfuerzo ha logrado preparar en su tiempo libre, que por cierto es muy poco. Mientras, espera que la maestra de la sala logre reunir a los 30 niños de 5 años que bulliciosos se niegan a formar la fila que los llevará al salón para realizar su clase de Educación Física como todas las semanas; piensa en la clase de Voleibol que dará por la tarde en el club Villa Nueva, y repasa una y otra vez los materiales que ha cargado en el baúl de su auto. Un gran silencio. Norma, la maestra, ha logrado ordenarlos, ya están en fila y listos para seguir su camino con Soledad.

Llegan al S.U.M. y comienza la clase. Soledad dispone las bolsitas por todo el lugar y sin dar mayores consignas "deja que los niños exploren el elemento". Algunos lo lanzan hacia arriba y tratan de atraparlo, otros se lo ponen sobre la cabeza e intentan caminar sin que se les caiga, un grupo de niñas la mece entre sus brazos simulando acunar a un bebé. Blanca, tímida y silenciosa, se ha quedado a un costado; quizás espera algo, una palabra, un gesto, algo que la invite a romper sus miedos y la mueva a unirse al grupo. Han 
pasado 10 minutos, se escucha "¡Listo, nos sentamos!, ¡Cada uno con su bolsita!, ¡Elegimos un lugar, ponemos la bolsita en el suelo y saltamos de un lado a otro!”, y sin más aclaraciones cada uno comienza a saltar una y otra vez esperando una nueva orden. “¡Alto, ahora la tiramos hacia arriba y tratamos de atraparla!”, obedientes hacen el intento, pero la bolsa rebelde se escurre entre sus manos. "¡Cambiamos, ahora la tiramos lejos y corremos a buscarla!" Soledad ensaya nuevas variantes, lo importante es gastar el elemento. Han pasado 35 minutos y la clase llega a su fin. Reúne a los niños y con esfuerzo forma una fila de niños y otra de niñas, que, en silencio o murmurando por lo bajo, recorren el jardín hasta llegar nuevamente a la sala donde los espera Norma para aprender matemáticas. Soledad guarda en su bolso el material y se retira del jardín, mientras piensa en que la clase que viene podría hacer lo mismo pero con aros. Sin embargo, una gran desazón la acompaña.

Resistencia, Chaco, julio de 2008. Tarde fría de invierno, bizcochitos sobre la mesa y un café a medio tomar en la sala de profesores de la Escuela Técnica Rafael Hernández. Dolores escucha atentamente a la directora que plantea el tema a debatir en la reunión: El trabajo interdisciplinario para la formación del hombre integral. La profesora de Filosofía comienza tímidamente a exponer su parecer, y habilita así a las profesoras de las demás disciplinas. Dolores calla, solo escucha atentamente esperando que se le ocurra algo inteligente para decir. Dolores calla y, en tanto, se pregunta a cada intervención cómo es que no se ha preguntado antes qué "hombre" quiere formar; si es que ha considerado siquiera por un instante a sus alumnos como un todo armónico, complejo e integral; si ha contribuido a su humanización; o por qué no vio antes la evidente relación entre el ecosistema y la clase de Educación Física que ella dicta. Dolores calla, y comienza a sentir a cada segundo que no ha hecho nada para contribuir a la humanización de sus alumnos. Poco a poco, siente que se va hundiendo en su silla y que nada sensato podrá salir de su boca, trata de asentir con la cabeza, de acompañar con gestos, pero no puede dejar de sentir agobio por no haber pensado en esto antes.

Son las 11:40 hs., y la reunión se da por terminada. Dolores suspira y siente alivio, pero las preguntas no le dan respiros ¿cómo se hace? ¿cómo llevo esto a mi práctica? 
2. Es claro que nuestro punto de partida es el presente y que los temas que nos interesan son del orden del aquí y ahora; sin embargo, es preciso recurrir al pasado para comprender ciertos aspectos de esta realidad que nos ocupa, es preciso mostrar que no es "natural" que las cosas sean de este modo, y eso no se logra sino revisando la historia, mostrando que nada de inocente hay en el modo en que se interpretan los hechos, que las "cosas" no han sido siempre así y que, por tanto, podrían ser de otro modo. Este cometido no se logra sin recurrir a su génesis, sin historizar, sin mostrar los nudos de esa trama que se ha ido tejiendo poco a poco para llegar a conformar este tapiz, esta Educación Física que nos tiene entrampados como la campanilla al perro de Pavlov.

Un poco verdad, un poco ficción, lo que describen las situaciones narradas en el punto 1 bien podrían ser situaciones reales escritas en primera persona por cualquier padre o por cualquier profesor o practicante de Educación Física, y cada una de ellas puede ser identificada con el discurso de la Educación Física y el Aprendizaje Motor. Lo que tienen de regular estas tres versiones es la idea de que existe una "naturaleza humana"; que hay algo así como "el hombre", universal y a-histórico, fijo e indiviso; que el cuerpo es equivalente al "organismo", a la carne, y por lo tanto también circunscrito al orden de lo natural; que el "medio" ambiente que condiciona y modela también aparece descrito en términos físicos, como marco contextual que rodea y enmarca, pero nunca que atraviesa. Por lo que tienen de regular estas tres perspectivas se podría decir que conforman un mismo dispositivo en torno al Aprendizaje Motor. Cada teoría cambia el nombre, cambia el modo de decirlo, pero no cambia el sentido; entonces me pregunto cómo se piensa y por tanto cómo se investiga el aprendizaje motor, cuál es el efecto que esto tiene en las prácticas, qué supone pensar en una naturaleza que dota de determinadas cualidades a unos y a otros, qué enmascaran las teorías del aprendizaje y del desarrollo motor, cuál es el soporte ideológico de estos modos de pensar, hacer y decir, y por último cómo se sale de este dispositivo.

El discurso del aprendizaje motor no carece de consecuencias sobre el cuerpo y todo lo que atañe al cuerpo. Sobre él encontramos, por ejemplo, el estigma del torpe y el talentoso; sobre él se inscriben las debilidades, los instintos, las pulsiones del animal devenido hombre, tanto como las afecciones del medio ambiente y de lo que lleva en la sangre. Sobre el cuerpo se inscribe también el peso de la identidad que congela y fija en términos esencialistas. La genealogía debe mostrar el cuerpo totalmente impregnado de historia, y la historia arruinando el cuerpo, pero el gran juego de la historia es para quien 
se apodere de las reglas, ocupe el puesto de los que las utilizan, se disfrace para pervertirlas, utilizarlas al revés y volverlas contra los que las habían impuesto. ¿Qué pasaría si se mostrara que nada de natural hay en el aprendizaje motor? ¿qué pasaría si, a sabiendas de que se trata de construcciones arbitrarias, de cortes y cesuras impuestos por la ciencia, alguien se atreviera a desafiar esas reglas impuestas y enseñar no de acuerdo con lo que marcan las "etapas" -como "deber ser"- sino a partir de la lógica del contenido a enseñar? ¿qué pasaría si el talentoso dejara de ser un tocado por la varita mágica y el gordo pudiera hacer algo más que ir al arco?

Contrariamente a lo que se ha hecho hasta acá, nuestro trabajo no supone mirar hacia adelante en términos de predicciones posibles en torno a una nueva teoría que explique "verdadera y efectivamente" cómo se aprenden las habilidades motoras; más bien, tomando al aprendizaje motor como objeto del discurso, intentaremos volver la vista hacia atrás, desandar el discurso del aprendizaje motor para romper con la idea establecida y reconstruir los modos y los procesos en que se han constituido esos campos de saber, poder y ética. Creemos que entonces sí podremos "desnaturalizar" estos discursos y cuestionarlos.

3. En el capítulo 1, "Estado de la cuestión", reconstruimos o, mejor, construimos un estado del arte en torno a las explicaciones del aprendizaje motor. Para ello, fue necesario armar nuestra propia línea de tiempo, problematizar la historia, cuestionar "lo dado". Cuando iniciamos este trabajo, advertimos que la historia funcionaba casi siempre mostrando continuidades lineales; por el contrario, nosotros nos encontramos con turbulencias, y casi como a contramano nos atrevemos a afirmar que el aprendizaje motor no aparece como "objeto de estudio" en el campo del discurso sino hasta bien entrado el Siglo XX, y que, por supuesto, no emerge "de la nada" sino como un problema histórico y político, como efecto de una "episteme". Recorreremos, entonces, las principales teorías y perspectivas -desde los planteos "conductistas" hasta los actuales "sistémicos"-, sus conceptos e ideas centrales, con el propósito de despejar aquello que de corriente aparece unido: Aprendizaje y Desarrollo. Nos encontramos con que no se trataba del mismo objeto (aunque en la bibliografía aparezcan casi siempre revueltos y pegoteados), no son los mismos autores ni se trata de las mismas fechas. ¿Por qué entonces no aparecen disociados? Por último, el recorrido de este capítulo nos permite afirmar que tres cuestiones se han acoplado para posibilitar la conformación del aprendizaje motor como 
campo de estudio específico: 1) el desarrollo de las neurociencias, el advenimiento de la psicología experimental y el desarrollo de distintas líneas como la psicología evolutiva, la psicología ecológica, la psicología del aprendizaje, el psicoanálisis freudiano y la psicología experimental; 2) el estudio de las diferencias individuales y la elaboración de teorías respecto del desarrollo infantil cuya unidad de análisis, el individuo aislado de otros individuos, conformará luego el área específica en torno al desarrollo motor; y 3) las investigaciones respecto de la influencia del medio ambiente y de la herencia en el comportamiento humano, de las cuales se desprende una serie de dispositivos destinados a la elaboración de pruebas de inteligencia y rendimiento que en nuestro caso se conocen bajo la forma de tests motores y psicomotores o evaluaciones para la detección de talentos naturales. Estas tres cuestiones se articulan entre sí con base en una única idea: existe una Naturaleza Humana que tiene una orientación prefijada y cobra sentido en relación a un porvenir y a un pasado.

En el capítulo 2 se desplegarán los tres discursos del Aprendizaje Motor que han dado cuerpo a nuestras prácticas. Tres modelos que en su intento por diferenciarse no han hecho más que reproducir un mismo patrón: tres modelos que responden a un único dispositivo discursivo. Se analizan las continuidades y las rupturas entre unos y otros en torno de la educación del cuerpo, para afirmar que el estudio del aprendizaje motor y del desarrollo motor a lo largo de todo el Siglo XX heredó de la Modernidad la preocupación por alinearse con las ciencias de la naturaleza y por reencontrar en el hombre la prolongación de las leyes que rigen los fenómenos naturales. La determinación de vínculos cuantitativos, la elaboración de leyes que operen a la manera de las funciones matemáticas, la puesta en marcha de hipótesis explicativas, son los intentos por los cuales se ha intentado aplicar, no sin artificio, una metodología que los lógicos creyeron descubrir en la génesis y el desarrollo de las ciencias de la naturaleza. Los postulados de estas teorías que quisieron y quieren ser un conocimiento positivo descansan sobre dos principios filosóficos: que la verdad del hombre se agota en su ser natural y que el camino de todo conocimiento científico debe pasar por la determinación de vínculos cuantitativos, la construcción de hipótesis y la verificación experimental. Por cuidar la objetividad, nos han llevado a querer reconocer en la realidad humana algo así como un sector de la objetividad natural, y a utilizar para conocerla métodos idénticos a los que las ciencias de la naturaleza podían proporcionar como modelo. Tenemos el convencimiento de que la única forma de volver inoperante este pensamiento naturalista, que se trasunta en las teorías del aprendizaje y del desarrollo motor, es entender cómo funciona para poder 
desactivarlo. Creemos que el proyecto de exactitud rigurosa debería ser abandonado, en tanto que ya no hace sentido esta forma de pensar (y por tanto de investigar) en el dominio de las ciencias humanas; por eso mismo, en el capítulo 3 tomamos posición en cuestión de método. Estamos convencidos de que en la teoría está el método, y que se investiga como se investiga porque se piensa como se piensa. Entonces, la posición teórica que se asume se refleja en todo el proceso de la construcción del objeto; en cada decisión, en cada recorte, en cada palabra elegida, lo metodológico está presente fijando posición de principio a fin. Sin embargo, es preciso describir nuestras herramientas y explicitarlas: la arqueología y la genealogía.

En el capítulo 4, el análisis de los discursos modernos nos lleva a afirmar, contrariamente a lo que se ha creído, que el nacimiento de la Educación Física moderna no formó parte de una estrategia disciplinaria, sino más bien biopolítica. Reconocemos en ella el brazo armado del biopoder que a partir del Siglo XIX hace entrar el cuerpo en la serie poblaciónprocesos biológicos-mecanismos reguladores-Estado, no ya como cuerpo individual sino como cuerpo colectivo y especializante; en este sentido, el discurso del Aprendizaje Motor no ha sido más que otro modo solapado del poder que se ejerce sobre el cuerpo. Por el trabajo analítico con las teorías del aprendizaje y del desarrollo motor seguiremos la sombra del hombre y la supuesta naturaleza humana desde el Siglo XIX al Siglo XX para llegar a la teoría de la herencia, más vulgarmente llamada del "talento". Si los individuos están predeterminados desde el nacimiento conforme a una vinculación biológica que ni la voluntad individual ni la educación pueden quebrantar, convirtiéndose en un destino del que nadie puede escapar, ¿cuál sería nuestro papel como maestros? Sin embargo, intentaremos demostrar que nada de inocente hay en estos supuestos: ¿qué implica sostener la idea de talentos naturales? ¿qué enmascaran todas estas teorías? ¿por qué y para qué se apela a la ideología de los dones? Si, como sostiene Bourdieu (2000:15), el funcionamiento del campo científico produce y supone una forma específica de intereses, si las practicas científicas no aparecen como "desinteresadas" más que por contraposición a intereses diferentes, producidos y exigidos por otros campos, y los conflictos epistemológicos son siempre conflictos políticos, analizaremos a qué intereses responde este modo de investigar y explicar en Educación Física. Se desplegará entonces la estrategia biopolítica de la modernidad, que abrió la puerta para justificar lo injustificable: el dominio, la opresión y la exclusión. Pero no basta con describir y denunciar. Toda investigación debe al mismo tiempo explicar y brindar alternativas, proponer una salida: de eso trata el capítulo 5. Si -como plantea Agamben- no es posible salirse de los 
dispositivos, entonces es preciso crear un dispositivo distinto que permita romper el circuito receptor-desinhibidor y subvertir los efectos del discurso del Aprendizaje Motor para pensar en los términos de una Teoría que se aparte del modelo del Uno para pensar en al menos Tres: maestro, aprendiz y saber, que puestos en relación hacen posible la Enseñanza y la Trasmisión. Por último, y a modo de cierre, dejaremos planteada la pregunta ¿qué es lo que podemos hacer con lo que hicieron de nosotros?, quizás pensar y pensarnos en los términos de un "saber que falta" trace nuevos horizontes. 


\section{CAPÍtulo I}

\section{ESTADO DE LA CUESTIÓN}

\subsection{LA CONFIGURACIÓN DE UN CAMPO DE ESTUDIO EN TORNO DEL APRENDIZAJE MOTOR: EL SIGLO XX Y LA PREOCUPACIÓN POR EL APRENDIZAJE}

Será la intención de este capítulo mostrar cómo se ha conformado el aprendizaje motor como área de estudio específica y cuáles son las principales teorías y conceptos relevantes y autores influyentes; en síntesis, intentaremos presentar el estado de la cuestión para luego, en los capítulos siguientes, poder extraer algunas categorías de análisis que nos permitan aproximaciones concluyentes respecto del sentido que tiene para la Educación y la Educación Física organizar la enseñanza a partir de las teorías del aprendizaje motor. Sin embargo, no es la intención de esta tesis hacer un trabajo de síntesis ni hacer un compendio de teorías, sino más bien trabajar con esas teorías como paradigmas en el sentido que le otorga Giorgio Agamben, es decir como

un objeto singular que, valiendo para todos los otros de la misma clase, define la inteligibilidad del conjunto del que forma parte y que, al mismo tiempo, constituye. [...] Más parecido a la alegoría que a la metáfora, el paradigma es un caso singular que es aislado del contexto del que forma parte sólo en la medida en que, exhibiendo su propia singularidad, vuelve inteligible un nuevo conjunto, cuya homogeneidad él mismo debe constituir (Agamben: 2009:24,25).

Esta definición de paradigma nos permitirá trabajar las teorías del aprendizaje motor de modo que, en ese movimiento de lo singular a lo singular, cada teoría se transforme en ejemplar de una regla general: las teorías del aprendizaje motor.

Como la tarea anteriormente descripta no puede formularse a priori, hemos decidido presentar en este primer capítulo un estado de la cuestión que nos permita no sólo situar las teorías y entender cuáles y cómo emergen, sino también extraer de ellas los conceptos fundamentales.

\subsection{EL APRENDIZAJE MOTOR}

En el estudio del aprendizaje motor son varios los autores que, a propósito de la revisión histórica de las teorías, proponen establecer una división también histórica, en períodos, aunque casi ninguno de ellos integra la bibliografía de consulta en Argentina; tal es el 
caso de Irión (1969), Adams (1992), Riera (1989), Schmidt y Lee (1999) y, más recientemente, el de la tesis doctoral de Batalla Flores, (2005).

En líneas generales, todos estos autores coinciden en delimitar el inicio de los estudios (fase temprana o primer período) en el Siglo XIX: Batalla Flores y Schmidt y Lee sitúan estas primeras investigaciones alrededor de 1820, Riera hacia1866, Adams e Irión en las décadas de 1880 y 1890 , respectivamente.

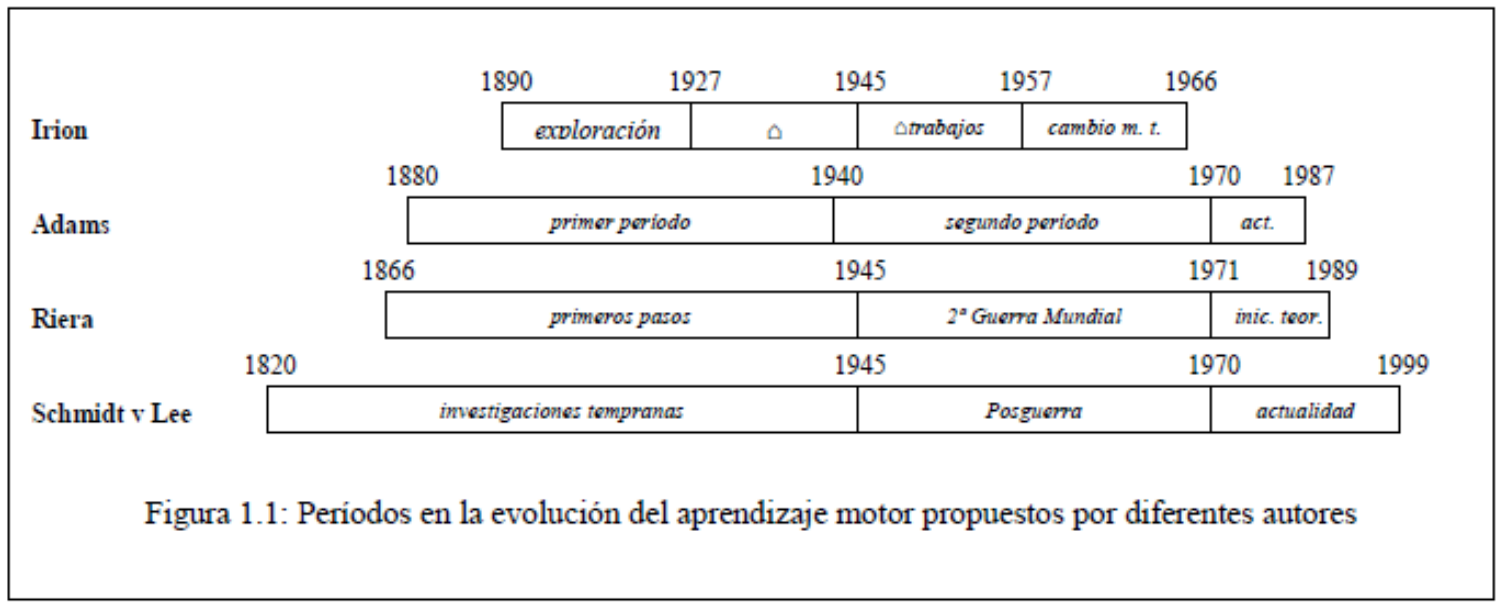

Cuadro 1: Extraído de Batalla Flores: 2005

El rastreo que nosotros hemos realizado de la bibliografía específica nos lleva a afirmar que el aprendizaje motor, como campo específico de investigaciones en el interior de la Educación Física y con producción propia de teoría, no se conforma hasta la segunda mitad del Siglo XX. Las investigaciones anteriores cobran algún sentido si podemos separar aquellas producciones que desde otros campos, como el de la Psicología o la Fisiología, han preparado el terreno para que luego pudieran tener lugar aquellas investigaciones más específicas en torno de lo motor y lo deportivo.

Las primeras investigaciones en el campo de la Educación Física comienzan a desplegarse alrededor de los años 1920, cuando Nicolai Bernstein crea el primer laboratorio ruso para el estudio de la motricidad; sin embargo, debido a la situación geopolítica del bloque socialista sus trabajos no se difundirán hasta muchos años después. Alrededor de 1930 aparecen los primeros laboratorios americanos que comienzan a indagar en torno del aprendizaje motor. Pero no será hasta después de finalizada la Segunda Guerra Mundial que comienzan a proliferar las investigaciones específicas que conformarán más tarde este campo de estudio. Resulta necesario, entonces, retomar el período de la Segunda Guerra Mundial y la Posguerra como un 
momento en el que aumenta el interés por investigar el aprendizaje motor; probablemente, la razón principal de este impulso deba buscarse en la necesidad de seleccionar y formar personal especializado en tareas con un fuerte componente perceptivo-motor, como el pilotaje de aviones, el manejo de armamento, la conducción de vehículos y el control de maquinaria (Adams, 1992; Cruz, 1997; Ruiz, 1994; Schimidt y Lee, 1999; Batalla Flores, 2005), al tiempo que los heridos que la guerra dejaba proponían también el desafío de ver cómo se seguía adelante en países donde gran parte de su población estaba formada por individuos amputados, ciegos, sordos o paralíticos. Para cubrir estas necesidades, los estados invirtieron grandes cantidades de dinero en investigaciones en torno a lo perceptivo y lo motor, hecho que atrajo a numerosos profesionales de la psicología al campo del aprendizaje motor, que así comenzaba a cobrar especificidad. En un principio, la investigación se centró en la selección del personal idóneo para desarrollar las diferentes funciones requeridas por el ejército. Se destaca el "Programa de Evaluación Psicomotriz de las Fuerzas Aéreas de los Estados Unidos", dirigido por Arthur Melton y en el que Edwin Fleishman (1982) desarrolló sus estudios sobre diferencias individuales y capacidades (Batalla Flores: 2005).

Será recién a partir de los años 1960, pero más específicamente en los años 1970 y 1980 , que logre armarse un campo de estudio cuyo objeto específico será el aprendizaje motor.

En este sentido podemos localizar tres grandes núcleos teóricos: a) Estados Unidos, b) la Unión Soviética y Alemania del Este, y c) Francia. Quedan afuera las producciones en habla portuguesa y española porque no resultan suficientemente significativas como para ser consideradas en sí mismas como polos de producción teórica en torno del aprendizaje motor, dado que, en general, recapitulan las producciones de los tres núcleos anteriores.Quizás sea por las secuelas económicas de la Segunda Guerra Mundial que este desarrollo teórico se dé en primer lugar en Estado Unidos, mucho más tardíamente en Alemania y la URSS y por último en Francia. A continuación podrá apreciarse (cuadro 2) cómo se ubica en el tiempo la producción teórica de los autores más relevantes. Incluimos aquí solamente las investigaciones que a nuestro criterio conforman el campo del aprendizaje motor. 


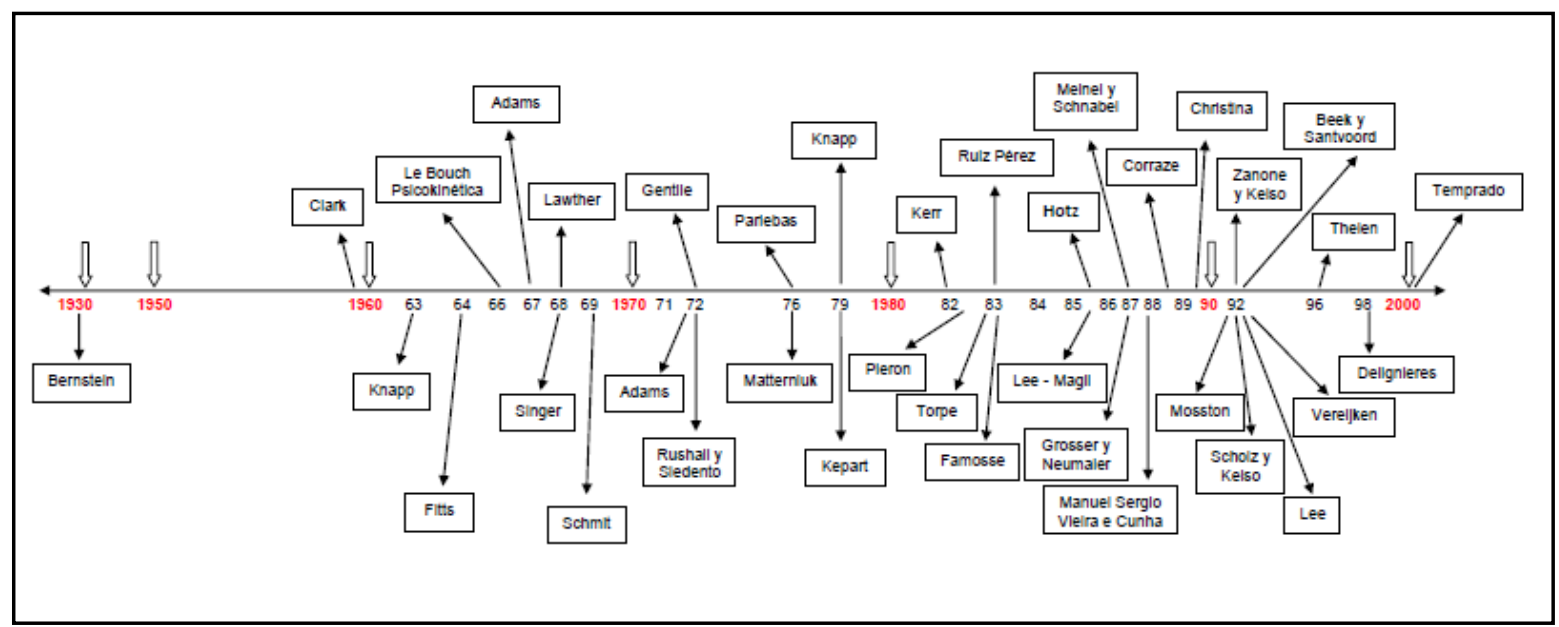

Cuadro 2:Nótese la concentración de trabajos a partir de 1960

\subsection{Principales teorías y PERSPECtivas: LAS EXPLICACIONES SOBRE EL APRENDIZAJe MOTOR}

En esta instancia, retomando los tres núcleos teóricos anteriores, nos interesa precisar qué se entiende por aprendizaje motor. En lo que respecta a la línea de trabajo americana, denominada motor learning, se sigue fundamentalmente el modelo de investigación en laboratorio cuyos iniciadores, alrededor de los años 1930, fueron John Lawther en la Universidad de Pensilvania y Clarence Ragsdale en la Universidad de Wisconsin. Lawther fue creador de uno de los primeros laboratorios americanos abocados al estudio del aprendizaje motor, que definió como "el cambio relativamente permanente de la conducta motriz de los alumnos, como consecuencia de la práctica y del entrenamiento" (Lawther, 1968 en Ruiz Pérez, 1997).Dentro de los precursores de la línea americana también podemos nombrar a Rushall y Siedentop (1972), que pondrán el acento en el rol del profesor como garante del aprendizaje. Aseguran estos autores que "para mantener un medio positivo de aprendizaje se debe reforzar positivamente la participación de los alumnos, dotarlos de experiencias de éxito, reforzar esfuerzos competitivos y reducir las experiencias de fracaso" (Ruiz Pérez, 1997:17).El profesor, entonces, debería considerar cuatro puntos para mantener un medio positivo de aprendizaje: a) reforzar positivamente la participación del alumno; dotarlo de experiencias de éxito; b) reforzar los esfuerzos competitivos; c) procurar refuerzos de tipo social; d) favorecer la participación en equipo y reducir al máximo las experiencias de fracaso. Además deberá seguir un conjunto de pasos para conseguir una estrategia de modelado: determinar qué se desea conseguir, es decir la conducta terminal; seleccionar él o los 
refuerzos que fortalecerán la conducta deseada; determinar la secuencia de la actuación; analizar y agrupar los diferentes segmentos de la conducta a enseñar; determinar el método para administrar las contingencias de reforzamiento; reforzar cada paso; valorar habitualmente la conducta terminal y reforzarla (Ruiz Pérez,1997:17).Tiempo más tarde, los avances en el campo de la Psicología y las Neurociencias harían virar el enfoque conductista y asociacionista que predominó en los laboratorios americanos hacia una posición cognitivista que coloca en el centro al sistema nervioso como servomecanismo encargado de analizar y procesar la información relevante para el aprendizaje: a esta nueva orientación teórica se la denomina teoría del procesamiento de la información. El procesamiento de la información se inscribe en el paradigma de la psicología cognitiva, que a su vez es tributario de un enfoque científico más amplio, la ciencia cognitiva, disciplina creada a partir de la convergencia de intereses de la lingüística, la informática, las neurociencias, las matemáticas -entre otras-, y cuyo objetivo es comprender los principios de la conducta cognitiva de los sistemas inteligentes, sean estos reales 0 abstractos, humanos o mecánicos. En el caso de la psicología cognitiva, se estudian los procesos cognitivos humanos utilizando una metodología experimental y tomando como verdad el supuesto fundamental de que las personas poseen representaciones mentales con eficacia causal (Norman, 1997; Bajo y Cañas, 1991; Pozo, 1996 en Batalla Flores, 2005). Dentro de esta perspectiva teórica podemos situar, por ejemplo, los trabajos de Jack Adams (1971) y Richard Schmidt (1975). Adams, con su "Teoría del Circuito Cerrado" (closed-loop) o "bucle cerrado", sostiene que "el papel de la práctica intencional y el conocimiento de los resultados obtenidos son la clave de un aprendizaje motor sin errores", ${ }^{\prime}$ lo que supone que el aprendiz debe generar un mecanismo detector de errores que favorezca los procesos de comparación entre los gestos realizados y el valor requerido para realizar dichos gestos. Todos los movimientos son realizados gracias a la existencia de un mecanismo de comparación que en forma continua permite al sistema contar con una referencia de exactitud que a su vez permite controlar la práctica mediante un trazo de percepción. Cuando un movimiento particular es realizado, el feedback inherente informa la situación particular de los miembros en el espacio. Estos estímulos dejan un rastro en el sistema nervioso central (el trazo perceptivo), y con la repetición sistemática el individuo mejora su perfomance, al tiempo que el trazo perceptivo se enriquece y amplía, constituyendo un tipo de colección de rastros. Como el aprendiz

\footnotetext{
${ }^{1}$ Cfr. Ruiz Pérez, 1997:38.
} 
comienza a mejorar sus respuestas después de los primeros intentos, el feedback proporciona información ligada al conocimiento de los resultados que tiende a mejorar la representación del movimiento correcto. A su vez, la colección de trazos perceptivos permite ajustar la calidad del feedback presente. Entonces, en los ensayos subsecuentes, el aprendiz irá ajustando la posición de su cuerpo de modo de reducir la diferencia entre el nuevo feedback y la colección de trazos al mínimo. Dado que el trazo perceptivo es más fuerte con cada nuevo ensayo, el conocimiento de resultados permite que los errores de actuación disminuyan con la práctica (Corraze, 1988; Ruiz Pérez, 1997; Gómez, 2005; Batalla Flores, 2005).

Por su parte, Richard Schmidt (1975), creador de la "Teoría del Esquema" como respuesta a la teoría de Adams, elaboró una nueva explicación en torno al concepto de esquema como estructura cognitiva que controla la realización del movimiento y que, en su perspectiva, toma el significado de una regla o fórmula. Según esta teoría, los alumnos y las alumnas, cuando practican de manera motriz, almacenan información que perfecciona un programa motor general (PMG) y no específico, lo que permite resolver el problema del almacenamiento en la memoria (Ruiz Pérez, 1984:40). Un PMG es, para Schmidt, un conjunto de coordinaciones motrices subyacentes a una clase de movimientos, a partir del cual se elaborarán los esquemas de respuesta motriz que especificarán el programa motor, lo que se traducirá en el exterior en un movimiento concreto, con consecuencias y resultados concretos (Corraze,1988; Ruiz Pérez, 1997; Gómez, 2005; Batalla Flores, 2005).Schmidt considera dos tipos de esquemas: el recall schema, responsable de la elección y producción de movimientos; y el recognition schema, responsable de la evaluación y ajuste de la respuesta. El primero se formará mediante la relación entre el resultado de una acción y los parámetros del medio utilizados para su producción. El individuo utilizará esta relación, establecida en el pasado, con condiciones iniciales similares a la situación en la que se encuentre para seleccionar la mejor respuesta. Primero, el individuo decide la respuesta determinando la naturaleza de las condiciones iniciales; posteriormente, con el recognition schema, estima las consecuencias sensoriales que se darán sise produce el movimiento. Desde esta perspectiva, todo esquema motor se reforzará mediante la variabilidad de la práctica (Schmidt, 1982 en Torrents Martins, 2005).

Por otra parte, en la línea de trabajo alemana, Kurt Meinel y Günter Schnabel (1988), establecen que 
el aprendizaje motores la apropiación (el desarrollo, adaptación y perfeccionamiento) de formas y modos de conducta, en especial de destrezas y acciones, cuyo contenido principal es el rendimiento motor. El objetivo del proceso de aprendizaje en la formación técnica deportiva y para toda ejercitación motora deportiva, es siempre llevar a cabo una tarea motora mediante la regulación del movimiento determinada por el objetivo de acción. [...] Aprendizaje motor significa entonces que, partiendo del objetivo propuesto, el resultado obtenido por medio de los movimientos está en primer plano, mientras que los conocimientos y capacidades intelectuales asociadas y necesarias para alcanzarlo son fundamentalmente un medio, un instrumento para lograr el objetivo motor del aprendizaje (184).

Cabe resaltar que, en la explicación de estos autores, el aprendizaje mental y el aprendizaje motor están combinados entre sí, condicionándose y desarrollándose el uno al otro, al tiempo que ambos colaboran en el desarrollo de la personalidad del ser humano. En términos generales,

aprender es un proceso básico en la vida del ser humano y supone la adquisición y perfeccionamiento de formas de conducta apropiadas mediante la confrontación activa del individuo con su medio, hecho que lo diferencia de los animales en tanto que ese medio en el que se desenvuelve, es un medio caracterizado por el desarrollo social y trasmitido en el que están presentes las fuerzas de la esencia humana (185).

Por su parte, Manfred Grosser y August Neumaier (1986) elaboraron el "modelo circular autorregulador del proceso de aprendizaje motor en el deporte", y entienden que el aprendizaje motor significa obtener, mejorar y automatizar las destrezas/técnicas deportivas como resultado de la ejecución repetitiva y consciente de las mismas, consiguiéndose progresos en el deporte sobre todo mediante una mejora de la coordinación entre sistema nervioso central y muscular. El objetivo del aprendizaje motor es siempre la creación de nuevas estructuras de coordinación y la optimización y fijación de las mismas. La realización de una técnica -sea en el proceso de aprendizaje, en el entrenamiento de la misma o en la aplicación en competición- se basa siempre en el proceso de la dirección y regulación del movimiento, es decir, la captación y asimilación de informaciones actuales (por ejemplo, retroalimentaciones propias precedentes a la realización del movimiento, instrucciones del entrenador, etc.), y en la comparación y relación de las mismas con el programa motor, al igual que con las experiencias motoras almacenadas en la memoria. Los factores más importantes implicados en el proceso de 
aprendizaje motor deportivo se pueden representar en el modelo cibernético: captación de información mediante los órganos sensoriales, asimilación de la información que llega a los centros nerviosos más elevados y formación de una imagen del movimiento (61-65). Para los autores, el papel del entrenador es fundamental en la organización del proceso de enseñanza.

De los autores franceses, Jean Le Boulch (1991b), creador de la Psicokinética ${ }^{2}$ y uno de los autores que más peso ha tenido en la Educación Física argentina a partir de la década de 1970, afirma que el aprendizaje es el resultado de la confrontación del organismo y del entorno dentro del proceso de adaptación. El canal de comunicación está representado por el sistema nervioso central, que es el intermediario entre los órganos sensoriales y los efectores musculares. El procesamiento de la información sensorial, en el origen de la respuesta motriz, puede localizarse en tres niveles diferentes de organización, lo que permitiría originar tres tipos de respuestas motrices: reflejas, automáticas e intencionales. En el ser humano, los automatismos vinculados con las funciones de relación deben estar organizados basándose en la experiencia motriz de cada uno. Esto significa que no existe un programa motor establecido en el nacimiento, sino simplemente potencialidades estructurales considerables, teniendo en cuenta la multiplicidad de relaciones sinápticas posibles. Por ello, y a medida que aumenta la maduración de las estructuras, la experiencia de adaptación provee al sujeto de un programa de respuestas automáticas (42). Entonces,

el aprendizaje permite adquirir nuevos "esquemas" de conducta, que la repetición fijará en forma de conductas estabilizadas: los hábitos. El hábito es, por ende, un producto terminal del aprendizaje y por ello se opone a los automatismos innatos y a la improvisación motriz en presencia de una situación nueva. Cuando el hábito motor es suficientemente complejo como para exigir la puesta en juego de movimientos coordinados, se le puede dar el nombre de "habilidad motriz" (9697).

El aprendizaje motor tiene una doble significación: 1) desemboca en la adquisición de una habilidad que nos lleva a la obtención de mejores resultados en el deporte (adquisición de un conocimiento), y 2) cuando el desarrollo del aprendizaje sigue un camino determinado,

${ }^{2}$ Concepto acuñado por Jean Le Boulch que refiere a la Educación Física en tanto que ciencia del movimiento humano, pero que para diferenciarse de ella debe forjar un método propio en función de su objeto particular: el movimiento. "La Psicokinética utiliza el movimiento humano para educar" (Le Boulch, 1991b:11). 
el esfuerzo para la adquisición del conocimiento requiere la puesta en marcha de un conjunto de funciones que mejoran con la repetición del ejercicio (37). Es muy importante en su teoría el concepto de esquema corporal, es decir, el "conjunto de estructuras neurológicas que procesan la información propioceptiva" (96-97).Este concepto reúne un conjunto de estructuras del sistema nervioso central que evolucionan hasta la pubertad y permiten el pasaje de una forma de procesamiento inconsciente de esta información a una interiorización consciente, condición necesaria para el pasaje de un aprendizaje por "ensayo y error" al "aprendizaje secundario provisto de representación mental". En la psicokinética leboulchiana conviven explicaciones provenientes principalmente de la fisiología por una parte y de la psicología por la otra; dice Le Boulch al respecto:

algunas veces utilizaremos un modelo fisiológico; otras un modelo psicológico de explicación y trataremos de ver en esos dos tipos de formalización dos fuentes de analogía, ejercitándonos en pensar en una según la otra, pero también limitando a veces una de ellas por medio de la otra (15).

En el plano de la estrategia educativa, el rol del educador no es el de trasmitir al sujeto que aprende la respuesta ideal sino el de hacer de mediador entre el sujeto y la situación.

Por último, en otra perspectiva se entiende al aprendizaje motor como el proceso según el cual "los seres vivos son sistemas complejos que poseen la capacidad de adaptarse al entorno, y en ocasiones, aprender" (Batalla Flores 2005:90-91).Este aprendizaje será, según Wallace (1996), producto de la autoorganización de situaciones alejadas del equilibrio, y supondrá en muchos casos la perdida de estabilidad de los patrones existentes y la emergencia de nuevos patrones de comportamiento. En palabras de Swinner (1996), "aprender no implica construir patrones de acción nuevos, sino con el trasfondo de sinergias, reflejos o patrones de coordinación intersegmentarios preexistentes" (49). En la idea de sistema los autores diferencian entre patrones que el sistema ya posee y los que debe o quiere adquirir, distinguiendo así entre la dinámica intrínseca (constituida por los modos preferidos de coordinación que ya existen en el sistema - estado inicial) y la dinámica extrínseca (constituida por las influencias específicas que suponen la tarea que se desea aprender y la intención de cambio respecto de la información relevante del entorno) que compiten y cooperan entre sí, lo que produce aprendizaje e incluso podría explicar para estos autores el fenómeno de la transferencia (cf. Batalla Flores:2005:43-50). 
Hagamos aquí un primer corte. En lo que a las definiciones de aprendizaje motor se refiere, es necesario reconocer distintos tipos de explicaciones; podemos ver que se pasa de una orientación basada en el resultado a una orientación basada en el procesamiento de la información primero y a una orientación sistémica después. Distinguimos entonces al menos tres grandes grupos de teorías:

a) TEORÍAS ASOCIACIONISTAS: fueron las primeras aproximaciones al estudio del aprendizaje motor y consideraban que el aprendizaje es producto de asociaciones, y entonces el aprendizaje motor se explica fundamentándose en las consecuencias de las respuestas y en su reforzamiento positivo o negativo. En este caso, el motor de la conducta se sitúa afuera del organismo, lo que supone que el aprendizaje siempre es iniciado y controlado por el ambiente.

b) TEORÍAS DEL PROCESAMIENTO DE LA INFORMACIÓN: posiblemente como consecuencia de los avances de la psicología y las neurociencias, se abandonaron las explicaciones conductistas y asociacionistas, considerando que se reducía a un rol pasivo a quien aprendía mientras que se cargaba todo el peso en quien enseñaba como facilitador, mediador o entorpecedor de los procesos de aprendizaje. Suponiendo que algo más debía ocurrir en el individuo que aprende, se impulsó la necesidad de conocerlo para poder enseñarle. Surgieron así las teorías que suponen que el aprendizaje motor se realiza por mediaciones del aprendiz respecto de la información proveniente del medio. Estas teorías, de base cognitivista, con el acento puesto en el procesamiento de la información, han sido las más difundidas en nuestro campo a partir de la década de 1970 y por ello profundizaremos un poco más en su análisis. El procesamiento de la información intentará cambiar la vieja fórmula de estímulo-respuesta o refuerzos positivosrefuerzos negativos para el logro de la conducta terminal por la idea de representaciones mentales que determinan la acción del sujeto; será la mente, entonces, la que determine la conducta a partir del análisis de la información que proviene del medio. A partir de este giro cobraron relevancia los mecanismos internos que se activan en cualquier situación de aprendizaje. Esta perspectiva teórica supone la existencia de un sistema individuo-medio donde la información, su captación, procesamiento y emisión de respuestas es de capital importancia. Siguiendo esta orientación, se ha tratado de explicar las conductas motrices interesándose por las transformaciones que sufre la información una vez que es captada (input), procesada (toma de decisión), y mostrada la respuesta (output) y su relación con cuanto pueda interferir en la canalización limitada de dicha información (ruido- 
incertidumbre), dado que siempre se actúa dentro de un ambiente estimulante. Este tipo de explicaciones pone el acento en el sistema nervioso como servomecanismo que procesa la información y, a partir de los datos analizados, selecciona la respuesta adecuada para efectuar la acción. Estas teorías se basan fundamentalmente en la cibernética y las neurociencias, y desde los años 1980 y 1990 han comenzado a ser criticadas.

c) TEORÍAS DE LOS SISTEMAS DINÁMICOS: surgen como reacción a las teorías del procesamiento de la información y tienen sus bases en la matemática y la física, sobre la base de la teoría formulada por Nicolai Bernstein en los años 1930. Si bien no han sido muy difundidas en la Argentina, a partir de la década de los años 1980 los artículos relacionados con el procesamiento de la información disminuyen de manera sustancial, mientras que aparece simultáneamente, y con mayor fuerza en los años 1990, esta nueva línea teórica y de investigación: las teorías dinámicas oscilatorias o teorías ecológicas, también denominadas action system, perspectiva dinámica, perspectiva ecológica, de los sistemas dinámicos, de los sistemas complejos o de la autoorganización. (Batalla Flores, 2005). El concepto de sistema dinámico proviene originariamente de la mecánica clásica y posee características muy deterministas derivadas de la mecánica de Newton y Laplace (Torrents Martins: 2005). ${ }^{3}$ Estas teorías sistémicas han afectado también a las ciencias del deporte, a partir de las cuales se organiza el entrenamiento desde una concepción sistémica que concibe al atleta como un sistema que funciona como un todo y que se ve afectado por el medio circundante (Gambetta, 1989; Solé, 1995 en Torrents Martins, 2005). Aparece así la idea del entrenamiento integrado, donde a través de la técnica y la táctica de la disciplina se desarrollan los aspectos físicos, psicológicos y visuales. Autores como Fidelus, Viru, Tschiene, Verchoshansky, García Manso o Ruiz y Sánchez Bañuelos conceptualizan el entrenamiento con estos términos, planteando el comportamiento del deportista de forma integrada con el ambiente en el que se desarrolla y no explicándolo únicamente desde el punto de vista biológico (Ruiz y Sánchez Bañuelos, 1997; García Manso, 1999; Tschiene, 2002 en Torrents Martins, 2005).

${ }^{3}$ Cf. Batalla Flores, 2005 y Torres Martins, 2005. 


\begin{tabular}{|c|c|c|}
\hline 1960 & $1970-1980$ & $1990-2000$ \\
\hline $\begin{array}{l}\text { Teorías conductistas y } \\
\text { asociacionistas }\end{array}$ & $\begin{array}{l}\text { Teorías cognitivas del } \\
\text { procesamiento de la } \\
\text { información }\end{array}$ & $\begin{array}{l}\text { Teorías interconductuales de } \\
\text { los sistemas dinámicos }\end{array}$ \\
\hline Aprendizaje & Aprendizaje & Aprendizaje \\
\hline $\begin{array}{l}\text { Sujeto } \\
\text { (E-R // Refuerzo positivo-Refuerzo } \\
\text { negativo) } \\
\text { Cambio relativamente permanente } \\
\text { en la conducta del aprendiz por la } \\
\text { experiencia o el entrenamiento. }\end{array}$ & $\begin{array}{l}\text { Sujeto } \longrightarrow \text { Medio } \\
\text { Representaciones mentales que } \\
\text { determinan la acción. Sistema } \\
\text { nervioso que recibe, procesa, } \\
\text { selecciona y emite respuesta. }\end{array}$ & $\begin{array}{l}\text { Sujeto } \longleftrightarrow \text { Medio } \\
\text { Sistema que funciona como un } \\
\text { todo y que se ve afectado por el } \\
\text { medio. }\end{array}$ \\
\hline $\begin{array}{l}\text { Rol del maestro: Administra los } \\
\text { refuerzos positivos o negativos } \\
\text { más adecuados. Busca } \\
\text { aprendizajes rápidos y efectivos. }\end{array}$ & $\begin{array}{l}\text { Rol del maestro: Controla el } \\
\text { grado de incertidumbre e } \\
\text { información. }\end{array}$ & $\begin{array}{l}\text { Rol del maestro: Identifica con } \\
\text { qué elementos del medio se está } \\
\text { relacionando al alumno y de qué } \\
\text { forma se relaciona. Es un } \\
\text { optimizador. }\end{array}$ \\
\hline Influencia: Psicología conductista & $\begin{array}{l}\text { Influencia: Psicología cognitiva - } \\
\text { Psicología evolutiva - } \\
\text { Neurociencias - Cibernética }\end{array}$ & $\begin{array}{l}\text { Influencia: Psicología ecológica - } \\
\text { Matemática - Física - Mecánica } \\
\text { Newtoniana }\end{array}$ \\
\hline
\end{tabular}

Por otra parte, las diferentes teorías señalan la existencia de momentos claramente diferenciables en el proceso de aprendizaje, a los que se denomina etapas o fases.

\subsection{FASES DEL APRENDIZAJE MotoR}

Según los estudiosos del tema, el aprendizaje motor no es un proceso que avanza de manera irregular o azarosa, sino que suele ocurrir de manera ordenada y lineal siguiendo una serie de fases o estadios que podrían ser identificados como comunes a todos los individuos. Así, se ponede relieve que todo nuevo aprendizaje se organiza de manera secuenciada y progresiva, integrando las estructuras aprendidas a las nuevas estructuras. Algunos de los autores más representativos distinguen las siguientes fases: Fitts y Posner (1969), cognitiva, asociativa y automática; Adams (1971), verbal motriz y motriz; Gentile (1972), exploratoria y fijación-diversificación; Meinel y Schnabel (1987), coordinación global, coordinación fina, y estabilización de la coordinación fina y desarrollo de la disponibilidad variable de la técnica; Le Boulch (1991a), fase exploratoria, de disociación y 
de estabilización de los automatismos. En todos los casos, se trata de un proceso continuo que hace que el alumno capte, elabore, programe, ejecute, corrija, capte nuevamente, reelabore, y vuelva a ejecutar. Según Famose y Durand (1988:72), la secuencia global del proceso de adquisición se describe como un conjunto de pasos, de los cuales son característicos los siguientes: a) percepción del alumno de lo que debe realizar, b) captación de los elementos importantes de la tarea en cuestión, c) elaboración de una forma grosera de comportamiento motor, d) realización de la respuesta, e) conocimiento de los resultados, f) elaboración de la tentativa siguiente, f) realización del segundo ensayo. Por su parte, Rigal (1990:51) distingue al menos 5 etapas: a) cognitiva: frente a una tarea motriz nueva el alumno y la alumna deben comprender la tarea, detectar y realizar un tratamiento de la información correspondiente y disminuir la incertidumbre; b) preparatoria: se planificará la respuesta; c) activa: se realizará la respuesta programada, lo que supone tensión y activación generalizada, creación de nuevos circuitos nerviosos e intervención del feedback intrínseco y extrínseco (conocimiento de los resultados); d) evaluativa: se evaluará la exactitud o error en la respuesta; e) mnésica: se reproduce el movimiento, se refuerzan nuevos circuitos, se interioriza la respuesta motriz, se crean engramas y se libera la conciencia. Laucken y Schick (1977:89) señalan que en todo aprendizaje se atraviesan los siguientes momentos: a) etapa de exploración: se confirma el problema y se busca y capta la información; b) etapa de planificación y programación: se formulan las hipótesis y se elabora un plan de acción, c) etapa de apreciación y elección: se aprecian las posibilidades de respuesta y se toma la decisión; d) etapa de ejecución: se realiza el movimiento programado; y e) etapa de verificación y revisión: se evalúa la acción y se reformula el problema (Ruiz Pérez, 1997:73-75).

Analizaremos de modo más detallado, y amanera de ejemplo, aquellos autores que influyen aún en el desarrollo de la Educación Física en la Argentina.

Meinel y Schnabel señalan que "el aprendizaje motor puede ser dividido en tres fases, de acuerdo al contenido predominante y el nivel coordinativo alcanzado. Estas fases representan siempre la estructura básica del proceso de aprendizaje motor, independientemente del tipo de deporte, de la edad y del nivel motor inicial" (1988:199). Para estos autores, la percepción y el procesamiento de la información tienen una importancia decisiva para la actividad del aprendizaje motor deportivo en cada una de las fases. 
Primera fase del aprendizaje: DESARROLlo DE LA COORDINACIÓN GLOBAL. Abarca el período que se extiende desde el primer contacto del alumno con el movimiento a aprender hasta un estadio en el cual puede ejecutar el movimiento bajo condiciones favorables. La capacidad de realización del movimiento en esta primera fase es todavía deficiente, y la estructura del movimiento sólo corresponde a los rasgos básicos de la técnica requerida. En este estadio surge una primera idea de movimiento que aún es difusa, incompleta y a veces errónea. A la comprensión de la tarea motora le siguen los primeros intentos de ejecución del movimiento. Los movimientos parciales aún no están combinados correctamente entre sí y la regulación de los miembros no transcurre en la forma deseada. El primer intento con éxito puede aparecer después de pocos intentos o puede requerir un tiempo prolongado; a esto le sigue normalmente una etapa en la que el educando tiene gran inseguridad para resolver la tarea, y recién después de seguir ejercitando la acción se alcanza el estadio de la coordinación global, en el cual se puede ejecutar casi siempre el movimiento correcto, pero sólo bajo condiciones normales y favorables, que se provocan y se mantienen constantes intencionalmente para el aprendizaje de movimientos nuevos.

SEGUNDA FASE DEL APRENDIZAJE: DESARROLLO DE LA COORDINACIÓN FINA. Esta segunda fase abarca el período entre el logro de la coordinación global hasta un estadio en el que el alumno puede ejecutar el movimiento casi sin errores. La estructura del movimiento corresponde en gran medida al objetivo motor, y de ese modo a la técnica pretendida. En este estadio se logra un nivel más elevado en el juego conjunto de las fuerzas, movimientos parciales y fases del movimiento. El desarrollo del movimiento se vuelve más armónico y cerrado, los movimientos adicionales superfluos desaparecen totalmente, la regulación de todo el movimiento se torna más controlada y exacta. La coordinación fina es una forma más racional, más adecuada y adaptada de moverse, sin la cual sería imposible tener rendimientos deportivos y laborales elevados. Frecuentemente se presentan estancamientos que provocarán más tarde rendimientos más elevados. El movimiento se presenta de manera fluida y sin "cortes" en la acción, resultando de suma importancia en esta fase el análisis y procesamiento de la información, proveniente de los órganos sensoriales y del habla, que conducentanto al perfeccionamiento del programa de acción, en especial de los subprogramas del plano regulativo interior y de la anticipación motriz, como al enriquecimiento de la memoria motriz. 
TERCERA FASE DEL APRENDIZAJE: ESTABILIZACIÓN DE LA COORDINACIÓN FINA Y DESARROLLO. Abarca desde el estadio de la coordinación fina hasta un estadio en el que el educando puede realizar el movimiento en forma segura y emplearlo en competencia siempre de manera exitosa. La facilidad que surge del movimiento y la sensación de prolijidad y de fluidez asociada al logro aparece generalmente junto con una sensación de alegría en el movimiento. El nuevo movimiento se debe realizar de ahora en más de modo tal que sea transferible a situaciones concretas diferentes, que sea disponible y que permita lograr un rendimiento deportivo elevado. El concepto de estabilización es tomado del campo de la biología, y significa que el organismo o la función correspondiente está organizado de forma tal que se puede adaptar a condiciones cambiantes y compensar perturbaciones dentro de un determinado campo de estabilización. La estabilización de la coordinación fina es, por consiguiente, un aumento del área de estabilidad de esa coordinación y no la fijación absoluta de determinadas estructuras coordinativas. Lo que se mantiene aproximadamente constante a través de esa estabilización coordinativa es la resolución adecuada de la tarea motora como resultado del movimiento. En el estadio final de la tercera fase de aprendizaje, la coordinación motriz alcanza una perfección funcional que agota las posibilidades individuales. Para ello, el requisito fundamental es la "extraordinaria plasticidad" de la actividad nerviosa superior y "sus colosales posibilidades"; gracias a ellas, el organismo es "un sistema que se autorregula en gran medida, que se conserva, regenera, corrige e incluso perfecciona a sí mismo" (190-198).

Jean Le Boulch (1991b:190-195) señala igualmente la existencia de tres fases en todo nuevo aprendizaje, a las que denomina:

FASE EXPLORATORIA GLOBAL. En ella, el sujeto se pone en contacto con el problema a resolver. Durante esta primera fase se van a producir asociaciones conscientes y sobretodo inconscientes entre las informaciones adquiridas acerca de la nueva situación y la experiencia personal del individuo. En la medida en que el individuo posee "esquemas" como resultado de una experiencia previa, podrá utilizarlos en presencia de una situación nueva. Es mediante su propia práctica y su propia exploración que el sujeto comprende la nueva situación y aprende a tratar las informaciones que obtiene de ella, y no mediante la referencia a la experiencia de los demás. Las explicaciones, las demostraciones, los films, no sólo no ayudan a la comprensión, sino que la entorpecen, ya que mientras realiza su propia experiencia el sujeto está obligado a considerar la de los demás, que nunca coincide exactamente con la suya. En esta fase el movimiento es difuso y las acciones 
motrices son imprecisas e implican numerosas contracciones inútiles, incluso contrarias al buen éxito.

FASE DE DISOCIACIÓN. Durante esta segunda fase, en cambio, el proceso de control y de inhibición actuará con el fin de seleccionar las contracciones eficaces. En este momento, se supone que el individuo ha comprendido la situación problema y la estructura de la respuesta motriz se afinará y se depurará con vistas a repeticiones posteriores. Se asocia esta fase con el aprendizaje por insight, por lo que se supone que el aprendiz es "consciente" del fin a alcanzar aunque las modalidades de las respuestas permanecen en el "nivel inconsciente". Si bien la comunicación simbólica y verbal no es un problema urgente, su importancia se manifiesta en determinados momentos del aprendizaje. Esa comunicación permite "una representación mental del modelo" a partir del cual se va a producir la remodelación de las estructuras preexistentes. A esto Le Boulch le llama "aprendizaje inteligente con programación consciente", lo que supone que la regulación propioceptiva se hará mediante el juego de los mecanismos de realimentación inconscientes, que estimularán, sobre todo, las estructuras subcorticales. Esta fase es de suma importancia ya que se fijará progresivamente el hábito motor. ${ }^{4}$

FASE DE ESTABILIZACIÓN DE LOS AUTOMATISMOS. Supone la última fase del proceso de aprendizaje, durante la cual los componentes del hábito motor acaban de automatizarse, y por tanto el movimiento se independizará casi por completo del control superior. Este automatismo supone la fijación de un nuevo "esquema" de actividad nerviosa en cuya organización interna la conciencia no debe intervenir. Ese nuevo automatismo será aplicado inconscientemente en actividades posteriores y nuevos aprendizajes. Sin embargo, Le Boulch distingue dos tipos de hábitos: los "rígidos", que son aquellos que se fijan por medio del entrenamiento, y los "plásticos" o "liberados", que gracias al control flexible permiten modificar de manera permanente algunos de los detalles de ejecución, en función de las condiciones variables de realización.

Es preciso señalar que en la bibliografía suele encontrarse, muchas veces de manera indiferenciada, explicaciones respecto del aprendizaje motor y del desarrollo motor, que a su vez prescriben acciones para la enseñanza. Nos vemos entonces en la necesidad de precisar que aprendizaje motor y desarrollo motor no significan lo mismo, y que es necesario separarlos para poder entender cómo es que estas teorías se han mantenido

\footnotetext{
${ }^{4}$ Lo que Le Boulch llama inconsciente no guarda relación con el inconsciente tal como lo entiende el psicoanálisis, sino que refiere a mecanismos de regulación automática.
} 
unidas y por qué aparecen en la bibliografía como un cuerpo teórico homogéneo. En términos generales, las teorías del aprendizaje motor incluyen explicaciones respecto del desarrollo humano y motor, en tanto que se considera fundamental entender cómo evoluciona el ser humano para poder explicar cómo aprende y qué habilidades es capaz de aprender acorde a su desarrollo.

\subsection{El DESARROLlo MOTOR}

Se entiende por desarrollo motor al área que estudia los cambios en las competencias motrices humanas desde el nacimiento a la vejez, los factores que intervienen en estos cambios y su relación con otros ámbitos de la conducta (Keogh, 1977). El desarrollo motor es un proceso de adaptación que determina el dominio de sí mismo y del ambiente, pudiendo el individuo ser capaz de utilizar sus capacidades motrices como medio de comunicación en la esfera social. Es un proceso en el que se manifiesta una progresiva integración motriz que comporta diversos niveles de intervención por parte del docente y de aprendizaje por parte de los alumnos. (Schilling, 1976).

Según Ausubel y Sullivan (1983) existen cuatro razones para estudiar el desarrollo motor:

a) favorecerá una mayor comprensión de los procesos humanos evolutivos e involutivos;

b) este conocimiento y comprensión permitirá una generalización, con precauciones, de dichos hallazgos para su posterior aplicación; c) permitirá evaluar la conducta humana de una manera más efectiva; y d) dotará de orientaciones teóricas a los diversos profesionales y promoverá futuras investigaciones (en Ruiz Pérez,1987).

Los estudios en torno del desarrollo motor realizados en el propio campo de la Educación Física se inician alrededor de 1940-1950. Sin embargo, son la consecuencia de investigaciones que se venían desarrollando desde mucho tiempo antes en otras áreas de investigación. Podríamos decir que ya desde finales del Siglo XVIII, Pestalozzi (17461827) y Herbart (1776-1841) introducían las primeras explicaciones en torno a cómo se suponía que evolucionaba el ser humano y tejían los primeros lazos con la cuestión educativa. A finales del Siglo XIX, este tipo de investigaciones comenzaron a proliferar bajo la influencia de la obra de Darwin (1877) sobre la evolución de las especies; incluso la descripción biográfica de uno de sus hijos sienta precedente para las investigaciones que vendrán a echar luz sobre la evolución ontogenética del ser humano. La teoría darwiniana y el naturalismo moderno han sido de gran importancia en torno de las explicaciones sobre el aprendizaje motor del siglo que lo sucede, y se entiende que este impulso forma parte del contexto en que emerge la Psicología Evolutiva como 
consecuencia de la atención renovada hacia el principio de crecimiento de la infancia. De este modo, en la Modernidad se conformó un saber sobre los procesos de crecimiento mental que desde entonces funciona como una premisa casi dogmática a la hora de estructurar la enseñanza. Ya hacia 1900 comienzan a elaborarse en el ámbito de la psicología los primeros instrumentos de medición en torno al rendimiento escolar con base en explicaciones evolutivistas. ${ }^{5}$

Siguiendo a Ruiz Pérez (1987:48-63), se distinguen básicamente dos grandes líneas de investigación. Por un lado está la perspectiva europea, con autores como de Ajuriaguerra (1959), para quien el desarrollo motor infantil atraviesa diversas etapas o estadios (organización del esqueleto motor, organización del plano motor y automatización) en los que se conforman las posibilidades de acción y se refina el movimiento, y que dependen de la maduración motriz y del desarrollo de los sistemas de referencia. Azemar (1969), por su parte, considera necesario potenciar la motricidad infantil pero sin imponer un dominio prematuro de técnicas específicas, y distingue dos etapas en el desarrollo motor infantil: una primera, que va desde 1 a 5 años, a la que denomina exploratoria y en la que dominan las holocinecias (movimientos en los que lo importante es el objetivo y no tanto la precisión); y una segunda etapa, de 6 años en adelante, en la que el desarrollo progresivo del cortex va permitiendo aprendizajes más complejos e ideocinéticos (en el movimiento no sólo importa el objetivo, sino también la precisión en su ejecución). Pikler (1987), a su vez, desarrolla un método que promueve la libertad de movimientos por sobre la restricción y el intervencionismo del adulto, para que el desarrollo motor del niño se lleve a cabo de forma espontánea según los dictados de la maduración orgánica y nerviosa. Respecto del papel del adulto, Pikler se plantea si abstenerse o intervenir, y sostiene que la autonomía debe desplegarse de una forma cómoda y segura sin la "enseñanza" del adulto. Del mismo modo, Le Boulch (1978-1984) sostiene que la motricidad infantil evoluciona a través de dos estadios: el primero, la infancia, momento en

\footnotetext{
${ }^{5}$ Hacia 1904 se constituye una comisión en el Ministerio de Instrucción Pública de Francia con el objetivo de elaborar un proyecto de Educación Especial. Binet es el encargado de elaborar un instrumento que permita distinguir con el mínimo error los retrasos escolares debidos a un déficit intelectual de los que pueden ser atribuidos a factores ambientales o a un déficit de escolarización previa. En 1905 Binet y Simon dan a conocer este instrumento, y hacia 1908, luego de revisado el instrumento, se concibe el desarrollo intelectual como la adquisición progresiva de mecanismos intelectuales básicos, de tal manera que el niño retrasado es aquel que no tiene adquiridos los mecanismos intelectuales que corresponden a su edad cronológica (Coll, 1988:35). Recién para 1948 Oseretsky elaborará en la URSS la primera batería de tests dedicados a evaluar la eficiencia motriz. Este tema de la medición (test) será desarrollado con mayor detalle cuando abordemos la relación individuo-medio e instrumentos de evaluación.
} 
que comienza la organización psicomotriz; el segundo, la pre-adolescencia y adolescencia, con la mejora de los factores de ejecución que dotan de una nueva dimensión a las prestaciones motrices. Por último, Da Fonseca (1987-1989) describe al desarrollo psicomotor infantil como el elemento imprescindible para el acceso a los procesos superiores de pensamiento. Al igual que los autores antes mencionados, distingue fases claramente diferenciadas en el desarrollo motor: la primera, que denomina "fase de movimiento", va desde el nacimiento hasta el año de vida; la segunda, denominada "fase de lenguaje", abarca desde los 2 a los 4 años; la tercera o "perceptivo motora" va desde los 4 a los 7,5 años; y la cuarta y última fase, de "pensamiento", desde los 7,5 en adelante. A su vez distingue cuatro tipos de inteligencia: neuromotora (0-2 años), sensomotriz (2-6 años), perceptivo-motriz (6-12 años), psicomotriz (12 años en adelante).

Por otra parte, en la perspectiva americana encontramos autores como Williams (1983), para quien el desarrollo perceptivo motor es una manifestación directa de la calidad del funcionamiento perceptivo-motor, que en términos prácticos se refiere al dominio de las conductas motrices básicas o fundamentales que permiten al sujeto una relación fructífera con su medio ambiente. Las conductas perceptivo-motrices pueden dividirse en cuatro etapas: conductas motrices globales, conductas motrices finas, conductas perceptivoauditivas-visuales-táctilo quinestésicas y conciencia corporal. Según Williams, estas conductas permitirían al sujeto una mayor comprensión de sí mismo como cuerpo, de sus movimientos y del medio ambiente que lo rodea. Cratty (1986), a su vez, elaboró la teoría o modelo de los 4 canales del desarrollo: perceptual, motor, verbal, cognitivo. Su teoría se apoya en resultados obtenidos en estudios neurológicos factoriales que destacan la diferenciación e integración de la conducta infantil y la posibilidad de desaparición de determinadas conductas que no son reclamadas por el ambiente para su utilización. Algunos de los temas destacados en su teoría son: el ritmo individual de desarrollo de las capacidades humanas, los cambios debidos a la edad, el papel del adulto en esos cambios, la existencia de períodos críticos para el desarrollo y el carácter motivante de la propia existencia motriz. Para Gallahue (1982), la evolución de la motricidad humana camina a través de diferentes fases caracterizadas por una serie de conductas motrices. Coloca en la base de una pirámide los movimientos característicos de los neonatos para llegar al punto máximo con la especialización motriz, en la que se ubica el dominio deportivo. Las fases intermedias son aquellas en que la motricidad infantil pasa de momentos de ajuste a momentos de especificación de las habilidades motrices que se 
consideran básicas (correr, saltar, lanzar, etc.) y sobre las que se apoyan posteriores adquisiciones.

A esta taxonomía de Ruiz Pérez podríamos agregar la perspectiva del desarrollo motor en relación a la emergente Teoría de los Sistemas Dinámicos. Podemos observar que los conceptos que se han usado en esta teoría para describir las características de los movimientos coordinativos y de su aprendizaje pueden ser aplicados también para comprender el desarrollo motor. Los conceptos de estabilidad, inestabilidad, transición, dinámica intrínseca o autoorganización son frecuentes ya en numerosos estudios sobre desarrollo. A su vez, estos estudios han influido en la investigación sobre aprendizaje que se ha explicado en el apartado anterior. Dentro de esta teoría se considera que los movimientos de los niños no son sólo producto de la acción del Sistema Nervioso Central, sino también de las propiedades energéticas y biomecánicas del cuerpo, de la influencia del medio y de los objetivos de la tarea, y que las relaciones entre ellos no serán jerárquicas sino autoorganizadas y no lineales (Thelen et al., 1996). La realización de una tarea nueva por un niño se interpreta como una transición, y para que se produzca se habrá pasado necesariamente por un periodo de inestabilidad. Dentro de este campo, una de las figuras más conocidas es Esther Thelen. La autora y sus colaboradores (Thelen y Smith, 1998) aplican la Teoría de los Sistemas Dinámicos para explicar el crecimiento y el desarrollo motor porque consideran que el resto de las teorías que se utilizan son descriptivas pero no explicativas, y que suelen obviar la participación de la intencionalidad. Por el contrario Thelen centrasu teoría en el proceso y en la formación de atractores estables a base de la repetición de patrones de actividad. Según la autora, los niños descubren la acción y las categorías de los objetos a través de las múltiples experiencias con ellos, que serán la causa y no el producto. Ésta explicación difiere radicalmente de la visión de Piaget, que asume que las modalidades sensoriales son diferentes y separadas, y que los reflejos forman parte del inicio de posteriores funciones motoras. Thelen defiende que hay separación y divergencia de información sensorial en muchas áreas funcionales, pero que están conectadas; en este contexto, la tarea del niño en el desarrollo no será la de construir, sino la de seleccionar de entre múltiples posibilidades de asociación. Se considera al movimiento como percepción y como un factor crítico en el desarrollo, que actúa como parámetro de control. El desarrollo no se ve como un proceso inevitable, consecuencia de tiempos genéticos de la maduración del cerebro, sino como una serie de contingencias y tareas. Cuando un niño está discapacitado para aprender sobre una modalidad del mundo, el sistema es capaz de 
encontrar otras modalidades; se observa una reorganización, y lo que cuenta no es el modelo sino la solución del problema. Se crean nuevos patrones que a su vez imponen condicionantes diferentes. Si se favorece la oportunidad para explorar se facilita la reorganización, ya que la exploración facilita la formación y estabilización de grupos neuronales. Se considera que en el desarrollo habrá periodos estables y otros de transición en los que el comportamiento es más inestable y fácil de ser modificado (Thelen et al., 1996 en Torrents y Martins, 2005). La solución definitiva no tiene porqué ser conocida de antemano por el aprendiz, sino que emergerá en un proceso de descubrimiento gradual por las complejas interacciones entre los componentes del comportamiento y la tarea. La práctica o la exposición a determinadas condiciones ambientales facilitarán el aprendizaje, aunque éste siempre estará en función de la dinámica intrínseca del sistema. Estas dos afirmaciones contrastan con la práctica basada en la observación de una solución impuesta o en la repetición de una respuesta que se supone que es la ideal y la misma para todos, por lo que desde esta perspectiva se ofrecen nuevas posibilidades y formas de aprender. El aprendizaje por descubrimiento, en el que el profesor o entrenador no dará unas instrucciones o un feedback preciso sino que reducirá el número de grados de libertad que el alumno debe controlar, es un ejemplo de esta propuesta. Si el niño no encuentra por sí mismo la solución, se buscarán estrategias para orientar el proceso, que incluso pueden incluir instrucciones verbales; de todas formas, siempre se conseguirá la formación de nuevas sinergias que mejorarán la coordinación motriz. No se propondrá ya el aprender patrones motores fijos ni se considerará el error de la forma tradicional, sino como una fluctuación del sistema necesaria para que se pueda producir la adaptación. Siguiendo estas premisas, se pueden plantear sesiones de aprendizaje en las etapas de desarrollo en las que se enfatice la variación de ejercicios para estimular los mecanismos individuales de adaptación. Tanto Thelen como el resto de los investigadores que siguen esta línea teórica proponen estudios de casos en vez de los tradicionales estudios de comparación de grupos; Thelen es capaz de defender que el desarrollo es lineal y cuantitativo, ya que se incrementa, pero a la vez es no lineal y cualitativo, ya que la complejidad lleva a nuevas formas y habilidades. Newell y Molenaar (1998) defienden también la no linealidad del crecimiento, teniendo en cuenta que se producen fases en las que no hay crecimiento alternadas con periodos cortos de crecimiento rápido. Estas conclusiones no pueden extraerse de los estudios tradicionales de grupos o longitudinales con demasiado espacio de tiempo entre tests, por lo que es una prueba más de la utilidad del nuevo enfoque. Los 
principios de la dependencia sensible a las condiciones iniciales; la equifinalidad, por la cual una multitud de caminos del desarrollo puede desembocar en el mismo resultado, con el consecuente ruido que esto comporta a los grupos experimentales; la preponderancia del proceso; y la posibilidad de que el comportamiento aleatorio esté condicionado por un atractor extraño irreconocible en un estudio de grupos, son otras razones que apoyan los estudios de casos para investigar los problemas del desarrollo motor.

A continuación mostraremos cómo se ubican en el proceso temporal los distintos autores que abonan a las teorías del desarrollo (Cuadro 3).

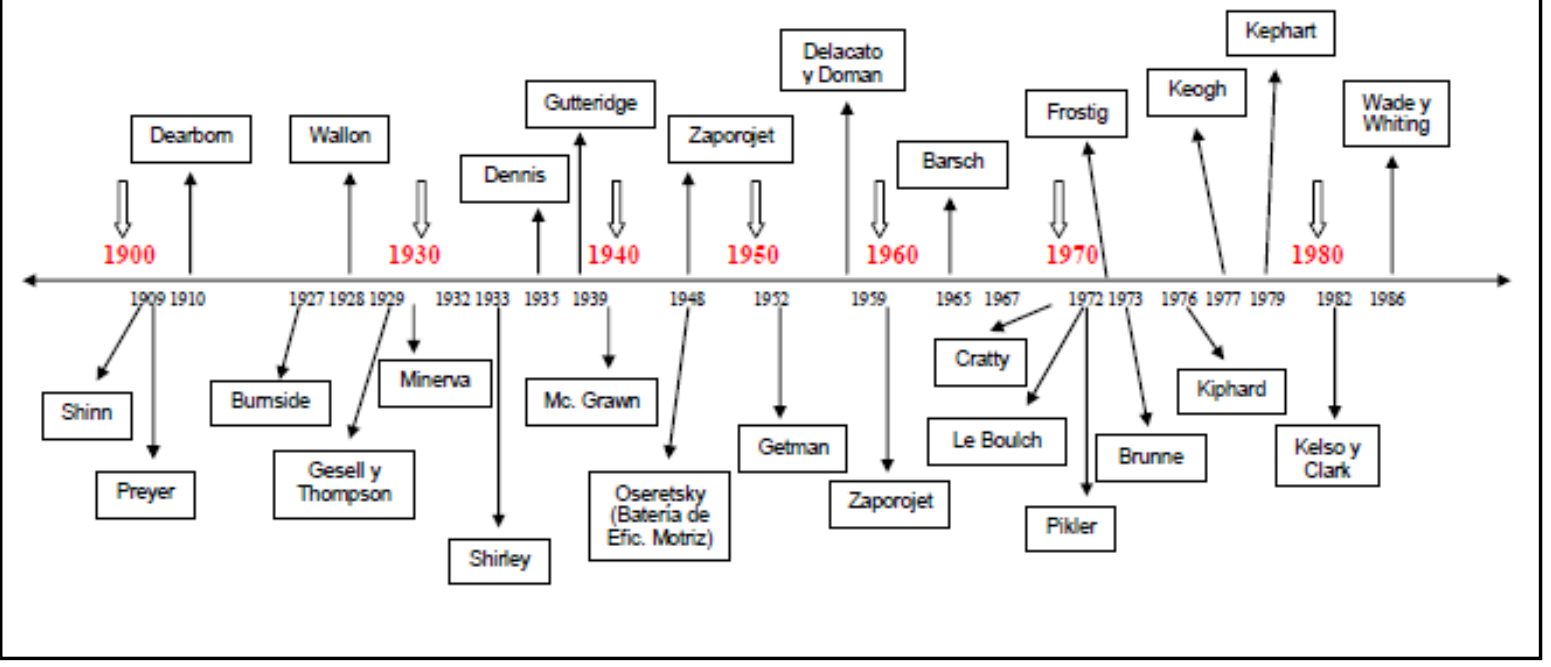

Cuadro 3: Línea temporal teorías del desarrollo motor

Por lo que hemos dicho hasta aquí, las teorías del aprendizaje no pueden ser comprendidas por fuera de las investigaciones en torno del desarrollo humano y motor; por esta razón, a lo largo de la tesis tomaremos como categorías de análisis conceptos que pueden ser identificados de manera indistinta tanto para el caso del aprendizaje motor como para el caso del desarrollo motor. En este cruce entre las explicaciones que intentan fijar patrones de desarrollo y patrones de aprendizaje, éste último será entendido como un proceso mediante el cual el individuo adquiere, organiza y utiliza la conducta motriz, y refiere a un asunto que tiene lugar mediante la experiencia y/o la práctica y que provoca cambios observables en la conducta que harán que la motricidad del individuo evolucione de forma progresiva hacia niveles cada vez más elevados de complejidad y eficacia a lo largo de su vida. Se entiende en estos términos que el aprendizaje motor 
acompaña el desarrollo ontogenético ${ }^{6}$ del individuo que permitirá a su vez la adquisición de determinados aprendizajes acordes a la etapa "evolutiva" en que éste se encuentra. Por otra parte, se fijan y establecen no solamente los aprendizajes que pueden ser adquiridos a cada edad sino también diferentes prescripciones para la enseñanza.

Retomaremos luego, de un modo más particular, algunos de los conceptos hasta aquí señalados.

Un primer asunto a señalar de este estado del arte es que, en nuestra consideración, tres cuestiones se han acoplado para posibilitar la conformación del aprendizaje motor como campo de estudio específico: 1) el desarrollo de las neurociencias, el advenimiento de la psicología experimental y el desarrollo de distintas líneas como la psicología evolutiva, la psicología ecológica, la psicología del aprendizaje, el psicoanálisis freudiano y la psicología experimental; 2) el estudio de las diferencias individuales y la elaboración de teorías respecto del desarrollo infantil cuya unidad de análisis, el individuo aislado de otros individuos, conformará luego el área específica en torno al desarrollo motor; y 3) las investigaciones respecto de la influencia del medio ambiente y de la herencia en el comportamiento humano, de las cuales se desprende una serie de dispositivos destinados a la elaboración de pruebas de inteligencia y rendimiento que en nuestro caso se conocen bajo la forma de tests motores y psicomotores o evaluaciones para la detección de talentos naturales. Estas tres cuestiones se articulan entre sí con base a una única idea: existe una Naturaleza Humana que tiene una orientación prefijada y cobra sentido en relación a un porvenir y a un pasado.

Como es a partir de estas cuestiones que se retomará el análisis de las teorías en los capítulos siguientes, cabe al respecto hacerse algunas preguntas: ¿qué esconden estas teorías? ¿cuáles son sus efectos sobre las prácticas? ¿qué supuestos teóricos y epistemológicos las sostienen? ¿a qué intereses políticos y económicos son funcionales?

\footnotetext{
${ }^{6}$ La Ontogénesis refiere al proceso evolutivo de un individuo dentro de la especie, mientras que la filogénesis que refiere al proceso evolutivo de la especie. Estos conceptos son de suma importancia en toda la bibliografía analizada y cobran relevancia en la explicaciones en torno al aprendizaje de las habilidades motoras, en tanto que se supone que existen ciertas habilidades que son propias de la especie, llamadas "Habilidades Motoras Básicas" o "Patrones Motores Fundamentales" como el caminar, correr, saltar, lanzar, etc. Estas habilidades serán estudiadas en términos individuales fijando patrones de desarrollo "normal" para cada período de edad. Abundan estudios que dan cuenta (de manera universal) de cómo evoluciona la motricidad mes a mes y año a año. Estos parámetros de normalidad desencadenan una serie de patrones "universales" que permiten clasificar a los individuos como "normales" en el caso de que se ajusten al modelo o "anormales" (retrasados, poco habilidosos, etc.) en el caso de no ajustarse a lo establecido.
} 
¿cuál es el lugar del maestro (docente) cuando la preocupación está puesta en quien aprende? 


\section{CAPÍtUlo II}

\section{En la teoría está el MÉtodo. Ciencia e ideología}

Cada vez más hay poderes interesados por nuestro poder de pensar. $Y$ entonces, si nosotros buscamos saber cómo se hace el que pensemos como pensamos, es a fin de defendernos contra la incitación, solapada o declarada, de pensar como se quisiera que pensemos.

(Cangilhem, El cerebro y el pensamiento)

\subsection{LA INVESTIGACIÓN DEL APRENDIZAJE MOTOR. EL SIGLO XX Y LAS METÁFORAS DE LA NATURALEZA}

La primera cuestión que nos interesa abordar en este capítulo es cómo se ha investigado el aprendizaje motor y, por tanto, cómo se ha llegado a formular estas teorías que, a la vez, funcionan como leyes generales que intentan explicar y predecir el comportamiento humano.

En palabras de Bryant Cratty, "una teoría del desarrollo de la conducta humana es un intento de explicar y predecir las formas en que el infante y el niño cambian en función de la edad" (1982:29). A partir de esta afirmación, uno bien puede preguntarse por qué se intentaría explicar pero, fundamentalmente, por qué se intentaría predecir el comportamiento humano; qué intereses se han puesto en juego a lo largo del Siglo XX para que la educación y la Educación Física asumieran el mandato de llevar adelante investigaciones con este objetivo; cómo se ha investigado el aprendizaje y el desarrollo motor, con qué métodos, y cuál ha sido la teoría que ha operado de soporte en la elección de los métodos y técnicas para investigar el aprendizaje motor.

Si, como dice Archenti,

el método, en cada investigación, es el resultado de un diseño específico que se elabora básicamente a partir de dos elementos: los conceptos que provee la teoría y las características de los datos disponibles. La adecuación entre el andamiaje conceptual y los datos construidos por el investigador constituye un fenómeno único, por lo que en cada investigación particular se produce una recreación metodológica, resultado de la aplicación de los criterios de adecuación a los objetivos de investigación y a la información recolectada (2009:67), 
entonces teoría y método conforman una unidad constitutiva del quehacer científico. La teoría establece el marco conceptual dentro del cual se desarrollará el método, y éste fija el horizonte de aplicabilidad de la primera en el marco del desarrollo técnico y tecnológico alcanzado. La particular relación entre teoría, método y datos le otorga a cada investigación un carácter específico. De este modo, en la realidad del proceso de investigación cada investigador es a la vez un teórico y un metodólogo que adecua las técnicas y herramientas con que cuenta (o las nuevas que desarrolla) a fin de alcanzar las metas que se propone. En esta tarea, la íntima relación entre teoría y método define los límites de la actividad del conocer, capturada dentro del aparato conceptual teorético y condicionada en sus formulaciones por potencialidades del método.

Como ha dicho Foucault (en Ball,1990:43), los discursos son prácticas que configuran sistemáticamente los objetos de los que hablan, que nunca se refieren a objetos, ni los identifican, sino que los construyen y al hacerlo ocultan su propia invención. Del mismo modo, limitan las posibilidades de pensamiento al combinar las palabras en formas específicas, excluyendo o desplazando otras combinaciones posibles. En la medida en que los discursos se construyen por exclusiones e inclusiones, por lo que no debe decirse tanto como por lo que sí puede ser dicho, mantienen relaciones antagónicas con otros discursos, otras posibilidades de significado, otras peticiones, derechos y posturas. La pregunta sería entonces por qué, en un momento dado, entre otras cosas que podrían decirse, sólo se dicen algunas; por qué aparecen determinados enunciados y no otros. Es claro que el mundo se percibe de forma diferente en discursos distintos.

Si los resultados de una investigación dependen del complejo de elecciones que el investigador ha realizado a lo largo de todo el recorrido, tenemos la expectativa de que, partiendo de un lugar diferente del que la Educación Física nos tiene acostumbrados, y marcando un recorrido distinto, arribaremos a un lugar "otro" del que han llegado todas las investigaciones realizadas hasta aquí en el campo del aprendizaje motor.

En este capítulo intentaremos dar cuenta de cómo se ha investigado el aprendizaje motor; en el capítulo siguiente procuraremos dar cuenta de nuestras propias elecciones teóricometodológicas. En el primero de los casos es necesario retomar la cuestión abierta en el capítulo primero respecto de las teorías del aprendizaje y del desarrollo motor como un sistema trinitario, en el que grandes líneas teóricas (teorías conductistas, teorías cognitivistas y teorías ecológicas) en ambos campos (el del aprendizaje y el del desarrollo) representan un único modelo/paradigma teórico y por tanto metodológico. Esto 
supone que nuestra investigación no intentará representar una cuarta línea, sino más bien un segundo modelo/paradigma muy distinto al anterior. El nuestro trata de un modelo teórico, un paradigma (en el sentido kuhniano) radicalmente distinto, que representaría, entonces sí, una verdadera alternativa.

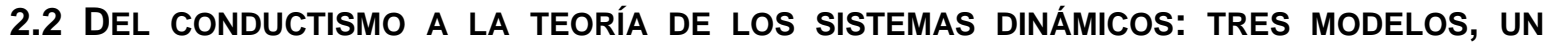 PARADIGMA}

A los efectos de analizar la cuestión metodológica es necesario establecer, primero, un panorama más amplio que nos permita comprender la cuestión de la elección del método no como un hecho fortuito ni antojadizo, sino como el emergente de una episteme, es decir, de un conjunto de relaciones que vinculan diferentes tipos de discursos y corresponden a una época histórica dada (Foucault, 1966:65), ${ }^{7}$ y que permitió en este caso a los investigadores del Siglo XX formularse determinadas preguntas y no otras, construir determinados objetos y no otros, y por lo tanto investigar utilizando determinados métodos y no otros.

Si bien nuestro objeto de estudio específico son las teorías del aprendizaje motor, hemos dicho en el capítulo anterior que éstas quedan a la vez configuradas por dos componentes: por una parte, las teorías del aprendizaje motor propiamente dicho; por la otra, las teorías del desarrollo motor. Unas y otras conforman el área del aprendizaje motor. Para los fines de nuestros análisis, las tomaremos como un exponente de una única manera de pensar al hombre.

Dice Ruiz Pérez:

diferentes autores del ámbito del aprendizaje se han preocupado por el estudio de las conductas infantiles. Para ellos las conductas infantiles están gobernadas por una serie de leyes del aprendizaje iguales para todos, lo que significa que la aplicación de dichas leyes explicaría el desarrollo, incluido el desarrollo motor (1991:40, las cursivas son nuestras).

El niño aparece aquí como universal, unificado y natural, reducido por un lado a la formula todos por igual, y por el otro a la versión más perfeccionada del animal. En tanto se remite a una cuestión de desarrollo, nuestra condición humana se supone gobernada por las leyes de la naturaleza.

\footnotetext{
${ }^{7}$ Todos esos fenómenos de relaciones entre las ciencias o entre los diferentes discursos científicos constituyen lo que se denomina episteme de una época. Cfr. Foucault, 1966.
} 


\subsubsection{El Método experimental en el estudio del apRendizaje Y EL DesarRollo MOTOR: LA CONDUCTA OBSERVABLE COMO UNIDAD DE ANÁLISIS}

Hemos dicho ya que estas investigaciones específicas de nuestro campo han sido subsidiarias del desarrollo que han seguido las investigaciones tanto en el campo de la psicología científica como de sus derivadas -por ejemplo, la psicología de la educación, la psicología del aprendizaje y la psicología del desarrollo. Veamos pues cómo es que éstas se organizan.

Para sintetizar el nacimiento de la Psicología, podríamos decir que si bien, como sostiene Canguilhem, "los verdaderos responsables del advenimiento de la psicología moderna como ciencia del sujeto pensante, son los físicos mecanicistas del Siglo XVII" (Canguilhem, 1956:4), el término Psicología, con el sentido de ciencia del yo, data del Siglo XVIII. Al acuñarse este nombre, se inicia un proceso que culmina con la conformación de la psicología científica a principios del Siglo XX. Con la adopción del trabajo de laboratorio y el uso del experimento, la psicología dio los primeros pasos que la conducirían a una definitiva institucionalización como disciplina independiente. Esta situación hace comprensible que los historiadores de la psicología señalen la fundación de dicha disciplina en el año 1879, año de la fundación del primer laboratorio de psicología experimental del mundo, creado por Wundt (1832-1920) en la Universidad de Leipzig. Sin embargo, este dato no es más que a los efectos de fijar un hito, porque la psicología experimental ya estaba en el ambiente, ${ }^{8}$ y fueron una serie de hechos los que posibilitaron su emergencia. La psicología encuentra entonces en el método experimental propio de las ciencias físicas y naturales el instrumento para separarse definitivamente de la filosofía, adoptando el experimento como modo de alcanzar conocimientos ciertos y objetivos. $^{9}$

Un experimento es una pregunta que hacemos a la naturaleza. Su respuesta dependerá de qué tan bien esté formulada la pregunta, y en parte de la posibilidad que tengamos de entender la respuesta dada por la naturaleza. La

\footnotetext{
${ }^{8}$ En varios escritos del siglo XIX previos a 1879 hemos encontrado claras referencias a la psicología experimental, y veremos luego que necesariamente tuvieron que darse determinadas condiciones de posibilidad durante todo este siglo para que pudiera aparecer algo así como la psicología que ocupará el centro de la escena en el siglo XX.

${ }^{9}$ Para más detalles sobre el nacimiento de la psicología experimental se puede consultar: Sáiz, Milagros, 2009, "Nacimiento de la Psicología científica" en Historia de la psicología, UOC, Barcelona. También se encuentran referencias en Coll (1998), Ardila (2001), Ferrater Mora (1964), Santamaría (2009), Carretero (2005) y Pozo (2006).
} 
experimentación en Psicología es igual a la experimentación en otras ciencias, en biología, en física, en química, etc., sin embargo el refinamiento de cada una de las disciplinas científicas varía con su desarrollo; la psicología es una de las ciencias más desarrolladas y más exactas a pesar de su juventud y a pesar de la creencia popular contraria. Los datos recogidos por el psicólogo experimental están a la altura de los datos recogidos por el físico o el biólogo, pueden matematizarse en forma semejante y permiten formular leyes generales del comportamiento, como en otras ciencias se deducen leyes de la materia orgánica o inorgánica (Ardila, 2001:6).

Al amparo de esta psicología experimental, durante las primeras décadas del Siglo XX el fenómeno educativo comienza a captar la atención de los psicólogos, y se fue conformando poco a poco un área de atención e interés en torno de los problemas de aprendizaje, tests mentales, medidas de comportamiento, psicología del niño y clínica infantil; todos ellos, referidos directa o indirectamente a la problemática educativa escolar, sintetizan lo que se llamará la psicología de la educación.

Dentro de lo que se denominó corriente conductista, los referentes más representativos son Watson (1878-1958), Pavlov (1849-1936), creador del condicionamiento clásico, y Thorndike (1874-1949), que aplicó y explicó la teoría del condicionamiento operante ideada por Skinner. A Thorndike se debe la primera sistematización consistente del estudio del aprendizaje, ya que en 1905 publicó Elements of Psicology, obra en la que formula una serie de leyes de aprendizaje que son fruto de las investigaciones realizadas tanto con seres humanos como con animales (Coll, 1998:26). Es preciso reconocer también la influencia de otro teórico del campo de la psicología del niño, el suizo Edouar Claparède (1873-1940), quien, siguiendo el postulado según el cual es necesario conocer al alumno para educarlo mejor, desarrolló investigaciones de laboratorio que lo condujeron a una concepción funcional de la psicología, la cual "intenta, ante todo, considerar los fenómenos psíquicos desde el punto de vista de su función en la vida, de su lugar en el conjunto de la conducta en un momento dado" (Claparède, 1972:39, en Coll, 1998:39).

Entre 1930 y 1960 apareció lo que se denomina neo-conductismo, corriente que -aun siguiendo los principios de Watson- adopta una postura que resulta menos dogmática y menos compleja. Dentro de esta corriente debemos destacar a Hull (1884-1952) y a Skinner (1904-1990), cuyos aportes a partir del entrenamiento de palomas resultaron 
sumamente relevantes y fueron retomados en el campo de la Educación Física por Lawther, Rushall y Siedentop para elaborar explicaciones sobre el aprendizaje motor.

De la psicología conductista se adoptan los criterios epistémico-metodológicos que permitirán investigar en torno de lo motor, a saber:

a) Monismo físico y metodológico: sus principios son contrarios a las ideas que sostienen el dualismo mente-cuerpo; al mismo tiempo, niegan la existencia de la mente en cualquier forma, ya como sustancia, ya como entidad conceptual que controla la conducta. El único método científicamente válido es el método experimental que garantizaría la objetividad en la investigación.

b) Positivismo: sólo es válido lo observable y cuantificable. Las conductas han de ser tratadas como conductas observables y no como expresión de estados profundos inobservables.

c) Ambientalismo: sitúa el principio motor de la conducta fuera del "organismo". El aprendizaje siempre es iniciado y controlado por el ambiente.

d) Empirismo: la conducta es fruto de la experiencia aprendida del sujeto, no de factores innatos o genéticos.

e) Atomismo: lo mismo que una molécula, la conducta humana consta de átomos y se analiza científicamente descomponiéndola y componiéndola en los estímulos y respuestas elementales.

f) Equipotencialidad y continuidad filogenética: las leyes del aprendizaje son igualmente aplicables a todos los ambientes, especies e individuos. Existe una sólida continuidad en la forma en que la conducta es aprendida y mantenida en todas las especies animales y en el hombre.

Estas primeras investigaciones fueron estrictamente desarrolladas en los laboratorios, con el método experimental como soporte. En aras de poder dar cuenta de los cambios en la probabilidad de aparición de la conducta, se desarrollaron estudios con base positivista que buscaban explicaciones de tipo causal sobre el aprendizaje, aptas para ser expresadas como leyes generales o declaraciones universales del tipo "siempre que A, entonces B". Para ello, los métodos de investigación debían asegurar principalmente el control de las variables y la uniformidad de los resultados. Entonces, se estudió el aprendizaje motor a partir de una metodología deductiva, una metodología en la que las hipótesis pueden ponerse a prueba contra la observación empírica y los casos particulares deducirse de una ley o de un sistema de leyes. En pos de una pretendida 
objetividad, se coleccionaban datos y más datos acerca de la presencia o ausencia de determinadas conductas relacionadas con ciertos parámetros, pero nada se explicaba del sujeto del aprendizaje (Crisorio, 2005). Se buscaba explicar el aprendizaje a partir de las causas y efectos que los estímulos generan en el individuo o, en su defecto, del papel que podía desempeñar el profesor como reforzador del aprendizaje, en tanto ejerza un riguroso control para mantener un medio positivo de aprendizaje (modelado de la conducta), suponiendo de este modo que los resultados obtenidos en el laboratorio podían ser replicados en situaciones reales de aprendizaje.

A pesar de la posición ambientalista, un concepto que sin embargo cobra cierta relevancia es el de maduración: para los autores adscriptos a estas teorías,

en el desarrollo infantil no se puede establecer una distinción cierta entre la madurez y el aprendizaje porque los factores adquiridos se aseguran solamente por medio de una modificación de una estructura ya existente. Toda madurez involucra un aprendizaje y en todo aprendizaje infantil existe una madurez hereditaria (Lawther, 1968:15).

Por ello, aunque se los considera ambientalistas, el debate sobre filogénesis y ontogénesis resulta de una importancia suprema en todos sus escritos; es incluso este debate el que permitirá sostener la idea de que los movimientos filogenéticos -agarrar, alcanzar, arrastrarse, gatear, etc.- forman la base fundamental de las destrezas motrices. En estudios de entrenamiento precoz se ha intentado demostrar que estos movimientos filogenéticos no ofrecen diferencias significativas entre individuos sometidos a entrenamientos tempranos y otros que no, lo que supone que se trata de movimientos naturales que serán, de todos modos, adquiridos por el solo hecho de pertenecer a la especie; en cambio, el entrenamiento es esencial para el aprendizaje de las actividades ontogenéticas tales como abrocharse la ropa, controlar esfínteres, recortar figuras, etc. (Lawther, 1968:15), que en el caso de la Educación Física serán representadas por las habilidades específicas y especializadas del deporte.

Del mismo modo, resulta necesario destacar especialmente que por individuo se entiende "un organismo unificado, no una dicotomía -ni tampoco un organismo bipartitocompuesto por cuerpo y mente" (50), lo que supone reducir el cuerpo al nivel estrictamente orgánico; en este contexto el cuerpo es el conjunto de huesos, articulaciones, músculos, sistemas y funciones orgánicas/fisiológicas que, además de ser reconocido como unificado con la mente, es reducido a una dimensión natural, susceptible 
de aprendizaje pero natural. El cuerpo es reducido a una dimensión orgánica y se lo supone movido por una fuerza interior: la motivación. Volveremos sobre estos conceptos más adelante; por el momento sólo diremos que es a partir de estas ideas que se arma el andamiaje teórico que permite delimitar las técnicas utilizadas para investigar.

En lo que al desarrollo motor refiere, hemos dicho que se trata de un área que se configura a partir del estudio del desarrollo humano. En este caso no fue estrictamente la psicología experimental la que orientó las primeras investigaciones, sino la psicología del desarrollo y la psicología infantil, por una parte, y el psicoanálisis freudiano por la otra. Más tarde se sumó también la psicología genética y la neurología del desarrollo. En Estados Unidos, Arnold Gesell contribuyó al desarrollo físico y psicológico del niño al poner en funcionamiento en 1911 una clínica infantil, la Yale Clinic of child development, en la que llevó adelante investigaciones longitudinales ${ }^{10}$ sobre el desarrollo infantil. Sin embrago, el método longitudinal no fue el único utilizado para el estudio del desarrollo motor. Para estos investigadores, la tesis madurativa ${ }^{11}$ es la causa fundamental de los cambios en las competencias motrices infantiles. Esta idea los llevó a montar investigaciones que permitieran observar las conductas motrices infantiles en cada período de edad, compararlas con las de otros individuos de la misma edad y establecer parámetros normales para cada período. Cobran relevancia, además del método experimental, los métodos transversales y mixtos (transversal-longitudinal). En lo que al método experimental se refiere, destacan las investigaciones por las cuales se seleccionan dos grupos: uno experimental, receptor del programa sistematizado y

\footnotetext{
${ }^{10}$ Son aquellos estudios en los que una persona o grupos de personas son estudiados a lo largo de grandes períodos de tiempo. La utilización del método longitudinal viene dada por la búsqueda de información que determine la máxima estabilidad en el proceso de desarrollo y permita detectar con mayor control las tendencias que pueden darse en el desarrollo (Ruiz Pérez, 1991:29). Por ejemplo, en 1931 y 1933 Shirley estudió las conductas motrices de 25 niños durante un período de dos años, midiendo y describiendo de forma detallada dichas conductas motrices. Finalmente la maduración fue el argumento más satisfactorio para explicar la progresión de las secuencias motrices. Por su parte, Theresa Jones (1939) también "ha realizado un amplio estudio de 24 niños desde el vigésimo primer mes al trigésimo tercero y luego nuevamente, del trigésimo sexto al cuadragésimo octavo. De dicho estudio la autora concluyó que los períodos cortos de entrenamiento especializado de menores no han dado resultados satisfactorios; el rendimiento posterior no revela diferencias significativas entre el grupo que recibió entrenamiento y el que no lo recibió. Aunque las dosis de práctica relativamente limitadas no ocasionan una superioridad permanente, existen pruebas de que un entrenamiento intenso acelera el desarrollo" (en Lawther, 1968:25).

${ }^{11}$ Maduración: proceso genéticamente determinado por el cual un órgano alcanza su desarrollo completo y permite que la función que controla se manifieste con el máximo de eficacia (Rigal, 2006:86). Las habilidades filogenéticas aparecen en el momento en que la maduración lo permite.
} 
estructurado de actividades físicas; y otro testigo, o de control, al que no se aplica ningún procedimiento especial, sino que continúa desarrollando su vida habitual. Luego del período de investigación, ambos grupos son sometidos a una batería de tests que permiten obtener información sobre los cambios de conducta que puedan haberse dado en el grupo experimental por comparación con el grupo control. Los estudios transversales, que utilizan la edad como variable independiente y consisten en seleccionar individuos de diferentes edades, tienen por finalidad producir datos normativos, es decir, deducir cuál es la norma o la edad promedio en la que se consiguen determinados resultados, así como las posibles variaciones en estas pruebas durante el desarrollo (cf. Ruiz Pérez, 1987:30-32). En cambio, el método mixto combina características de los diseños transversal y longitudinal, combinación mediante la que el investigador puede estudiar, por ejemplo, tres grupos de edades diferentes y seguirlos durante su desarrollo, o compararlos entre sí por un período de tiempo determinado. ${ }^{12}$

También los estudios con gemelos han sido muy difundidos. A partir de ellos se ha tratado de verificar la preponderancia del papel de la herencia por sobre el ambiente. Estos estudios sirvieron para "documentar" el carácter universal de ciertas conductas infantiles, dando énfasis a la descripción de los productos del desarrollo motor (Clark y Whithall, 1989). ${ }^{13}$

Todos estos estudios, tanto en lo que refiere al aprendizaje como al desarrollo motor, han adoptado una metodología de investigación que se sostiene en la ilusión de que en las ciencias humanas y sociales es posible mantener la pretendida objetividad de las ciencias físicas y naturales. Establecer conclusiones universales a partir de las conductas observadas en situación de laboratorio, para luego aplicar esas mismas leyes a

${ }^{12}$ En un estudio que se publicó en 1972, basado en la observación de más de 700 niños durante 17 años, Emma Pikler aportó datos a la controversia sobre la posibilidad de que distintos tipos de condiciones ambientales iniciales provoquen cambios notables en el desarrollo motor (Cratty, 1982).

13 “En 1935 Myrtle Mc Grawn publicó los resultados sobre los gemelos Johnny y Jimmy. Su intención era determinar el efecto del entrenamiento precoz en el desarrollo de las habilidades motrices. A uno de ellos se lo sometió desde los 21 días a los 22 meses, a un medio altamente estimulante que incitaba a la ejecución de actividades vigorosas y variadas. Se lo alentaba y se le ofrecían oportunidades diarias para que realizara tanto actividades filogenéticas como ontogenéticas, es decir estímulos para los diversos tipos de movilidad, tales como ascender, descender en planos inclinados, subirse y bajarse de plataformas, etc. Mientras tanto, al hermano no se le proporcionó ningún entrenamiento específico, permanecía la mayor parte del tiempo en su cuna. A los 22 meses se lo inicio en las mismas actividades que su hermano gemelo ya había experimentado. Después de dos meses y medio de entrenamiento Jimmy se aproximó al nivel de rendimiento de Johnny, aunque nunca logró alcanzarlo" (Lawther, 1968:26). 
situaciones de clase, es producto del empeño de los investigadores por mantener en las ciencias humanas y sociales la misma relación entre la teoría y la práctica que puede establecerse entre las ciencias físicas y sus correspondientes tecnologías. Este intento de estudiar los fenómenos sociales con los métodos y la exactitud de las ciencias naturales es propio de la corriente positivista, que surgió en el Siglo XIX con Auguste Comte, quien intentó unificar las ciencias en un único sistema afín tanto a las ciencias naturales como a las sociales. Este monismo metodológico tiene sus precedentes en el Siglo XVII, en Bacon y en Descartes, y consiste, como bien explica Marradi (2007:67), en la utilización del método "hipotético- deductivo" elaborado a partir de la reflexión filosófica acerca de la física del Siglo XVII en adelante. Para esta corriente, cualquier investigación que se precie del más mínimo rigor científico comporta los siguientes pasos: primero se define el problema; luego se lo formula en los términos de un particular cuadro teórico, y se imaginan una o más hipótesis relativas al problema utilizando los principios teóricos ya aceptados; a continuación, se determina el procedimiento a utilizar en la recolección de datos para controlar la hipótesis; se recolectan los datos y por último se los analiza para averiguar si la hipótesis es verificada o rechazada (Marradi, 2007:67). Esta manera de entender a las ciencias sociales supuso y supone que es posible estudiar de la misma manera una piedra, un árbol, el mundo animal y la cultura, y por tanto el objeto de conocimiento no se construye sino que está, se descubre y hay que preservarlo de toda subjetividad. Estas ideas fomentan una concepción determinista del hombre y de la sociedad al restar importancia a los factores considerados exclusivamente humanos. Nótese el argumento de Lawther en defensa de los incentivos (estímulos externos que el individuo quiere, desea y le gusta obtener) y en relación con la motivación.

Algunas de la motivaciones del hombre, tal vez lo que se quiere significar cuando decimos necesidades físicas más que orgánicas, están relacionadas con su aparente ansiedad de permanecer activo y de explorar y manipular su medio. Estos motivos no solamente son casi universales en la especie humana, sino también característicos de la conducta animal. La mayor parte de esta actividad ha sido caracterizada como juego [...] No se debe pensar que estas necesidades psíquicas son productos del aprendizaje, aunque la dirección de sus expresiones convertidas en actividad involucre aprendizajes. Por ejemplo, la necesidad humana de compañía de un semejante es algo innato [...] hasta algunas especies animales revelan necesidad de afecto (Lawther, 1968:135). 
Esta continuidad con el animal, al igual que la reducción de la vida humana al simple resultado de una fusión de fuerzas que interactúan de manera que se produzca una secuencia de conducta determinada (Hughes y Sharrock, 1999:63-70), implica no sólo una manera de concebir al hombre, sino también de estudiarlo. El método será entonces el que se utiliza para estudiar los fenómenos naturales: el método experimental hipotéticodeductivo. Se supone que este método permite observar hechos con la máxima objetividad, comprobar hipótesis y establecer normas o leyes. Se presume así una relación sujeto-objeto de conocimiento $(S \rightarrow O)$ teóricamente neutral, en la que el investigador puede y debe mantenerse neutral a la hora de estudiar un fenómeno, y se entiende esa distancia y neutralidad como condición necesaria para la producción de conocimiento científico. Por lo tanto, se trata de modelos explicativos que han sido creados en situaciones experimentales y sólo en forma parcial pueden explicar el funcionamiento real de los procesos de aprendizaje en el patio o en la vida cotidiana. De hecho, el rigor de la epistemología positivista se asienta precisamente en la simplificación de las situaciones reales, en el control de la neutralidad o inactividad de unas variables para comprobar los cambios que la manipulación ejerce en otras variables.

Tal como se ha dicho antes, podemos ver cómo se han tomado muestras de las que un grupo control se convierte en testigo para estudiar en condiciones de laboratorio, indagar por comportamientos y luego concluir que todos los individuos sometidos a determinadas condiciones de enseñanza aprenderán determinadas conductas, como EL SALTO, LA CARRERA y otras. Del mismo modo, pensar en el desarrollo, el crecimiento y la maduración como factores endógenos del organismo implica suponer que el aprendizaje del sujeto está regido por la evolución de esos factores, reduciendo al individuo a una Naturaleza que no sólo lo condiciona sino que también lo determina. Así, solemos encontrar en la bibliografía formulaciones del tipo Crecimiento+Maduración+Aprendizaje=Desarrollo, creyendo que existe una vinculación determinante entre el desarrollo motor y el aprendizaje de las habilidades o que hay una secuencia necesaria e invariable que va desde las habilidades motoras básicas, pasa por las específicas y llega al deporte propiamente dicho, y arguyendo además la necesidad de emplear tal o cual metodología para la enseñanza de estas habilidades, y a su vez la imposibilidad de desvincular dichos aprendizajes de las etapas evolutivas. Es común encontrar en la bibliografía apartados descriptivos que establecen criterios universales respecto de cada período concreto de edad, formulados casi siempre bajo el título el niño de 1 año, 2 años; incluso para los primeros años de vida, desde el período embrionario en 
adelante, se establecen estas descripciones de manera muy específica y detallada. Parafraseando a Spinoza, vale decir que el concepto de niño no habla: ${ }^{14}$ se trata sólo de un concepto, de una categoría, de una abstracción, y nunca la abstracción "el niño de 2 años" representará a los niños de 2 años. La pregunta sería entonces por qué intentar hacer del estudio de la motricidad humana un campo científico en el que los "investigadores se arroguen el derecho y la autoridad que hay quienes les reconocen, para decir la verdad sobre cómo aprenden los sujetos, como si éstos fueran objetos clasificables y no sujetos también clasificadores" (Bourdieu, 1994:58).

Para decirlo con Cangilhem, tanto en las teorías del aprendizaje como en las del desarrollo motor se estima poder pasar del animal al hombre (sin discontinuidad), y no se está lejos de identificar domesticación y aprendizaje, de considerar como un medio a cualquier entorno, comprendido el hecho social y cultural, para terminar deslizándose progresivamente del concepto de educación hacia el de manipulación.

La creencia de que el espíritu humano está vacío le suministra una justificación a todo tipo de sistemas autoritarios. Si el espíritu humano está vacío, cualquier método para tornear los espíritus a su manera es legítimo y encuentra sus desarrollos extremos, con Skinner por ejemplo; todo culmina en una especie de esquema fascista (Cangilhem, 2004:12).

Por suerte, el ser humano escapa a este intento de reducción porque habita el lenguaje. Hablar es significar, dar a entender, pensar; en síntesis: vivir en el sentido. El sentido es aquello por lo que el sujeto se escapa a cualquier reducción que intente ponerlo en una configuración orgánica o mecánica.

Pasemos entonces a las teorías cognitivas, cuyo mayor desarrollo en el campo de la Educación Física se da en aquellas corrientes llamadas del procesamiento de la información.

\footnotetext{
${ }^{14}$ La frase de Spinoza es "el concepto de perro no ladra" y remite al concepto de abstracción. Abstracción: toda ciencia, por definición, es abstracta: porque aspira a la generalidad de una ley, de una relación, o de un concepto, y no a la singularidad de una existencia; porque no existe, en tanto que ciencia, sino a condición de apartarse (abstrahere) de lo real inmediato. Abstraer es separar, aislar con el pensamiento lo que sólo existe junto a otra cosa, o por el contrario, juntar lo que sólo existe separadamente (Andrè Comte - Sponville, 2001, Diccionario filosófico, Francia).
} 


\subsubsection{Las inVestigaciones cognitivistas y la analogía del Ser Humano con un PROCESADOR DE INFORMACIÓN: LA MENTE COMO UNIDAD DE ANÁLISIS}

Ahora debemos preguntarnos cómo se arma este grupo de teorías que hemos reunido bajo el titulo de teorías cognitivas del aprendizaje motor, y en virtud de qué supuestos teóricos y epistemológicos se arma el andamiaje que las sostiene. Como ya hemos señalado en el capítulo anterior, aquí se reúnen teorías elaboradas a partir del conocimiento generado por una parte en la psicología cognitiva y las neurociencias: para el caso de las teorías del aprendizaje motor propiamente dichas y de la psicología cognitiva, la psicología del desarrollo, la psicología genética, el psicoanálisis freudiano; para el caso del desarrollo motor, las neurociencias. La principal influencia vendrá dada por el paradigma de la ciencia cognitiva, ciencia creada a partir de la convergencia de intereses provenientes de la lingüística, la matemática, la informática, las neurociencias y la psicología, cuyo propósito es comprender los principios de la conducta cognitiva de los sistemas inteligentes, sean éstos abstractos o reales, humanos o mecánicos. Dentro de ésta, la psicología cognitiva estudia los procesos cognitivos humanos utilizando para ello una metodología experimental y partiendo del supuesto fundamental de que las personas poseen representaciones mentales con eficacia causal (Batalla Flores, 2005). Dentro de la psicología cognitiva, a su vez, pueden distinguirse dos corrientes o vías de desarrollo: la perspectiva europea y la perspectiva americana. Dentro la primera podemos destacar autores como Bartlett, Piaget o Vigotsky, quienes basaron sus trabajos en supuestos cognitivos claramente constructivistas, mientras que en la línea americana se sitúan los trabajos adscritos al procesamiento de la información. Si bien las teorías cognitivas son mucho más amplias, e incluso difieren del procesamiento de la información, éstas últimas han sido las que más se han expandido en el ámbito específico del aprendizaje motor.

Pozo (2006) sitúa el origen del cognitivismo en psicología en el año 1956, fecha en la que se celebró el Segundo Simposio sobre Teoría de la Información, en el Massachusetts Institute of Technology (MIT). Allí se reunieron figuras relevantes como Chomsky, Newell, Simon y Miller, y ese año se publicaron algunos trabajos fundacionales del nuevo movimiento. Probablemente el surgimiento de esta nueva corriente haya sido la respuesta a las nuevas demandas tecnológicas impulsadas por las necesidades bélicas de la Segunda Guerra Mundial; en todo caso es claro que el movimiento había empezado a gestarse mucho antes de la década del '50. El nuevo movimiento cognitivista adoptó un enfoque acorde a esas demandas en el que el ser humano pasó a concebirse como un 
procesador de información (cf. Pozo, 2006:40-42), por lo tanto activo en el proceso de conocer. ${ }^{15}$ A diferencia de los conductistas, este movimiento supone una concepción constructivista del ser humano. La idea constructivista se basa en la existencia de una mente que, mediante procesos dirigidos desde arriba (top-down), determina la forma en que la información es procesada y la naturaleza de las representaciones construidas por el sujeto. Esta orientación cognitiva centró sus estudios en una variedad de actividades mentales y procesos cognitivos, tales como la percepción, el pensamiento, la representación del conocimiento y la memoria. El supuesto fundamental de este paradigma es entonces considerar a la mente como un sistema manipulador de símbolos, y como consecuencia entiende que la actuación de las personas está determinada por las representaciones que elaboran o han elaborado.

Del paradigma cognitivista ${ }^{16}$ se pueden señalar los siguientes principios:

g) Positivismo: se sigue manteniendo el criterio de cientificidad positivista. El método experimental seguirá siendo utilizado en tanto se supone que garantiza la objetividad. Las investigaciones de laboratorio serán acompañadas de instrumentos cinemáticos (fotos y videos) que permiten descomponer el movimiento con el objeto de analizar el proceso de aprendizaje.

h) Mentalismo: hace referencia al carácter cognitivo del aprendizaje motor con la atención puesta en la mente. Sin embargo, no se termina de abandonar la cuestión epigenética. $^{17}$

i) Constructivismo: se replantea el carácter pasivo que el conductismo asignaba al individuo en el proceso de aprendizaje. Para los cognitivistas el aprendiz es activo en el acto de conocer. ${ }^{18}$

\footnotetext{
15 "Lejos de considerar al aprendiz o deportista como un sujeto pasivo que recibe un conjunto de estímulos, debemos concederle el papel de actor y constructor de su propia capacidad de movimiento. La consideración del sujeto como agente de sus aprendizajes motores supone la aceptación de algún tipo de actividad cognitiva para elaborar sus respuestas" (Ruiz Pérez, 1997:50).

${ }^{16}$ Para mayor detalle de las explicaciones que se brindan bajo este paradigma en el campo de lo motor, cf.: Meinel y Schnabel, 1988; Corraze, 1988; Grosser y Neumaier, 1986; Singer, 1986; Ruiz Pérez, 1987; Le Boulch, 1991; Adams, Schmith Batalla Flores, 2005; entre otros.

17 "Nuestras posibilidades cognitivas y nuestros comportamientos se adquieren por epigénesis. Ésta es una organización progresiva de las características morfológicas, cognitivas, motrices o socioafectivas que dependen a la vez de factores genéticos y ambientales (alimentación, estimulación, experiencias, relaciones). Lo adquirido (lo elaborado) se apoya en las interacciones de lo dado (genética) y lo ofrecido (entorno). El entorno es mucho más favorable al desarrollo del niño cuando es positivo, estimulante y motiva la acción de éste así como las interacciones con los demás" (Rigal, 2006:90).
} 
j) Procesual: no importa tanto la conducta terminal como el proceso que el individuo pone en juego para que el aprendizaje tenga lugar. Se asigna un valor fundamental a las representaciones mentales y a la memoria.

k) Control jerárquico: el sistema nervioso es determinante en la explicación del aprendizaje.

l) Control del ambiente y retroalimentación: es fundamental que se mantengan controlados todos aquellos factores ambientales (externos) que pueden perturbar o entorpecer el aprendizaje. La retroalimentación informativa durante la acción será fundamental para la regulación del movimiento.

En virtud de estos principios, las investigaciones desarrolladas (tanto en campo como en laboratorio) han intentado responder cuestiones tales como: ¿qué mecanismos y procesos son los responsables de registrar, almacenar o recuperar la información sobre las habilidades motrices o deportivas? ¿cuáles son las características de dichos procesos y cómo operan con el tiempo y con la práctica? ¿cómo integran los aprendices la información sobre el movimiento, de tal forma que el sistema motor sea capaz de producir un movimiento hábil? ¿cómo cambian dichos mecanismos y procesos por efecto de la edad y la experiencia? En palabras de Schmidt (1982),

se hace necesario comprender cómo la información sobre el movimiento es codificada y almacenada, cómo son representadas dichas acciones motrices; y cómo se procesan las informaciones emanadas de nuestros errores, para que el fenómeno del aprendizaje se lleve a cabo (Ruiz Pérez, 1987:28).

Respondiendo a este interés de controlarlo todo, se llevó a las tareas motrices a los laboratorios con el objeto de superar la medición global de las conductas motrices y penetrar en la comprobación de los procesos específicos. Los estudios de los tiempos de reacción, las tareas con rotores de persecución o las de posicionamiento lineal fueron habituales en estos estudios. A propósito de ello, Ruiz Pérez (1987) señala que, si bien los niveles de control eran elevados, su significación y posibilidades de aplicación al mundo real, donde las habilidades son muy diferentes y complejas, resultan dudosas.

\footnotetext{
18 “El aprendizaje motor significativo supone que el alumno o deportista participa en la construcción de sus acciones, partiendo de sus conocimientos y habilidades ya adquiridas así como de las estrategias y patrones básicos de movimiento. Esta concepción constructivista del aprendizaje motor supone que se aprenden habilidades motrices cuando se aprende a obtener las informaciones necesarias, cuando se domina una serie de reglas de acción aplicables a un conjunto amplio de problemas motores y cuando se aprenden a auto-dirigir el propio aprendizaje" (Ruiz Pérez, 1997:52).
} 
El procesamiento de la información afirma que los sujetos construyen su propio conocimiento a partir de sus estructuras y procesos cognitivos, pero lo que no logran explicar es cómo se construyen esas estructuras y procesos iniciales. Así, el procesamiento de la información puede explicar cómo actúa el individuo ante una tarea de decisión motora, atribuyéndole ciertas estructuras de memoria motora, pero no puede explicar cómo se han adquirido los conocimientos almacenados en esa memoria. Nótese por ejemplo la siguiente reflexión de Ruiz Pérez:

es probable que muchas de las percepciones de los alumnos sean directas, que comprendan de forma directa la utilidad del balón, que sirve para lanzarlo, rodarlo o botarlo; que las vallas son para saltarlas o pasarlas, o que el peso es para lanzarlo; pero este acto comprensivo supone, a nuestro entender, un análisis de la situación en relación con sus propias competencias o sus propios programas de acción, que sean utilizados y adaptados a cada situación (Ruiz Pérez, 1987:50).

¿Cómo sería posible pensar en la percepción directa de los objetos, e incluso saber qué hacer con cada uno, si en este argumento no se apelara a la idea de que existen ciertas "representaciones" innatas? Pensemos en el concepto de Esquema Corporal que tan difundido ha sido por la teoría psicomotriz. Para Le Boulch, "el esquema corporal es el conjunto de estructuras neurológicas que procesan la información propioceptiva. Se refiere a los datos neurológicos y corresponde a un conjunto de estructuras del sistema nervioso central que evolucionan hasta la pubertad, mientras que la imagen mental se utiliza para designar el contenido mental correspondiente" (1991b:42-43), aunque luego asegure que "no se trata de un dato inicial, ni de una entidad biológica o física, sino que es el resultado de una estructuración cuya evolución y enriquecimiento prosigue de manera permanente en virtud del perpetuo y renovador contacto del ser global motor, intelectual y afectivo con el mundo exterior" (225, las cursivas son nuestras). ${ }^{19}$ No cabe más que asegurar que efectivamente se trata de un sistema percepción-conciencia que preexiste al individuo y que resulta a todas luces tan natural como el resto de los sistemas orgánicos. Se cree, como hace notar Canguilhem, que "el cerebro secreta pensamientos como el hígado la bilis" (Canguilhem, 1980:5). Dice Le Boulch respecto del sistema nervioso:

si analizamos las características del mundo animal no podremos dejar de sentirnos conmocionados por esa característica expresada por Vandel: en todos los grandes

\footnotetext{
${ }^{19}$ Nótese que nuevamente se apela a la idea del individuo como un organismo unificado.
} 
filums del reino animal la evolución se orienta, de modo constante, hacia la adquisición de un sistema nervioso complejo, correlativo a un psiquismo elevado, de modo que podemos afirmar que el desarrollo del sistema nervioso y del psiquismo representa la tendencia fundamental de la evolución animal (1991b:50$51)$.

Para el autor, "en la medida que nos elevamos en la escala animal comprobamos que el sistema nervioso cumple cada vez con mayor sutileza las funciones de: a) asegurar la dirección y la coordinación central de la actividad neuromotriz, en función de las aferencias sensoriales; b) contener, en forma de circuitos genéticamente determinados, modelos de conductas más o menos complejos y descargarlos en función de estímulos particulares; y c) analizar, filtrar e integrar una representación del mundo exterior, adaptada a los niveles de rendimiento especifico del animal." (1991:50-51)

Por lo expuesto, cabría pensar que las teorías cognitivas en general, y las del procesamiento de la información en particular, no logran librarse de la idea de que existe una naturaleza que dispone y preforma; así, el ser humano es pensado como un ser biológico, reducido a la condición contingente que lo mantiene unido con su condición animal, y no un efecto de la cultura. Nuevamente, nos encontramos frente a argumentos que si se extreman dan por resultado un individuo, es decir un organismo unificado compuesto por cuerpo y mente..$^{20}$ De hecho, tampoco logran desembarazarse de las ideas conductistas que plantean la continuidad entre el animal y el hombre. Meinel y Schnabel, por ejemplo, sostienen que

el término aprendizaje es la denominación para cualquier modificación de la conducta en relación al ambiente como consecuencia de un procesamiento individual (intrínseco) de informaciones. Aprender consiste en la formación o corrección del contenido de memoria del individuo. Esta caracterización esencial para todos los sistemas vivos y no vivos que tienen la capacidad de aprender, también vale para el aprendizaje motor del ser humano (Meinel y Schnabel, 1988:187).

No vemos en el pasaje de un paradigma a otro un verdadero desplazamiento de métodos y técnicas de investigación, y la respuesta más certera a esto es que en verdad no se ha producido un verdadero cambio de paradigma, porque por sobre todas las cosas lo que

\footnotetext{
20 “El aprendizaje mental y el aprendizaje motor están íntimamente relacionados, combinados entre sí y condicionándose el uno al otro" (Meinel y Schnabel, 1988:184).
} 
no se ha desplazado es el modo en que se piensan lo problemas humanos y por lo tanto lo humano en sí mismo. Al no haber en efecto un cambio teórico, nada ha cambiado respecto de cómo se lo investiga.

Por último, tampoco vemos que este grupo de teorías se haya logrado desprender de algunos conceptos conductistas tales como estímulos, refuerzos positivos y negativos, motivación, motivos, ${ }^{21}$ que siempre refieren a una interioridad en el ser humano que pasa por alto la cultura. Por lo dicho hasta aquí, nos atrevemos a decir con Lakatos que el cognitivismo no resulta un verdadero cambio en el programa de investigación, en tanto y en cuanto sólo modifica las ideas auxiliares que conforman el cinturón protector, pero no ataca el núcleo firme constituido por las ideas centrales del paradigma conductista. ${ }^{22}$

En lo que a las teorías del desarrollo se refiere, entre 1925 y 1950 se advierte una gran influencia de la paidopsiquiatría, la psicología del desarrollo y el psicoanálisis, que se pone de manifiesto en las acciones pedagógicas en torno de la educación perceptivomotora (línea americana) y la educación psicomotriz (línea europea). Los estudios más destacados de este período fueron los de Henry Wallon, que aún hoy continúa siendo un referente importante en el área y principal responsable del nacimiento del movimiento de reeducación psicomotora conducido años más tarde por Julián de Ajuriaguerra y Giselle Soubiran. Wallon estudió el desarrollo psicomotor y mental del niño, y lo dividió en etapas o estadios: impulsivo, tónico-emocional, sensorio-motor, proyectivo y personalítico. Así mismo, inició una línea de investigación y publicaciones sobre determinados aspectos de la psicomotricidad. ${ }^{23}$ En su tesis sobre el niño turbulento (1925) analizó trastornos del desarrollo mental y psicomotor del niño basándose en la unidad psicobiológica del individuo, en la que psiquismo y motricidad representan la expresión de las relaciones del

${ }^{21}$ Cf. Meinel Schnabel (1998), Le Boulch (1991), Grosser y Neumaier (1986), Ruiz Pérez (1987), Knapp (1975), etc. Todos ellos dedican un apartado al tema de la motivación, los estímulos, incentivos, etc.

${ }^{22}$ Para Lakatos (1978), todo programa de investigación consta de dos componentes distintos: un núcleo firme constituido por las ideas centrales, y un cinturón protector de ideas auxiliares cuya misión es impedir que el núcleo pueda ser refutado empíricamente. Lakatos considera que nunca una teoría puede ser falsada por un hecho. Los datos en contra de una teoría son simples anomalías. Toda teoría, en la medida que no explica todo, convive con numerosas anomalías simultáneamente. Frente a esto, el programa puede reaccionar de dos maneras: o bien las desestima, o bien las incorpora a su cinturón protector; en cualquier caso el núcleo de la teoría o programa se mantiene intacto. La falsación de una teoría no la producen los datos, sino la aparición de otra teoría mejor.

${ }^{23}$ El concepto de psicomotricidad es bastante anterior a este período, se cree que fue acuñado por Ernest Dùpre en 1909. Para más detalle cf. Rocha Bidegain, 2009. 
individuo y el medio. Al mismo tiempo, profundizó en la importancia del tono muscular como telón de fondo de todo acto motor y de la trama en la que se teje la emoción como expresión de la actividad de relación. Dentro de este fenómeno tónico concedió gran importancia a la función postural de comunicación, y a lo largo de su obra trató de demostrar la importancia del movimiento en el desarrollo psicológico del niño y en la construcción de la personalidad. Por otra parte, destacó la importancia de la "toma de conciencia" del propio cuerpo como base para la individualización y la identidad personal (Miguel Sassano, 2003).

Los estudios de Wallon fueron sucedidos por los de Heuyer (1936), el primer catedrático europeo de psiquiatría infantil y una de las figuras más influyentes en el surgimiento de la reeducación psicomotriz, que intentó poner de relieve la interdependencia de la motricidad, la inteligencia y la afectividad en el desarrollo infantil, estableciendo programas de tratamiento que vinculaban los trastornos en el carácter con los trastornos en las funciones motrices (Miguel Sassano, 2003)

Paralelamente, y aunque nunca se abocó a la educación, los estudios de Piaget han sido retomados en este sentido, reforzando los supuestos de cierta preeminencia del plano motor en el desarrollo infantil. Sus investigaciones ponderaron la importancia de la actividad motriz, sobre todo en los primeros años de vida, en el desarrollo de la inteligencia y de las nociones mentales de cantidad, espacio y tiempo. Para Piaget, "las acciones mentales no son más que acciones físicas interiorizadas", y la coordinación de acciones y operaciones que el niño interioriza, junto con la información que le proporciona la relación con los objetos, traerá como resultado la construcción de esquemas. Estos esquemas se desarrollarán sobre la base de las invariantes funcionales en un doble proceso de asimilación y acomodación. ${ }^{24}$

Por otro lado, la teoría psicoanalítica de Freud ejerció su influencia al revitalizar lo corporal en el desarrollo de la personalidad infantil y adulta. La división del proceso de desarrollo en una serie de fases o estadios (oral, anal, fálico, latencia, genital, etc.) denotan una marcada centralización en diferentes zonas corporales. Varios autores han retomado a

\footnotetext{
${ }^{24}$ Mecanismos por los cuales cada vez que el sujeto se enfrenta a una situación nueva aplica pautas de conducta o esquemas de comportamiento, físicos u operatorios, adquiridos en experiencias previas. Al mismo tiempo, los objetos o las situaciones en su conjunto ofrecen una cierta resistencia al individuo, lo que tiene por consecuencia la necesaria acomodación del individuo a la situación. Cuando asimilación y acomodación están en equilibrio el individuo se ha adaptado.
} 
Freud en este sentido, como Ericsson, Klein, Wolf, Ana Freud, Winnicot y Spitz. (Ruiz Pérez, 1987). Los estudios de René Spitz (1945) sobre las repercusiones psicológicas de las carencias afectivas en el primer año de vida establecieron una cierta importancia al cuerpo y a las precoces experiencias sensoriales y motrices en el desarrollo posterior del individuo. Es necesario recordar que el interés principal de Freud fue la conducta anormal de los adultos. Sus estudios se centraron en analizar la evolución de la personalidad desde las primeras etapas, el papel de lo sexual en esta evolución y la interacción entre las necesidades del niño y sus deseos frente al trato recibido de la madre $u$ otros adultos. Lo que los escritos de todos estos autores tienen en común, en lo que se refiere al desarrollo motor, es que éste se refleja en la capacidad de movimiento y depende esencialmente de dos factores: la maduración del sistema nervioso y la evolución del tono.

1- La maduración del sistema nervioso, o mielinización de las fibras nerviosas, sigue dos leyes: céfalo caudal (de la cabeza a las extremidades) y próximo distal (del eje a las extremidades).

2- La evolución del tono es el fondo sobre el cual surgen las contracciones musculares y los movimientos, por lo que es responsable de toda acción corporal y factor que permite el equilibrio necesario.

Para estos autores, el desarrollo humano se entiende en los términos de una línea vectorizada hacia el progreso y sobre la que es dable esperar que aparezcan, cronológicamente, determinadas habilidades que van de los movimientos reflejos característicos de los neonatos - pasando por la motricidad infantil, con sus momentos de ajuste y de estabilización de las habilidades motrices básicas (caminar, correr, saltar, lanzar, etc.) sobre las que se apoyan posteriores adquisiciones más complejas- hasta el dominio deportivo, considerado invariablemente como el grado máximo de la especialización motriz. Recuérdese por ejemplo que para de Ajuriaguerra (1978) las fases del desarrollo son: organización del esqueleto motor, organización del plano motor y automatización de las adquisiciones; para Gallahue: fase de los movimientos reflejos, fase de movimientos rudimentarios, fase de habilidades motoras básicas, fase de habilidades motoras específicas y fase de habilidades motoras especializadas. Esto lleva a considerar la marcha, la carrera, el salto, el lanzamiento, la recepción, como habilidades que preexisten -por lo menos como potencia o proyecto, lo que implica abstraerlas y descontextualizarlas. En lo que a los métodos de investigación refiere, los autores se han 
mantenido a caballo entre la investigación básica y la aplicación pedagógico-clínica, aunque estas últimas han sido las predominantes. Por otra parte, la utilización de fases en el desarrollo motor forma parte de una metodología deductiva que supone que "el ser humano progresa de lo simple a lo complejo y de lo general a lo especial", por lo que para poder acceder a conductas motrices más complejas (progresar a la fase siguiente) es necesario superar la fase anterior, en un proceso gradual e integrador.

El sistema nervioso y el sistema percepción-conciencia han tenido un lugar preponderante en este tipo de estudios, donde lo importante no es tanto la conducta observada como tratar de dilucidar cuáles son los mecanismos (servomecanismos) que se ponen en juego para la regulación de los movimientos infantiles. Todo este conjunto de exposiciones tiene como común denominador el tratar al niño como una unidad que se expresa por sus conductas cotidianas, donde la motricidad se muestra como factor de primer orden (Ruiz Pérez, 1987).

Por otra parte, a partir de estas explicaciones se pone en juego toda una serie de dispositivos que permiten evaluar y medir el desarrollo perceptivo motor de los infantes. Ozeretsky y luego Guilmain fueron responsables de la elaboración de los primeros tests motores y psicomotores, que en línea con los tests de inteligencia de Binet y Simon "intentan situar, desde el punto de vista de la motricidad una edad motriz, por encima o por debajo de la edad cronológica." ${ }^{25}$ Con la aplicación de estas pruebas se estudiarían los factores neuropsicomotores del comportamiento, estableciendo patrones para la realización de tareas concretas a cada edad. Por su parte, de Ajuriaguerra y Diatkine, discípulos de Heuyer, desarrollaron una técnica terapéutica para la reeducación y educación de los débiles motores, la reeducación psicomotriz, poniendo nuevamente el énfasis en la solidaridad entre motricidad y pensamiento y estableciendo parámetros tanto respecto del desarrollo infantil normal como del "patológico". Por su parte Bergès, continuador de de Ajuriaguerra, desarrolla un test que evaluaría la imitación de gestos, el esquema corporal y la lateralidad (Bernardo de Quirós Aragón, 2006:35-37).

En lo que refiere a la continuidad del animal al hombre, también se refuerza la idea de que "la ontogénesis motriz recapitula y supera la filogénesis de la motricidad humana" (Da

\footnotetext{
25 "El test de Ozeretsky, luego revisado y ajustado por E. Guilmain, se compone de 6 pruebas que se aplican a individuos entre 4 y 16 años y miden la coordinación estática, la coordinación dinámica de las manos, la coordinación dinámica de los miembros inferiores, rapidez de movimientos, corrección de movimientos simultáneos y sincinesias" (Blázquez Sánchez, 1989: 123).
} 
Fonseca, 1984 en Ruiz Pérez, 1987:140). Este tipo de teorías sostiene que muchos de los reflejos del neonato no son sino

remanentes de conductas ancestrales, en su momento importantes para la supervivencia de los individuos. La existencia de reflejos de agarre plantar y palmar tendría relación con la vida arbórea del hombre; el reflejo natatorio con su adaptación al medio acuático en una etapa concreta de la evolución humana, la existencia de un reflejo de trepa, como expresión del comportamiento mostrado por las crías para alcanzar el seno materno mediante la trepa por el abdomen de la madre (Ruiz Pérez, 1987:141).

\section{Entonces, estas teorías del desarrollo humano y motor}

son, en cualquier caso, teorías de sus causas, procesos y efectos orgánicos; no tratan de la acción corporal sino de los mecanismos y procesos neuropsicofisiológicos que la hacen posible en todos los seres humanos, considerados unificados, equiparables y normales, con lo que prescinden de la condición particular y la separan al mismo tiempo, del cuerpo y de la cultura, es decir del sentido. Esto hace prácticamente imposible operar con ellas en las prácticas educativas, en las que la subjetividad y el sentido no pueden excluirse (Crisorio, 2003:4).

Por lo dicho hasta aquí, vemos que, en lo que al desarrollo motor refiere, se ha intentado operar desde categorías psicológicas, neurofisiológicas y psicogenéticas, mediante una práctica centrada en la organización de las nociones "estructurales" ligadas al "cuerpo pensante" -esquema corporal, espacio, tiempo, objeto, ajuste, etc. Estas nociones, al igual que "las inclusiones de clase, las invariantes geométricas o las conservaciones físicas, en su mayor parte se hubieran constituido en los niños sin mediación de la situación de aprendizaje" (Crisorio, 1995:175), lo que supone nuevamente apelar de algún modo al innatismo, y a fin de cuentas a la naturaleza. La evolución del individuo es descrita así a la vez como un proceso de diferenciación -movimiento horizontal de expansión hacia lo múltiple- y por un movimiento de organización jerárquica -movimiento vertical de integración en la unidad. Así procedieron las especies en el curso de su evolución y así procederán las sociedades en el curso de su historia; así procede el individuo en el curso de su génesis psicológica, desde el feeling indiferenciado hasta la unidad múltiple del conocimiento (cf. Foucault, 1994).

Lo que se ha perdido de vista hasta aquí es que los seres humanos somos seres culturales, no biológicos. Como dice Maturana: 
Lo humano surge en la historia evolutiva de los primates bípedos a que pertenecemos, con el lenguaje. Cuando esto ocurre, el vivir en el lenguaje se hace parte del fenotipo ontogenético que define nuestro linaje cultural, y en torno a cuya observación se dan todas las variaciones estructurales que llevan al ser biológico homo sapiens sapiens. Pero en esta historia, el lenguaje y el lenguajear permanecen siempre como rasgos fenotípicos que establecen de novo en cada individuo en el ámbito de su vivir cultural. Las culturas son redes de conversaciones, modos de vivir en el entrecruzamiento del lenguajear y emocionar, por lo que el ser cultural implica vivir en una red de conversaciones, entonces lo humano surge en la culturización del homo sapiens sapiens, no antes; nos hacemos humanos en el vivir humano. Por tanto los seres humanos haremos de lo humano lo que de hecho hagamos al vivir porque nada de lo que hagamos será inocuo incluso para nuestra biología" (Maturana, 1996:144)

La pregunta que el autor se hace a continuación -“¿qué mundo queremos vivir?”- no es una cuestión irrelevante para nosotros. Como veremos más adelante, en buena medida ha sido el concepto de vida el que ha ordenado el pensamiento moderno.

\subsubsection{LAS INVESTIGACIONES ECOLÓGICAS Y LAS TEORÍAS DE LOS SISTEMAS DINÁMICOS: EL SER HUMANO COMO AUTORREGULADOR DE SUS CONDUCTAS MOTRICES}

Este grupo de teorías resulta el más sorprendente de todos, no sólo porque aún se están gestando/formulando, y por ello mismo parecerían ser las explicaciones que en poco tiempo ocuparán la atención de investigadores y docentes, sino también porque reactualizan viejas discusiones, apelando de manera anacrónica a autores de la década de 1930.

El concepto de sistema dinámico proviene originariamente de la mecánica clásica. Éste posee características muy deterministas, derivadas de la mecánica de Newton y Laplace. Posteriormente, la termodinámica estudiará los sistemas desde una perspectiva diferente, en la que se considera al sistema una entidad en sí, como un todo, y no reducido a partes como en la mecánica clásica. Esto se observa en la denominada segunda ley de la termodinámica, o ley de la disipación de la energía. Ésta describe que todo sistema físico aislado o cerrado evolucionará espontáneamente en la dirección de un creciente desorden. Para expresar en términos matemáticos precisos esta evolución, los físicos introdujeron una nueva medida que llamaron entropía. Según dicha ley, la entropía de un sistema físico cerrado irá incrementándose, y dado que esta evolución viene acompañada 
de desorden creciente, la entropía puede ser también considerada como una medida de éste.

Siguiendo a Torrents (2005), podemos decir que el concepto de sistema se extendió a otras ciencias, como las sociales, las humanas o la ingeniería. Las máquinas son sistemas, ya que son entidades complejas formadas por partes en mutua interacción de la que deriva un comportamiento global. En biología se cuestionó el consolidado reduccionismo, la división en partes de los organismos, para pasar a enfatizar el todo, el holismo, la perspectiva sistémica o ecológica (Capra, 1996 en Torrents, 2005). Las propiedades esenciales de un organismo o sistema viviente serán propiedades del todo que ninguna de las partes posee, sino que emergen de la interacción entre ellas. En psicología, esta concepción es representada por la psicología de la Gestalt. El término gestalt significa en alemán forma orgánica, y el filósofo Christian von Eherengields (18591932) fue el primero en usar gestalt en el sentido de una pauta perceptual irreducible afirmando que el todo es más que la suma de las partes. Así, el todo será irreductible, y los conjuntos organizados exhibirán cualidades ausentes en sus partes. Las condiciones en un lugar influirán sobre lo que sucede en otro lugar y viceversa. Los principales representantes de la Gestalt son Köheler y Kofka (cf. Pozo, 2006). También en psicología, Gibson describió la perspectiva ecológica (Gibson, 1979). Ésta enfatiza la información que da el medio como causante de las actividades del organismo (entendido siempre como un todo). El medio, las sustancias, las superficies, los objetos, los lugares, y los otros animales son affordances para el organismo en cuestión. Les darán beneficio o perjuicio, vida o muerte. Por eso tienen que ser percibidas. Las posibilidades del medio y la forma de vida van unidas inseparablemente; el medio condiciona lo que hace el organismo.

Según Torrents (2005), la física cuántica también se centrará en la importancia de las interconexiones. La visión del mundo que emerge de la física moderna se caracteriza por ser orgánica, holística y ecológica. Se la podría llamar una visión de sistemas, en el sentido de teoría general de sistemas. El mundo ha de concebirse como una unidad indivisible y dinámica cuyos elementos están estrechamente vinculados y pueden comprenderse sólo como modelos de un proceso cósmico. La teoría general de sistemas define como sistema a un complejo de elementos interactuantes y pretende establecer principios generales para todos los sistemas, independientemente de su naturaleza física, biológica o sociológica. La comprensión de la realidad será a partir de su totalidad, y los niveles de dependencia entre los elementos variarán en función del tipo de sistema al que 
se haga referencia, volviendo así a resaltar la importancia del todo y de las redes de relaciones. Los sistemas se clasifican en abiertos o cerrados. Los cerrados son sistemas físicos aislados, proceden espontáneamente en la dirección de un creciente desorden o entropía, y la energía que se disipa es irrecuperable. Los abiertos, en cambio, necesitan un constante flujo de materia y energía proveniente del entorno, a la vez que decrece la entropía. Dentro de este segundo grupo se habla de "sistemas dinámicos", que son todos aquellos cuyo comportamiento puede describirse mediante leyes que dependen del tiempo. Todo organismo viviente es ante todo un sistema abierto, que se mantiene en continua incorporación y eliminación de materia, alcanzando un estado uniforme diferente del estado de equilibrio químico y termodinámico. Las estructuras biológicas son multifuncionales: el mismo grupo de componentes anatómicos se utiliza para diferentes funciones, o diferentes componentes realizan la misma función. El sistema nervioso central dejó de ser considerado un órgano aislado que recibe señales procedentes de los sentidos y que se descarga en los músculos para pasar a formar parte de un proceso circular, paso fundamental para estudiar el sistema nervioso como una totalidad integrada. Se defiende también la auto-organización de los sistemas en contraposición a la organización jerárquica que defendían los enfoques más analíticos.

En el campo del aprendizaje motor, las corrientes sistémicas influyeron categóricamente en el pensamiento de una de las figuras fundamentales del estudio del comportamiento motor, Nicolai Bernstein (1896-1966), autor soviético cuyas investigaciones de la década del 1930 recién fueron traducidas en 1967 (quizás a ello se deba la tardía aparición en la palestra científica del aprendizaje motor). Los movimientos ocurren, según Bernstein, por los desequilibrios de las fuerzas causadas por cambios en la tensión muscular, pero no hay una relación de uno a uno. Los movimientos del cuerpo provocan consecuencias mecánicas en el sistema físico, se generan fuerzas centrípetas e inerciales, a la vez que el cuerpo está sometido a la fuerza de la gravedad. Estas fuerzas contribuyen e influyen en todos los movimientos mientras están sucediendo, y constituyen un campo de fuerzas en continuo cambio, provocando una multitud de variables independientes que afectan a este movimiento. Para realizar una acción coordinativa se deberá reducir el número de variables independientes que hay que controlar, es decir, se deberán reducir los grados de libertad del sistema. Generalmente, el organismo tiene más grados de libertad de los que necesita para realizar una tarea, y debe encontrar una forma de reducir los "superfluos". Un microcomponente puede participar en muchas estructuras coordinativas en diferentes ocasiones, a la vez que una estructura coordinativa puede requerir el uso de 
microcomponentes distintos. Bernstein estudió cómo se produce el aprendizaje, y cómo los principiantes parecen eliminar tetánicamente el exceso de grados de libertad, de manera que se realiza la tarea de forma rígida. Con la experiencia, el cuerpo pierde esta rigidez y es capaz de utilizar de forma más eficaz las fuerzas pasivas del medio, la fricción, la inercia y las fuerzas reactivas. Mediante el estudio de la estructura de la coordinación, el autor buscaba observar la organización de la estructura del cerebro. Al mismo tiempo demostró que la organización del movimiento podía ser entendida como la armonización recíproca de muchos procesos cinéticos e informacionales simultáneos. Al darse cuenta de la naturaleza abstracta del fenómeno comprendió la imposibilidad de explicarlo únicamente desde una visión neurofisiológica; propuso así el modelaje matemático para planear y buscar soluciones, a pesar de reconocer que un punto de vista puramente matemático nunca podría capturar toda la organización del movimiento de los seres vivos. Bernstein identificó como punto de partida para comprender el movimiento de todo el organismo la formulación del programa motor, y como principal corrector de la dinámica de la acción motriz al feedback.

En lo que al aprendizaje se refiere, estas teorías podrán ser también acusadas de innatistas, en virtud de la debilidad que muestran a la hora de explicar cómo es que la resolución de problemas y el aprendizaje pueden subordinarse a la autoorganización del individuo en tanto que sistema. Al afirmar la influencia de la organización o estructura sobre la asociación pero negar la relación inversa de la asociación a la estructura, incurren plenamente en una paradoja del aprendizaje. Sostienen que todo lo que se aprende es un efecto de la organización previa; por lo tanto, si las nuevas estructuras están ya contenidas potencialmente en las estructuras anteriores, se está negando la posibilidad de aprendizaje, apelando exclusivamente a la maduración.

Por otra parte, y dado que se trata de recuperar la dimensión singular del proceso de aprendizaje (no hay dos organismos que respondan de manera idéntica), los métodos para estudiarlos se centran fundamentalmente en el estudio de individuos aislados y sometidos a condiciones bien específicas de experimentación. Un método tradicional de investigación que se supone respeta la individualidad es el estudio de casos. Se defiende este tipo de estudios con el argumento de que si un investigador puede generalizar de una manera lógica a partir de sujetos cuyos resultados o características están bien especificadas como parte de un grupo homogéneo, entonces también se podrá generalizar lógicamente a partir de un solo individuo cuya respuesta y características 
estén bien especificadas. Para aumentar la base para la generalización a partir de un experimento de caso único, se propone la repetición del mismo experimento varias veces a individuos similares, y para aumentar la fiabilidad se propone repetirlo al mismo individuo. La consistencia de los resultados en más de un individuo permite formular conclusiones favorables acerca del procedimiento.

De más está decir que este grupo de teorías, lejos de representar un paradigma emergente diferente de los anteriores, no sólo refuerza todos los términos de las críticas realizadas anteriormente respecto del modo en que se ha pensado lo humano -y por lo tanto, del modo en que se lo ha investigado-, sino que redobla la apuesta en tanto que no se utilizan eufemismos para identificar al sujeto humano con un mero organismo que, reducido a la dimensión natural e individual (y por lo tanto también indiviso), es equiparable a otros organismos y sistemas ya no sólo animales sino físicos. Este recrudecimiento naturalista nos alerta y nos obliga a pensar y pensarnos con perspectiva de futuro. Lejos de abandonar el positivismo decimonónico, vemos con claridad que se refuerza la idea de volver a la naturaleza (si bien, como ya vimos, esta idea nunca se abandonó) y sumirnos cada vez más en un modelo inmunitario que pone al hombre, en tanto que individuo, en el centro de la escena, lo que supone a todas luces suspender la diferencia entre lo humano y lo animal. Sobre esto volveremos más adelante, ya que no nos resulta ingenuo este modo de pensar y suponemos que se trata de un pensamiento funcional a las políticas neoliberales de nuestro tiempo.

En síntesis, a lo largo de todo el Siglo XX el estudio del aprendizaje motor y del desarrollo motor heredó de la llustración la preocupación por alinearse con las ciencias de la naturaleza y por reencontrar en el hombre la prolongación de las leyes que rigen los fenómenos naturales. La determinación de vínculos cuantitativos, la elaboración de leyes que operen a la manera de las funciones matemáticas, la puesta en marcha de hipótesis explicativas, son los intentos por los cuales se ha intentado aplicar, no sin artificio, una metodología que los lógicos creyeron descubrir en la génesis y el desarrollo de las ciencias de la naturaleza. Los postulados de estas teorías que quisieron y quieren ser un conocimiento positivo descansan sobre dos principios filosóficos: que la verdad del hombre se agota en su ser natural y que el camino de todo conocimiento científico debe pasar por la determinación de vínculos cuantitativos, la construcción de hipótesis y la verificación experimental. Por cuidar la objetividad, nos han llevado a querer reconocer en la realidad humana algo así como un sector de la objetividad natural, y a utilizar para 
conocerla métodos idénticos a los que las ciencias de la naturaleza podían proporcionar como modelo. La única forma de volver inoperante este pensamiento naturalista que se trasunta en las teorías del aprendizaje y del desarrollo motor, es entender cómo funciona para poder desactivarlo. Creemos que el proyecto de exactitud rigurosa debiera ser abandonado, en tanto que ya no hace sentido esta forma de pensar (y por tanto de investigar) en el dominio de las ciencias humanas. No nos es aceptable seguir pensando en los términos de las teorías del aprendizaje; sí creemos, como cree Agamben, que, en nuestra cultura, el hombre ha sido siempre pensado como la articulación y la conjunción de un cuerpo y de un alma, de un viviente y de un logos, de un elemento natural (o animal) y de un elemento sobrenatural, social o divino. Tenemos que aprender, en cambio, a pensar el hombre como lo que resulta de la desconexión de estos dos elementos y no investigar el misterio metafísico de la conjunción, sino el misterio práctico y político de la separación. Trabajar sobre estas divisiones y cesuras, preguntarse en qué modo -en el hombre- el hombre ha sido separado del no-hombre y el animal de lo humano es urgente (Agamben, 2002:35). 


\section{Capítulo III}

\section{NUESTRA OPCIÓN TEÓRICA Y METODOLÓGICA}

Sólo un pensamiento que no esconde su propio no-dicho, sino que de manera incesante lo retorna y lo desarrolla, puede pretender eventualmente ser original

(Agamben, Giorgio: 2010).

\subsection{SEGUIR LA PROPIA SOMBRA}

Decíamos en la introducción que, si bien hemos reservado este capítulo al análisis del método, lo metodológico y las técnicas utilizadas, la toma de posición teórica atraviesa todo el cuerpo de la tesis, con la convicción de que el enfoque que se asume se refleja en todo el proceso de la construcción del objeto. Esto último supone ya una posición: el objeto no está dado, no está ahí esperando ser develado, sino que se construye en cada decisión, en cada elección que el investigador hace a lo largo de todo el recorrido. Asegura Rockwell que

el objeto de estudio no es la "cosa real", sino el producto del proceso de construcción. Es (diría Geertz) una ficción, en el sentido de algo que se fabrica, para dar cuenta de ciertos aspectos de la realidad. El objeto de estudio se construye teóricamente, mediante el uso de categorías que vinculan las relaciones conceptuales con el referente empírico $(1987: 15) .{ }^{26}$

Por lo tanto, la definición del objeto de estudio corresponde a la perspectiva teórica del estudio; en este línea, entendemos que nuestro objeto ha empezado a construirse desde la página 1 en todas y cada unas de las decisiones que hemos tenido que tomar en términos teóricos. Actuar según este enunciado implica entonces una tarea inmensa y una serie de trabajos de algún modo previos. Entre estos trabajos está, sin duda en primer lugar, dejar de pensar las prácticas educativas que toman por objeto al cuerpo como dependientes de las ciencias naturales, de sus planteos y de sus métodos, para investigarlas en los términos de las ciencias sociales, que no hay que confundir con los de las ciencias humanas, en tanto que por "ciencias humanas" entendemos al conjunto de discursos que toman al hombre en lo que tiene de empírico y que por ello mismo

\footnotetext{
${ }^{26}$ El "referente empírico", es aquella localización física y particular donde se realiza el trabajo que provee la base documental para la investigación, que en nuestro caso son los libros, papers, tesis, etc. dónde podemos rastrear el discurso/los discursos en torno del aprendizaje motor.
} 
permanecen en dependencia de las ciencias naturales. Dice Foucault al respecto que el dominio de las ciencias del hombre está cubierto por tres "ciencias" o regiones epistemológicas, subdivididas todas en el interior de sí mismas y entrecruzadas todas unas con otras; esas regiones se definen por la triple relación de las ciencias humanas en general con la biología, la economía y la filología. El hombre aparece sobre la superficie de proyección de la biología como un ser que tiene funciones que recibe estímulos (fisiológicos, pero también sociales, intrahumanos, culturales) y responde, se adapta, evoluciona, se somete a las exigencias del medio, compone con las modificaciones que impone, trata de borrar los desequilibrios, actúa según regularidades y tiene, en suma, las condiciones de existencia y la posibilidad de encontrar normas medias de ajuste que le permitan ejercer sus funciones. Sobre la superficie de proyección en la economía, el hombre aparece como un ser que tiene necesidades y deseos, que trata de satisfacerlos teniendo pues intereses, pensando en las ganancias, oponiéndose a otros hombres; en breve, aparece en una irreductible situación de conflicto; esquiva estos conflictos, huye de ellos o logra dominarlos, encontrar una solución que calme, cuando menos en un nivel y por un tiempo, la contradicción; instaura un conjunto de reglas que son, a la vez, limitaciones y vueltas del conflicto. Por último, sobre la superficie de proyección del lenguaje, las conductas del hombre aparecen como queriendo decir algo; sus menores gestos, hasta sus mecanismos involuntarios y sus fracasos, tienen un sentido; y todo aquello que coloca en torno a él: ritos, hábitos, discursos; todo el surco de huellas que deja tras de sí constituye un conjunto coherente y un sistema de signos. Así estas tres parejas de la función y de la norma, del conflicto y de la regla, de la significación y del sistema, cubren sin residuos todo el dominio del conocimiento del hombre. (Cfr. Foucault 166:346)

En este sentido, el discurso del aprendizaje motor, tradicionalmente plegado al discurso humanista, debe ser desplazado hacia las ciencias sociales, tanto en términos teóricos como en sus técnicas y sus métodos de investigación. Este planteo nos lleva a reflexionar, en segundo lugar, sobre la necesidad de considerar también la dimensión histórica de las teorías, de las instituciones y de las sociedades en las que estas prácticas (teóricas y prácticas) aparecen, es decir la dimensión histórica y política de esas prácticas, considerando que "el presente puede ser interrogado para intentar descifrar en él los signos anunciadores de un próximo acontecimiento” (Foucault, 1984:2). 
En su conjunto, estos dos planteos implican empezar a pensar en una Educación Física indagada en los procesos, en los hechos, en las estructuras y en las prácticas en las que se manifiesta; es decir, requiere comenzar a pensarse, como dijimos, en los términos de una ciencia social. Este propósito supone reconocer expresamente que el entorno cultural es un efecto histórico y no un dado natural. En esta óptica, el pensamiento no es una función puramente cerebral, un producto biológico, sino un efecto histórico y político relativo al tipo de cultura en la cual interviene.

Entonces, esta tesis se sostiene en una línea de investigación que, a la manera de Foucault, entiende a las prácticas como la racionalidad o la regularidad que organiza lo que los hombres hacen ("sistemas de acción en la medida en que están habitados por el pensamiento"), que tiene un carácter sistemático (saber, poder, ética) y general (recurrente), y que por ello constituye una "experiencia" o un "pensamiento". En un sentido más amplio, las prácticas constituyen modos de hacer, pensar y decir que intentan captar regularidad y recurrencia (Castro, 2006:303). Haremos nuestra entonces la prerrogativa foucaultiana de pensar la crítica a la modernidad positivamente, intentando hacer el análisis de nosotros mismos como seres que hemos sido históricamente determinados por la modernidad, lo que supone emprender, de algún modo, una serie de indagaciones históricas orientadas hacia los límites actuales de lo necesario, es decir, hacia aquello que nos es indispensable, o no lo es más, para la constitución de nosotros mismos como sujetos.

Foucault índica que el trabajo ha realizar deberá tener su generalidad, su sistematicidad, su homogeneidad y su apuesta.

Sabrá disculpar el lector la extensa paráfrasis siguiente, pero es pertinente (es más: necesaria) para el desarrollo de nuestro trabajo.

A continuación desarrollaremos estos conceptos. Sabrá entender el lector nuestra decisión de retomar casi textualmente las palabras de Foucault, en un punto en que nuestros desarrollos teóricos coinciden plenamente con los del autor.

Generalidad: estas indagaciones histórico-críticas son muy particulares, en el sentido de que ellas versan siempre sobre un material, una época, un cuerpo de prácticas y discursos determinados. Pero, al menos en la escala de las sociedades occidentales de las que provenimos, esas indagaciones poseen su generalidad, en el sentido de que han sido recurrentes hasta nuestros días. Lo que hay que comprender es en qué medida lo 
que sabemos de esa generalidad, las formas de poder ejercidas en ella y la experiencia que en ella tenemos de nosotros mismos no constituyen más que figuras históricas determinadas por una cierta forma de problematización que define objetos, reglas de acción y modos de relación consigo mismo. El estudio de los modos de problematización (es decir, de lo que no es ni constante antropológica ni variación cronológica) es, por tanto, la manera de analizar cuestiones de alcance general en su forma históricamente singular.

Sistematicidad: estos sistemas prácticos provienen de tres grandes dominios: el de las relaciones de control sobre las cosas, el de las relaciones de acción sobre los otros y el de las relaciones consigo mismo. Esto no quiere decir que ellos sean tres dominios completamente extraños entre sí. Sabemos bien que el control sobre las cosas está mediado por las relaciones con los otros, lo que implica, a su vez, relaciones consigo mismo y viceversa. Pero se trata de tres ejes cuya especificidad e interconexiones hay que analizar: el eje del saber, el eje del poder y el eje de la ética. En otras palabras, la ontología histórica de nosotros mismos tiene que responder una serie abierta de preguntas; tiene por delante la faena de hacer un número no definido de indagaciones que se pueden multiplicar y precisar tanto como se quiera, mas respondiendo todas a la siguiente sistematización: cómo nos hemos constituido como sujetos de nuestro saber, cómo nos hemos constituido como sujetos que ejercemos o soportamos las relaciones de poder; cómo nos hemos constituido como sujetos morales de nuestras acciones.

Homogeneidad: esto conduce al estudio de lo que podríamos llamar "los sistemas prácticos". Se trata de tomar como dominio homogéneo de referencia, no las representaciones que los hombres se dan de sí mismos, ni tampoco las condiciones que los determinan sin que ellos lo sepan, sino aquello que hacen y la manera como lo hacen. Es decir, por una parte, las formas de racionalidad que organizan las maneras de hacer (lo que podríamos llamar su aspecto tecnológico) y, por otra parte, la libertad con la que actúan en esos sistemas prácticos, reaccionando a lo que hacen los otros y modificando, hasta cierto punto, las reglas del juego (esto es lo que podría llamarse la vertiente estratégica de esas prácticas). La homogeneidad de estos análisis histórico-críticos está por tanto asegurada por ese dominio de prácticas, con sus vertientes tecnológica y estratégica. 
Su apuesta: Está indicada por lo que se podría llamar "la paradoja (de las relaciones) de la capacidad y del poder y el trabajo. La apuesta es entonces; ¿cómo desconectar el crecimiento de las capacidades y la intensificación de las relaciones de poder?

La clave está en adoptar una actitud crítica frente a los tres dominios de relaciones (saber, poder y ética) que nos constituyen en lo que somos, para poder entonces sí, a partir de un análisis histórico (arqueológico y genealógico) de los límites que nos han sido impuestos, poder pensar y experimentar la posibilidad de rebasar esos límites, correrlos, empujarlos tanto como se pueda para establecer nuevas relaciones con el saber, con los otros y con nosotros mismos (cf. Foucault:1996:106-110).

Siguiendo estas orientaciones de Foucault, nuestro trabajo también tendrá su generalidad, su sistematicidad, su homogeneidad y su apuesta. Nuestra apuesta entonces supone el desafío de desbiologizar las prácticas del aprendizaje motor y, por ende, desbiologizar la Educación Física y la Educación.

En este sentido, acordamos con Esposito en que no existe una naturaleza humana definible e identificable en cuanto tal, con independencia de los significados que la cultura, y por ende la historia, han impreso en ella a lo largo del tiempo (Esposito, 2006:50); por eso, revisar las prácticas del aprendizaje motor y negar la existencia de algo así como el hombre, la conciencia y la naturaleza humana nos obliga a intentar comprender cómo y por qué surgen determinadas teorías y supuestos, cómo, porqué y para qué penetran en nuestras prácticas. Contrariamente a lo que se ha hecho hasta acá, nuestro trabajo no supone mirar hacia adelante en términos de predicciones posibles en torno a una nueva teoría que explique "verdadera y efectivamente" cómo se aprenden las habilidades motoras; más bien, tomando al aprendizaje motor como objeto del discurso, intentaremos volver la vista hacia atrás, desandar el discurso del aprendizaje motor para romper con la idea establecida y reconstruir los modos y los procesos en que se han constituido esos campos de saber, poder y ética. Creemos que entonces sí podremos "desnaturalizar" estos discursos y cuestionarlos. En esta perspectiva, indagar en torno del aprendizaje motor resulta mucho más complejo y, también, mucho más interesante para nosotros que los trabajos que hasta aquí se han hecho, ya que conjuga dimensiones diversas y contradictorias que exigen pensarlo en toda su extensión.

El trabajo que emprendemos consiste en seguir la sombra del discurso del aprendizaje motor. Para ello hemos decidido investigar tanto aquello que ha sido dicho, como aquello que no ha sido dicho ni pensado (ni por tanto problematizado) y que por ello mismo ha 
quedado en las sombras de lo que sí ha sido dicho y pensado. De otro modo, lo forcluído retorna sin cesar de manera solapada, constituyéndonos como sujetos en las relaciones con el saber, en las relaciones con los otros y en relación con nosotros mismos en esas relaciones de saber y poder.

Compartimos con Agamben que "la presente reflexión sobre el método debería implicar una cautela arqueológica, esto es, retroceder en el propio recorrido hasta el punto en que algo ha quedado oscuro y no tematizado" (Agamben, 2010:10).

Para que este trabajo sea posible será necesario rearmar el estado de cosas en torno de la producción teórica del Siglo XIX y del XX, disecar esos discursos y, a partir de un análisis minucioso, intentar ver qué dicen cuando dicen y qué piensan donde no dicen. Pero cabe tomar el recaudo de no confundir esta labor con un trabajo histórico. No es nuestra intención hacer un trabajo de historia que narre linealmente una serie de acontecimientos con relación al aprendizaje motor a lo largo del Siglo XX, del cual podría deducirse entonces el estado de las prácticas presentes; tampoco se trata de realizar una descripción de aquellos discursos que toman al aprendizaje motor por objeto dado desde una concepción naturalista del aprendizaje y del ser humano, lo que equivaldría a cierto estado del arte; lo nuestro trata de otra cosa. Podría decirse que lo nuestro se trataría de un trabajo inverso al de la historia: partiendo de un problema presente, la inoperancia de todas y cada una de esas teorías, nos vemos en la necesidad de recurrir al pasado para mostrar cómo se han ido gestando esos saberes y esas teorías, a qué intereses responden esas formaciones discursivas. En términos positivos, podemos decir que nuestro trabajo trata de desnaturalizar lo que se ha ido sedimentando en esos discursos y que por ello mismo opera con fuerza en el presente suponiendo cierto efecto de verdad.

En síntesis, decidimos analizar la contemporaneidad, en el sentido que le da Giorgio Agamben:

La contemporaneidad se inscribe en el presente y lo marca, ante todo, como arcaico, y sólo quien percibe en lo más moderno y reciente los indicios y las marcas de lo arcaico puede ser contemporáneo. Arcaico significa: cercano al arké, es decir, al origen. Pero el origen no está situado sólo en un pasado cronológico, él es contemporáneo al devenir histórico y no cesa de actuar en éste. La división y, al mismo tiempo, la cercanía, que definen la contemporaneidad tienen su fundamento en esta cercanía con el origen, que en ningún punto late con tanta fuerza como en el presente. Esto significa que el contemporáneo no es sólo aquel que, percibiendo la oscuridad del presente, comprende la luz incierta; es también 
aquel que, dividiendo e interpolando el tiempo, es capaz de transformarlo y de ponerlo en relación con los demás tiempos, de leer de forma inédita la historia, de "citarla" según una necesidad que no proviene de ninguna manera de su arbitrio sino de una exigencia a la que él no puede responder. Es como si esa invisible luz que es la oscuridad del presente proyectara su sombra sobre el pasado y éste, tocado por este haz de sombra, adquiriera la capacidad de responder a las tinieblas del presente. Algo más o menos semejante debía tener en mente Michael Foucault cuando escribía que sus investigaciones históricas sobre el pasado son solamente la sombra de su interrogación teórica del presente (Agamben, 2011:2829).

\subsection{LAS CIENCIAS DEL HOMBRE Y LA EDUCACIÓN}

Como hemos mostrado en el capítulo 2, la investigación del aprendizaje motor no ha hecho más que reproducir los métodos y técnicas de investigación de las ciencias de la naturaleza, lo que en ciencias sociales se ha llamado positivismo. Al principio, estas pesquisas eran realizadas mediante la observación asistemática; luego supusieron que, para volver a estos conocimientos "ciertos y rigurosos", no bastaba con conocer el desenvolvimiento de "uno", pues esto volvía imposible la generalización, por lo que apelaron a una observación tan variada y tan múltiple como fuera posible, para inducir, una vez reunidos los datos necesarios, esas leyes generales que buscaban formular. Más tarde, cayeron en la cuenta de que no bastaba con la observación, por atenta que fuera, de los fenómenos que se ofrecen espontáneamente, sino que era preciso provocarlos en determinadas circunstancias, para lograr su comprobación: así pasaron a los laboratorios. Por último, si lo que se buscaba era formar una "ciencia de la actividad física" o una "ciencia de la motricidad", sería preciso entonces reunir y comparar datos, porque de acuerdo a este modo de entender las cosas, la base científica no puede encontrarse más que en una abundante y cuidadosa estadística de aquello que puede ser evidentemente contabilizado, calculado, medido y comparado, es decir cuantificado y pasible de ser generalizado.

En términos epistemo-metodológicos, este modelo de investigación supuso y supone un modo de dar respuestas que proviene de la concepción heredada de la ciencia, y que, obedeciendo a la impronta de la tradición científica, intenta dar respuestas sobre las prácticas de aprendizaje desde la mirada de las ciencias biológicas o psicobiológicas que se supone aportan datos "objetivos" de lo real. Para que ello sea posible se reduce la complejidad fenoménica de las prácticas, estableciendo parámetros universales que 
jalonan la vida del individuo en etapas universales, de las cuales se derivan criterios para la enseñanza que funcionan con un fuerte carácter prescriptivo y normativo. Fundado sobre los principios de una "ciencia natural", se ponen en series lineales los elementos que se recortan sobre el supuesto de una "representación" evidente y universal, es decir, se elige un conjunto acabado y relativamente limitado de rasgos, en los que se estudiará, en todos los individuos que se presenten, las constantes y las variaciones. Este sistema

delimita tales o cuales de los elementos que su descripción yuxtapone con minuciosidad. Estos elementos definen la estructura privilegiada, y en verdad, exclusiva a propósito de la cual se estudiará el conjunto de identidades o de diferencias. Toda diferencia que no remita a uno de estos elementos será considerada como indiferente (Foucault, 1968:140).

Pero, como bien dice Foucault, no es posible alcanzar el sistema natural sino después de haber establecido con certeza un sistema artificial: en la elección del método se supone que el éste permitirá resolver el problema, porque en lugar de recortar dentro de la totalidad descrita los elementos - escasos o numerosos - consiste en deducirlos progresivamente, es decir sustraerlos a partir de rasgos arbitrariamente elegidos, que se describen al detalle y se los compara con los de otros individuos. Esos rasgos comunes son los que luego se establecerán de manera positiva, constituyendo las taxonomías.

Los trabajos realizados por los precursores de la investigación en Educación Física se deducen a partir de la experimentación. Marey (1830-1903), por ejemplo, se dedicó al estudio de la locomoción en todos los seres vivos para obtener leyes generales, con la idea de aclarar el juego normal de los órganos y llegar a una mejor utilización en los animales domésticos o el trabajo del hombre en las profesiones manuales; y Demeny (1850-1917) se ocupó especialmente de los movimientos humanos, de los movimientos naturales, con el propósito de aplicar sus descubrimientos a la Educación Física. Fue este último el primero en comenzar a utilizar y perfeccionar la cartografía para registrar los movimientos naturales y deportivos, así como el primero en utilizar aparatos de laboratorio con el fin de medir y cuantificar la actividad física: compás inscriptor, toracómetro, aparatos inscriptores de perfiles, espirómetro registrador, etc. (Suaudeau, 1946: 58-60).

Todo este trabajo "científico" es llevado adelante con el objeto de clasificar a los individuos y establecer "tipologías" de los seres humanos y de las poblaciones. En un libro de Educación Física de mediados del S. XX puede leerse: "desde el S. XVIII se tiende a clasificar a los individuos según su morfología externa” (Suaudeau, 1946:8). Así nació la 
ciencia de la morfología humana, que demoro más de un siglo en separarse de las ciencias naturales. Primero, Gall quiso clasificar a los individuos según el aspecto exterior del cráneo, y creó la frenología (fin del S. XVIII); luego, Brocca se interesó en la forma interna del cráneo y de las circunvoluciones del cerebro e imaginó la craneología. Las nociones de dinamometría y de espirometría ensancharon luego el campo de la antropometría; aparatos de medición cada vez más perfeccionados permitieron la creación de la biometría, ciencia exacta. Los médicos estudiaron de cerca un fenómeno de repercusiones morfológicas importantes: el crecimiento. Los militares, buscando índices de robustez, aportaron su óbolo a las ciencias nueva. Por otra parte, con Binet, que no temió introducir el estudio de la agudeza visual y auditiva y el "cociente intelectual" en sus investigaciones, nació la antropometría y psicometría escolar. Finalmente los teóricos de la Educación Física hicieron su importante colaboración: Demeny y Marey inventaron los primeros aparatos de medición indispensables y dieron origen a toda una escuela de constructores. Los suecos establecieron croquis-tipo para delinear las deformaciones, realizando la morfología estructural tan evidente y llamada a un brillante porvenir. Con Sigaud y sus alumnos nacen las nuevas ciencias del hombre. Estas Ciencias del Hombre presentan las siguientes características: 1) se considera al hombre normal, es decir al hombre sano, normalmente constituido, y no al enfermo o al ser debilitado. Se trabaja sobre cualquier individuo y se trata de descubrir en él caracteres específicos normales y no caracteres patológicos; 2) se apoyan en medidas exactas, hasta minuciosas, a veces en estudios serios de fisiología y de anatomía; 3) tienden a lo universal; 4) extienden su dominio y sus referencias no sólo sobre lo físico, sino también sobre el intelecto y hasta sobre la moral; 5) para resaltar su carácter, tienden a lo general, resolviendo en fórmulas simples o en croquis-tipo. Son netamente esquemáticas: consideran al hombre en el trabajo, es decir, en actividad, y tratan de definir al hombre en su integridad, abrazando en una clasificación general el físico, el intelecto y la moral (Suaudeau, 1946:99-101).

Veamos un ejemplo de cómo opera esta metodología por la cual se realizan "científicamente" las clasificaciones:

$1^{\circ}$ Se consideran los caracteres morfológicos. Se procede a tomar medidas extremadamente numerosas y muy precisas. Según los resultados obtenidos y las diferentes proporciones reveladas entre los segmentos, se clasifican los individuos en cuatro categorías, designadas respectivamente por las letras A, B, C, D. Se da luego al 
individuo una clasificación en cifras según el aspecto de conjunto, y esa clasificación es expresada por un número entero que varía de 0 a 3.

$2^{\circ}$ Se realizan las mismas operaciones en lo que respecta a los caracteres biológicos y fisiológicos. Se establecen otras cuatro categorías que son respectivamente G, H, I, K (lo que da, por combinación con las cuatro categorías morfológicas, dieciséis categorías). Esta vez también se clasifica de 0 a 3 .

$3^{\circ}$ Igual operación con los caracteres psíquicos: con los tests se divide a los individuos en cuatro series, L, M, N y O; se clasifican en su categoría de 0 a 3.

4 la operación se continúa por pruebas físicas, especie de concursos en los que el individuo afronta todas las manifestaciones atléticas imaginables; según los resultados obtenidos, es clasificado en una de las categorías $P, Q, R$ o $S$ y afectado a la nota 1, 2 ó $3 .^{27}$

5을 Para terminar, se somete al individuo a pruebas intelectuales que recuerdan bastante a un examen ordinario también regulado por tests. Resulta de ello una clasificación en otras cuatro series $\mathrm{T}, \mathrm{U}, \mathrm{V}, \mathrm{X}$, y se agrega una última nota (también de 0 a 3).

Así todo individuo pertenece a una de las siguientes categorías: AGLPT, AGLPU, AGLPV, etc.

Establecida la clasificación se obtiene, según testimonian los "científicos", una serie de ventajas:

1 Se los individualiza. Para ello se puede partir de dos individuos que presentan características muy semejantes:

\begin{tabular}{|c|c|}
\hline$\underline{\text { 1er. Individuo }}$ & $\underline{\text { 2do. Individuo }}$ \\
Estudiante, 21 años, normalmente & Atleta notable, soldado enganchado pero \\
constituido, sano, que tiene éxito en la & poco inteligente. \\
Universidad pero no practica ningún & \\
deporte. & \\
& \\
\hline
\end{tabular}

Los símbolos se presentan así:

A2 H2 L3 Q1 V2

A3 G2 N1 Q3 V0

${ }^{27}$ Nótese que en este caso no se incluye el 0. 
Estos símbolos indican las aptitudes generales de cada individuo, sin necesidad de otro comentario, y para los técnicos ofrece la posibilidad de compararlo con símbolos tipo, minuciosamente establecidos y que representan al deportista ideal:

El corredor de velocidad ideal tiene por símbolo

A3 G3 L2 P3 T2

El levantador de pesas

B3 H3 L 2 R3 T2

El jugador de básquetbol

C1 K3 L2 Q3 V2

De allí se deduce que el atleta debe destacarse especialmente en Basquetbol, pero que aun en ese deporte está lejos de ser excepcional; el estudiante, por otro lado, resulta alejado del éxito (Suaudeau, 1946:101-111).

Lo que nos interesa subrayar es que estos procedimientos clasificatorios de la ciencia penetran en otras regiones -como la educación- que, por vía de la Pedagogía y la Didáctica, determinan las acciones posibles en términos de aprendizaje y por ende de enseñanza.

Entonces, toda vez que se afirma con rigor científico qué se puede aprender, se determina además qué se debe enseñar en cada período del desarrollo (ver cuadro 4). Se establece además cierto parámetro de normalidad/anormalidad, de acuerdo con la presencia o ausencia de determinadas conductas, y se prescribe al maestro qué hacer en torno de la enseñanza, lo que supone al mismo tiempo reducir su labor a la de ser un mero aplicador de teorías, pasivo en el acto de enseñar. En fin, el maestro queda relegado en su función a la mínima expresión que lo convierte en una correa de paso; no es más que "otro ladrillo en la pared". ${ }^{28}$ Entonces, el maestro es el primero en entrar a la "máquina de hacer chorizos", el primero en ser normalizado y callado haciendo suyo el mandato de "hacer" sin "pensar". Podríamos afirmar entonces que el concepto de normalización empezó a aplicarse antes al maestro que al alumno. Foucault dice al respecto que en Alemania se produjo la normalización de los médicos, pero en Francia la normalización de las actividades a nivel estatal se orientó, en un principio, a la industria militar; o sea, se normalizó primero la producción de cañones y fusiles, a mediados del Siglo XVIII, con el fin de asegurar la utilización de cualquier tipo de fusil por cualquier soldado, la reparación de cualquier cañón en cualquier taller, etc. Una vez que se

\footnotetext{
${ }^{28}$ En 1979 la banda de música británica Pink Floyd publicó su álbum "The Wall", en el que el protagonista se ve abrumado por una serie de sucesos que lo aíslan y lo llevan a un mundo de fantasía. Del sufrimiento del protagonista surge una clara crítica a la opresiva educación recibida, desde la perspectiva del que aprende.
} 
normalizaron los cañones, Francia procedió a la normalización de sus profesores. Las primeras escuelas normales destinadas a ofrecer a todos los profesores el mismo tipo de formación y, por consiguiente, el mismo nivel de competencia, se crearon en 1775 y se institucionalizaron en 1790-1791. En síntesis, mientras Alemania normalizaba sus médicos, Francia normalizó sus cañones y sus profesores (Foucault, 1977:89-108).

Veamos cómo opera esta normalización del saber. En el caso del dribling, habilidad genérica que resulta de la combinación de dos habilidades básicas, se establece como esperable que: en el primer ciclo (6-8 años), la pelota tome contacto con los dedos golpeándolos; en el segundo ciclo (8-10 años), la pelota tome contacto con la mano completa y sin ser golpeada, sino guiada; en el tercer ciclo (10-12 años) se tiene un buen control de la pelota, lo que permite variedad de desplazamientos y ritmos de pique, combinando trayectorias y velocidades (Gallahue, 1982). Necesariamente, aquello que "el niño puede" va acompañado de "el profesor debe", prescribiendo y normalizando su práctica.

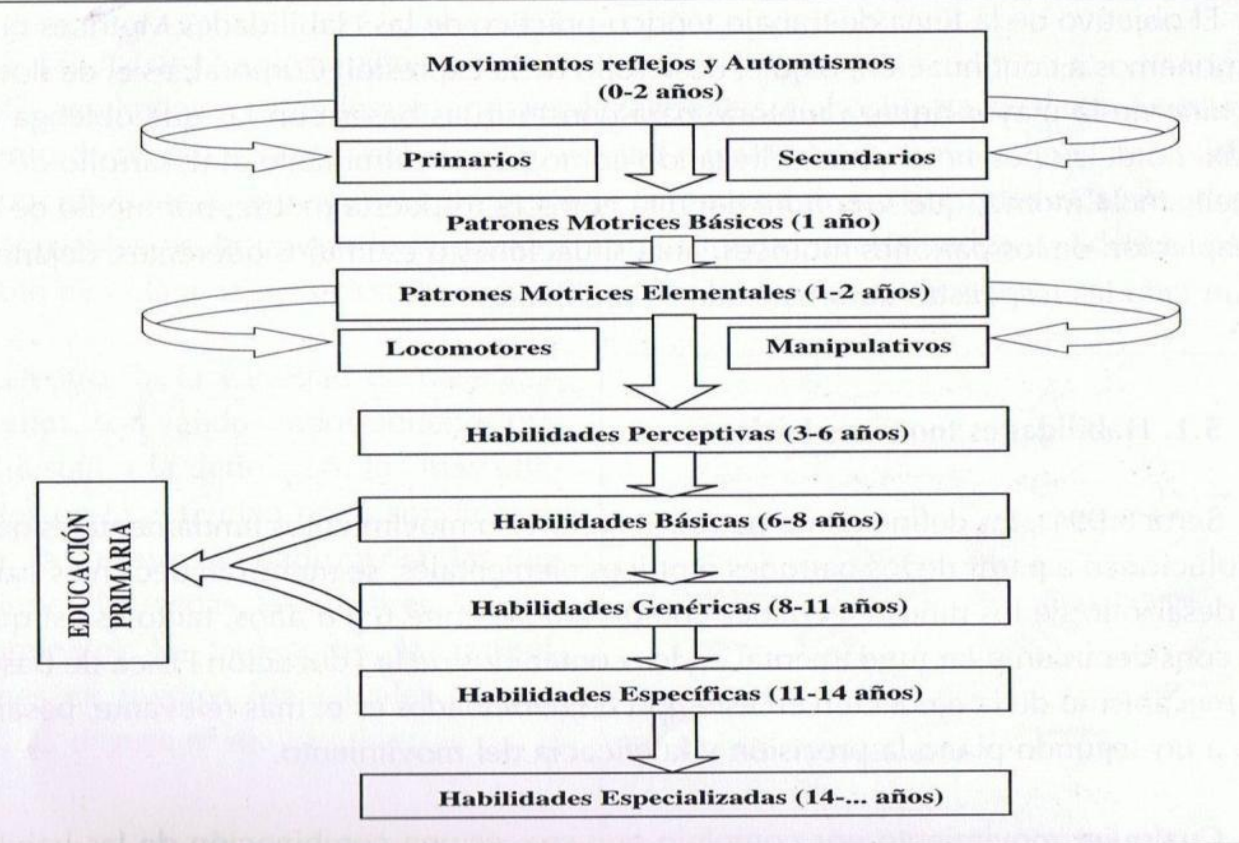

$\underline{\text { Cuadro } 4}$

Entendemos que, si operamos sobre el discurso para provocar el corrimiento de la prescripción dada por la pedagogía y la didáctica hacia una lógica interpretativa y analítica de la práctica, se terminará formalizando una nueva episteme -en sentido foucaultiano- o un nuevo saber que opere en el campo disciplinar. Así, ya no habrá universalidades fijas y verdades certeras, sino interpretaciones que deben hacerse a la luz de otras interpretaciones. Abandonar la Pedagogía y la Didáctica, sesgadas por la epistemología 
empirista implica abandonar ideas de naturalezas, designios, dones, continuidades, universales, leyes, representaciones. ¿Por qué? Porque las ideas de Pedagogía y Didáctica se rigen en la Educación Física bajo la episteme de la ciencia moderna, connotando la lógica humanista como rectora de las prácticas. Esto supone que hay un orden empírico fijo, real y natural, y al mismo tiempo hay teorías que explican el por qué de ese orden y no otro. Pasar de la pedagogía y la didáctica que sostienen un ser y un deber ser desde la lógica naturalista a la política, es en primera instancia cambiar la herramienta interpretativa y analítica de las prácticas. Implica una nueva forma de analizar el discurso que se presenta, y por tanto una nueva forma de establecer la verdad y el saber (Lescano, 2010:2).

\subsection{CAUCiOneS METOdOLÓGicas}

el problema consiste en dejar actuar el saber del pasado sobre la experiencia y la práctica del presente. No es de ningún modo para reducir el presente a una forma reconocida en el pasado que supuestamente tiene validez hoy. Esa transferencia de los efectos políticos de un análisis histórico bajo la forma de una simple repetición es sin duda lo que hay que evitar a cualquier precio.

(Foucault, 2007:157)

Partiendo de las ideas de Foucault, intentamos entonces emprender un trabajo arqueológico-genealógico. Arqueológico en el sentido de la descripción del archivo como conjunto de reglas que, en una época dada y para una sociedad determinada, definen los límites y las formas de su decibilidad, conservación, memoria, reactivación y apropiación; y genealógico en tanto no nos abocaremos a buscar orígenes supuestos de una práctica discursiva o no discursiva, sino a rastrear en la superficie de los hechos las condiciones de posibilidad de su emergencia. Este trabajo demanda minuciosidad en la lectura de mucho material acumulado, oponiéndose a la investigación del origen de un conjunto de prácticas y a una visión historicista conservadora, pero siempre tratando de percibir lo que se instala como verdadero a fuerza de continuidades y discontinuidades, desviaciones o accidentes.

Por otra parte, planteamos la ausencia de un supuesto progreso que nos brinde elementos para comprender las condiciones de posibilidad que permitieron que ciertos discursos emerjan, lo que nos permite también cuestionar las líneas de tiempo, es decir las cronologías elaboradas hasta aquí, y proponer una nueva elaboración histórico-crítica en función de cortes y cesuras que a nuestro modo de ver configuran un objeto total y absolutamente diferente. Mientras que la tradición teórica insiste en establecer 
continuidades temporales y narrar los hechos con criterio evolutivista, nosotros hemos puesto la mirada no solamente en lo que aparece como continuidad, sino también en los cortes, en lo discontinuo pero a la vez repetitivo. En el capítulo 1, hemos circunscrito el aprendizaje motor a la segunda mitad del Siglo XX, porque creemos que en el campo discursivo es allí donde podrá establecerse la conformación de éste como objeto de discurso. He allí una ruptura: ese "acontecimiento" resulta al mismo tiempo un quiebre que inaugura una nueva época para pensar el acto de enseñanza a partir de la figura del alumno; sin embargo hay, hemos podido ver, continuidades, retornos, y repeticiones que se gestan mucho antes, en los discursos del Siglo XIX. Como ya hemos mostrado en los capítulos 1 y 2 , en lo que al aprendizaje y desarrollo motor refiere, el Siglo XX, al que llamamos el Siglo de la Psicología, ha centrado su preocupación en tratar de establecer cuáles son los mecanismos por los cuales se aprende, fundamentalmente a partir de las teorías psicológicas o neuropsicológicas. Sin embargo, y aunque dijimos que no vemos que pueda hablarse estrictamente de aprendizaje motor antes de la segunda mitad del siglo pasado, también hemos rastreado continuidades en los discursos, lo que nos lleva a pensar que esta preocupación respecto a cómo la gente aprende no es más que el efecto del deslizamiento respecto de las preocupaciones del período anterior: el Siglo XIX, en adelante el Siglo de la Fisiología. Al mismo tiempo, podrán rastrearse rupturas, cesuras y cortes entre los discursos conductistas, cognitivistas o de los sistemas dinámicos: mientras que para los conductistas lo central será la aplicación de estímulos adecuados para lograr la conducta deseada, los cognitivistas desplazan la atención al medio interno, y bajo el aura de la mente "aparecen" ideas o conceptos fuertes -estructura, esquema, | representaciones mentales, sistema percepción-conciencia, etc.-; finalmente, los sistémicos vuelven a introducir un corte en el discurso del aprendizaje con el concepto de autorregulación, poniendo nuevamente la mirada en el medio externo como favorecedor o entorpecedor del aprendizaje. Las continuidades entre unos discursos y otros no cesan de aparecer: el individuo, el organismo, el medio, la evolución, el desarrollo, la conciencia, la unidad, en fin, la naturaleza humana. A partir del análisis del discurso, intentaremos mostrar entonces cuáles son esas continuidades y rupturas en torno del aprendizaje motor, qué es lo que inauguran y qué es lo irrenunciable en ellas, cómo y porqué se da este deslizamiento, qué relaciones tejen con otros discursos como el de la biología, la psicología, la fisiología o la física, con los que se cruza pero que también le prestan la palabra. 
Lo nuestro será entonces partir de problemas presentes, contemporáneos e intentar destejer la madeja, desandar ese camino y mostrar que nada de natural hay en el modo en que estos problemas se piensan. Supongamos que el aprendizaje motor, el desarrollo, la mente, la conciencia, la habilidad o los talentos deportivos no existen; el trabajo consistirá entonces en intentar ver a qué formaciones discursivas obedece la conformación de estos universales. A la manera de Foucault, lo que intentaremos hacer entonces no es interrogar los universales utilizando la historia como método crítico, sino partir de la inexistencia de los universales para preguntar qué historia puede hacerse (Foucault, 2007:19). Preguntarse entonces qué lugar ocupa, en lo que se nos da como universal, necesario y obligatorio, lo que es singular, contingente y producto de limitaciones arbitrarias, es tratar de transformar la crítica ejercida en la forma de una limitación necesaria, en la forma de una posible trasgresión. Esto tiene por consecuencia, evidentemente, que la crítica no ha de ser ejercitada como búsqueda de estructuras formales con validez universal, sino más bien como investigación histórico-crítica de los acontecimientos que nos han conducido a constituirnos y reconocernos como sujetos de lo que hacemos, decimos y pensamos. La crítica no es en este sentido trascendental y no tiene como meta hacer posible una metafísica: es genealógica en su finalidad y arqueológica en su metodología. Arqueológica -y no trascendental- en la medida en que no intenta identificar las estructuras universales de todo conocimiento o de cualquier posible acción moral, sino que busca tratar los discursos que designan lo que decimos, pensamos o hacemos en diversos acontecimientos históricos. Genealógica en el sentido de que no deduce de la forma de nuestro ser lo que pueda ser imposible hacer o saber para nosotros, sino que separará de la contingencia que nos ha hecho lo que somos la posibilidad de no ser, hacer o pensar más tiempo lo que somos, hacemos o pensamos, dando así un nuevo impulso al indeterminado trabajo de la libertad (Foucault 1996:104109). Este trabajo crítico supone adoptar una actitud teórica y al mismo tiempo práctica que nos permita recomponer la relación política-vida, no ya en el sentido biológico y organicista de puro mantenimiento orgánico, sino en el de una vida calificada y de relación que obviamente incluye a otros.

Lo que intentamos sacar a la luz es un objeto de otro tipo, que no tiene las mismas fechas, ni la misma superficie o las mismas articulaciones, pero que puede dar cuenta de un conjunto de enunciados para los cuales el término aprendizaje motor no es más que una rúbrica reflexiva, secundaria y clasificatoria. Todos los objetos del discurso del aprendizaje motor han sido modificados desde Lawther hasta Thelen: no son de los 
mismos aprendizajes de los que se trata aquí y allá; no se trata en absoluto de los mismos aprendizajes. Cada uno de esos discursos ha constituido su tema y lo ha elaborado hasta traspasarlo por completo. No son los objetos los que se mantienen constantes, ni el dominio que forman, no son siquiera su punto de emergencia o su modo de caracterizarlo, sino el establecimiento de una relación entre las superficies en que pueden aparecer, en que pueden delimitarse, en que pueden deslizarse y especificarse. No se trata de reconstruir lo que podría ser el aprendizaje motor en sí mismo; tal historia del referente es posible, y la hemos hecho en el capítulo 1. De lo que sí se trata es de atravesar su espesor para alcanzar lo que permanece silenciosamente más allá de él. Se trata de definir el objeto aprendizaje motor, refiriéndolo al conjunto de reglas que permiten formarlo como objeto de discurso y constituyen así sus condiciones de aparición histórica. Nuestro trabajo intentará hacer una historia crítica del aprendizaje motor que no lo hunda, en tanto que objeto del discurso, en la profundidad común de un suelo originario, sino que despliegue el nexo de las regularidades que rigen su dispersión. La tarea que nos proponemos será, entonces, analizar positividades, es decir,

mostrar de acuerdo con qué reglas una práctica discursiva puede formar grupos de objetos, conjuntos de enunciados, juegos de conceptos, series de elecciones teóricas. Los elementos así formados no constituyen una ciencia, con una estructura de idealidad definida; su sistema de relaciones es seguramente menos estricto; pero no son tampoco conocimientos amontonados los unos junto a los otros, procedentes de experiencias, de tradiciones o descubrimientos heterogéneos, y unidos solamente por la identidad del sujeto que los guarda. Son aquellos a partir de lo cual se construyen proposiciones coherentes (o no), se desarrollan descripciones más o menos exactas, se efectúan verificaciones, se despliegan teorías (Foucault, 1979:304-305).

\subsection{ARQUeOlogía y GENEALOGÍA: PRESENTE, PASADO Y FUTURO DEL APRENDIZAJE MotoR}

Siguiendo el sentido que Nietzsche y Foucault han otorgado a la Arqueología y a la Genealogía, el método que utilizaremos será entonces arqueológico-genealógico. Con esto se trata de recusar definitivamente las teorías del Aprendizaje y del Desarrollo Motor,

sacudir la quietud con la cual se las acepta; mostrar que no se deducen naturalmente, sino que son siempre el efecto de una construcción cuyas reglas se trata de conocer y cuyas justificaciones hay que controlar; definir en qué condiciones y en vista de qué análisis ciertos son legitimas; indicar las que, de 
todos modos, no pueden ser ya admitidas. ¿Qué son? ¿Cómo definirlas o limitarlas? ¿a qué tipos distintos de leyes pueden obedecer? ¿de qué articulaciones son capaces? ¿a qué subconjuntos pueden dar lugar? ¿qué fenómenos específicos hacen aparecer en el campo del discurso? Se trata de reconocer que quizás no sean, al fin y al cabo, lo que se creía a primera vista. Que exigen una teoría, y que esta teoría no puede formularse sin que aparezcan, en su pureza no sintética, el campo de los hechos de discurso a partir del cual se los construye (Foucault, 1979:39).

Este trabajo nos pone de cara a dos cuestiones: a) trabajar con las prácticas (en tanto que modos de hacer, pensar y decir), y b) desmontar el pasado no como origen, sino en términos de procedencia.

Foucault, en Nietzsche, la genealogía y la historia (1994:17-18), nos advierte que la genealogía no pretende remontar el tiempo para restablecer una gran continuidad más allá de la dispersión del olvido; su tarea no es mostrar que el pasado está ahí, bien vivo en el presente, animándolo todavía en secreto, después de haber impuesto a todos los obstáculos del camino una forma trazada desde el principio. Nada que semeje a la evolución de una especie, al destino de un pueblo. Seguir el hilo complejo de la procedencia es, al contrario, conservar lo que ha sucedido en su propia dispersión: localizar los accidentes, las mínimas desviaciones -o al contrario, los giros completos-, los errores, las faltas de apreciación, los malos cálculos que han dado nacimiento a lo que existe y es válido para nosotros. Es descubrir que en la raíz de lo que conocemos y de lo que somos no hay ni el ser ni la verdad, sino la exterioridad del accidente. La búsqueda de la procedencia no fundamenta; al contrario, agita lo que se percibía inmóvil, fragmenta lo que se pensaba unido, y muestra la heterogeneidad de lo que imaginábamos conforme a sí mismo. Por otra parte, nos parece relevante este enfoque, en tanto y en cuanto la genealogía, como análisis de la procedencia, está, pues, en la articulación del cuerpo y de la historia. El discurso del aprendizaje motor no carece de consecuencias sobre el cuerpo y todo lo que atañe al cuerpo. Sobre él encontramos, por ejemplo, el estigma del torpe y el talentoso; sobre él se inscriben las debilidades, los instintos, las pulsiones del animal devenido hombre, tanto como las afecciones del medio ambiente y de lo que lleva en la sangre. Sobre el cuerpo se inscribe también el peso de la identidad que congela y fija en términos esencialistas. La genealogía debe mostrar el cuerpo totalmente impregnado de historia, y la historia arruinando el cuerpo, pero el gran juego de la historia es para quien se apodere de las reglas, ocupe el puesto de los que las utilizan, se disfrace para 
pervertirlas, utilizarlas al revés y volverlas contra los que las habían impuesto. ¿Qué pasaría si se mostrara que nada de natural hay en el aprendizaje motor? ¿qué pasaría si, a sabiendas de que se trata de construcciones arbitrarias, de cortes y cesuras impuestos por la ciencia, alguien se atreviera a desafiar esas reglas impuestas y enseñar no de acuerdo con lo que marcan las "etapas" -como "deber ser"- sino a partir de la lógica del contenido a enseñar? ¿qué pasaría si el talentoso dejara de ser un tocado por la varita mágica y el gordo pudiera hacer algo más que ir al arco?.

Si interpretar no es sacar a la luz una significación enterrada, sino apropiarse, violenta o subrepticiamente, de un sistema de reglas que en sí mismo no tiene significación esencial e imponerle una dirección, plegarlo a una nueva voluntad, hacerlo entrar en otro juego y someterlo a reglas secundarias, entonces el devenir de la humanidad consiste en una serie de interpretaciones. Así, el niño de 6 años no "es" sino a partir de un discurso que lo interpreta, lo encauza, lo normaliza, lo universaliza y equipara a otros niños de 6 años; pero también aquello que "puede y debe" hacer o aprender es reinterpretado a la luz de la genealogía. ¿Qué pasaría si el docente se atreve a desafiar las progresiones metodológicas y en lugar de "respetarlas", "obedecerlas", las subvierte, las desafía, y las contraría? Habría que ver entonces, cuál sería el efecto de mostrar que el cuerpo no se agota en las leyes de su fisiología, sino que está atrapado en una serie de regímenes que lo modelan, lo rompen y lo intoxican.

La historia "efectiva" se distingue de la historia de los historiadores en que no se apoya en ninguna constancia: nada en el hombre -ni siquiera su cuerpo- es lo suficientemente fijo como para comprender a los demás hombres y reconocerse en todos ellos. Entonces, se trataría de fragmentar lo que permitía el juego consolador de los reconocimientos. La historia será "efectiva" en la medida que nos introduzca lo discontinuo de nuestro mismo ser, divida nuestros sentimientos, dramatice nuestros instintos, multiplique nuestro cuerpo y lo oponga a sí mismo; no deje nada sobre sí que tenga la estabilidad tranquilizadora de la vida de la naturaleza, ni se deje llevar por ninguna muda obstinación hacia un final milenario; socave aquello sobre lo que se la quiere hacer reposar, y se ensañe contra su pretendida continuidad. $Y$ es que el saber no está hecho para comprender, está hecho para zanjar (cf. Foucault, 2004:27-47).

Entonces, en la arqueología foucaultiana, como en la genealogía, lo que está en cuestión no es propiamente un pasado, sino una emergencia a la que esa arqueología puede acceder sólo remontándose hacia atrás hasta el punto en el cual ha sido cubierta y 
neutralizada por la tradición. La emergencia, la arké de la arqueología, es lo que advendrá, lo que llegará a ser accesible y presente sólo cuando la indagación arqueológica haya cumplido su operación. Tiene por lo tanto la forma de un pasado en el futuro, es decir, de un futuro anterior (Agamben, 2009:145).

Pensar las prácticas, como se las ha pensado, a partir de cómo se sospecha que aprende el alumno, supone al mismo tiempo la conformación de un tipo de intervención reguladora de los métodos de enseñanza que está en estrecha correlación con la emergencia de un maestro cuya función es la de desinhibir las fuerzas naturales. En la sacralización de las teorías, se vuelve inoperante no sólo el maestro que queda desinvestido de todo saber, sino también el saber mismo, porque lo importante no es el contenido a enseñar sino el "individuo que aprende". Por el contrario, poner en cuestión estas ideas de naturaleza y aprendizaje obliga a desplazar al alumno del lugar de supuesto soberano del proceso educativo en el que ha sido puesto en el Siglo XX, al tiempo que invita a pensar de manera urgente no solamente en la figura central del maestro sino también en la dirección de la enseñanza. Entonces, nos parece necesario pensar estas cuestiones respecto del Aprendizaje para desplazarlas hacia una genuina preocupación por la Enseñanza.

En síntesis, suponemos que reflexionar sobre estas cuestiones será la contracara de lo que hasta aquí se ha construido como objeto en torno al aprendizaje motor, porque tenemos el convencimiento de que problematizar de este modo nos hace escapar de la pura "repetición", nos hace "pensar", y pensar es "no repetir" haciendo un mejor ejercicio de nuestra libertad. Creemos que este trabajo en buena medida invitará a pensar al lector y a preguntarse: “¿qué es lo que podemos hacer con lo que hicieron de nosotros?" 


\title{
Capítulo iV \\ BIOPOLÍTICA Y EDUCACIÓN
}

\begin{abstract}
Las ciencias biológicas habían reconocido desde un principio que la vida -en sí misma y como proceso productivo- sólo puede conservarse si permanece activa. En la visión de la biología, los equilibrios y los estados son el resultado de actividades. En consecuencia estas actividades son un elemento irrenunciable para la conservación y el mejoramiento de la vida.
\end{abstract}

(Caruso, 2005:156)

\subsection{De la Enseñanza del S. XIX al Aprendizaje Motor del S.XX}

Adelantábamos en el capítulo anterior que el Aprendizaje Motor se ha constituido como objeto por el conjunto de lo que ha sido dicho en el grupo de todos los enunciados que lo nombran, lo recortan, lo describen, lo explican, cuentan sus desarrollos, indican correlaciones con otros campos que lo juzgan y eventualmente le prestan la palabra, para que el aprendizaje motor la articule a discursos que deben pasar por ser los suyos. Intentaremos en este capítulo disecar esos discursos y mostrar cómo se han ido articulando, cuáles son las continuidades y cuáles las cesuras con el discurso educativo moderno del Siglo XIX.

Michel Foucault nos advierte que, desde segunda mitad del S. XIX, el poder tiende a transformarse con el objeto de gobernar a los individuos por medio de un cierto número de procedimientos disciplinares. Por otro lado, a través del proceso de medicalización de las sociedades, se convierte a estos individuos en "población", ejerciendo una política y una gestión de la vida. Así, por medio de los poderes locales, el estado se ocupará de la gestión de la salud, de la higiene, de la alimentación, de la sexualidad, de la natalidad, etc. El saber médico -y en especial el de la fisiología y la psiquiatría- se convierte en el parámetro de todo saber legítimo, y trascendiendo al enfermo y las enfermedades pasa a ocuparse de otros campos de saber. Se pone en marcha una tecnología reguladora de la vida, cuyo objetivo no sería tanto regular los cuerpos individuales cuanto el cuerpo social: las poblaciones. Estas tecnologías, junto con las tecnologías disciplinarias, individualizantes e individualizadoras que se centran en los cuerpos y en los individuos, ponen en marcha técnicas de racionalización y economía: tecnologías de un poder poco visible, microfísicas y capilares, actuando en la formación de nuevos saberes e instituciones destinados a jerarquizar, clasificar, vigilar y adiestrar los cuerpos (este es el análisis más frecuentemente realizado dentro de la Educación Física), pero, y por sobre 
todo, saberes e instituciones destinados a la gestión global de la vida, entre cuyos exponentes figura la higiene pública, la estadística (Revèl:2005), y a nuestro entender también la Educación Física.

Es a partir del Siglo XIX que el hombre, en tanto que viviente y perteneciente a una especie biológica, ocupará el centro de la escena (Castro, 2006:190). Según Foucault, la instauración del hombre en el campo del saber (la formación de la analítica de la finitud y de las ciencias humanas), a la vez sujeto y objeto de conocimiento, implica un imperativo que atormenta el pensamiento desde el interior, bajo la forma de una moral, de una política, de un humanismo: el deber de hacerse cargo del destino occidental, la obligación de cumplir con la tarea de funcionarios de la historia. Es el humanismo el que ha inventado, alternativamente, estas soberanías sujetadas que son el alma (soberana sobre el cuerpo, sometida a Dios), la conciencia (soberana en el orden del juicio, sometida al orden de la verdad), el individuo (soberano titular de sus derechos, sometido a las leyes de la naturaleza o a las reglas de la sociedad), la libertad ${ }^{29}$ fundamental (interiormente soberana, exteriormente consintiente y acordada con su destino). A partir de este fenómeno de medicalización de la sociedad, la preocupación estará puesta en definir y diferenciar lo científico de lo no científico, lo racional de lo irracional, y lo normal de lo patológico o anormal. Es en este umbral biológico de la modernidad que la ciencia comienza a preocuparse por establecer parámetros para cada edad, y a clasificar como anormal o desviado a todo aquel que no responda a los parámetros establecidos. ${ }^{30}$ Sin embargo, el discurso de la Educación Física, al igual que todas las disciplinas nacidas a la sombra de la biopolítica, no es un discurso ingenuo; por el contrario, es un discurso que legitima y hace posible la circulación del proyecto del liberalismo burgués. Como dice Judith Revèl respecto del análisis de Foucault, para que un cierto liberalismo burgués haya sido posible a nivel de las instituciones, fue preciso, en el nivel de los micro-poderes, un investimento mucho más fuerte de los individuos, fue preciso organizar el

\footnotetext{
${ }^{29}$ El problema de la libertad puede verse fundamentalmente en el discurso de las teorías de los sistemas dinámicos. También en Lawther (1983:38-40), bajo el titulo "El niño necesita enfrentarse con variadas experiencias y actuar con independencia y libertad".

30 "Todos los defectos orgánicos se van aumentando de generación en generación, cuando en el transcurso de la vida individual no se hace algo para combatirlos. Los padres degenerados 0 depauperados engendrarán casi seguramente hijos también degenerados. [...] El desarrollo ontogenético del hombre se encuentra reproducido a grandes rasgos, según las leyes bien conocidas; en el desarrollo filogenético del individuo, y aún desde aquí hasta el período de la pubertad, viniendo a marcar una serie de normas bien precisas para el desarrollo individual del organismo (Spitzy, 1917:19)
} 
escudriñamiento de los cuerpos y de los comportamientos (Revèl:2005:22); en este contexto, la Educación Física, al reproducir modelos y métodos de investigación, ha apuntado a reducir al sujeto a la suma de sus comportamientos, que a su vez intenta evaluar según procedimientos llamados "científicos", que son inadecuados a su objetos. ${ }^{31}$

Este fenómeno instaló un quiebre. Con la constitución de los estados-nación se buscó racionalizar los problemas planteados a la práctica gubernamental por los fenómenos propios de un conjunto de vivientes en cuanto población: salud, higiene, natalidad, longevidad, raza. ${ }^{32}$ Esta nueva forma del poder ya no se ocupó tanto del individuo en particular, y sí del individuo en tanto que formando parte de la población. A partir de allí, la preocupación estará centrada en: 1) fenómenos poblacionales (no individuales sino múltiples) como la proporción de nacimientos, de decesos, de las tasas de reproducción, de la fecundidad de la población -en una palabra, de la demografía-; 2) enfermedades endémicas producto del hacinamiento en las ciudades, es decir de la naturaleza, extensión, duración e intensidad de las enfermedades reinantes en la población; 3) higiene pública que pone en relación el problema del medio geográfico con el clima, el urbanismo y el medio ambiente.

A partir de este momento, el centro de la escena estará ocupado por el hombre, en tanto que viviente y perteneciente a una especie biológica, y con él, el problema de la vida. Las siguientes preguntas se imponen: ¿cómo se traduce en términos de educación -y educación del cuerpo- la apuesta moderna que pone al hombre en un lugar central? ¿cuál será el efecto de verdad de estos discursos y cómo se desplazan luego a la pregunta por el aprendizaje?

De los documentos de la época podemos deducir recogemos que, debido a los cambios políticos y culturales que se instauran en la Modernidad, el Siglo XIX estuvo centrado en la enseñanza. Existía por entonces una clara preocupación por la trasmisión de conocimientos, expresada en términos de enseñanza (aunque para nosotros se trata de

\footnotetext{
31 "Todo descubridor de un nuevo sistema se considera obligado a dar una explicación fisiológica altisonante de su descubrimiento para así protegerlo bajo la bandera de la crítica científica"; "la biología, la medicina social, la terapéutica, la ortopedia y la higiene nos enseñan, con perfecto acuerdo la necesidad de llevar a cabo la educación física en los primeros años de la vida" (Spitz 1917:2 y 31 respectivamente).

${ }^{32}$ El problema de la raza es una de las grandes preocupaciones de la Modernidad. Como sostiene Hannah Arendt, las investigaciones fisiológicas o biológicas son consecuencia del pensamiento racial y no al revés (recordemos cuando decíamos que en la teoría está el método), ya que el racismo es la principal arma ideológica de las políticas imperialistas modernas. Cfr. Arendt, 1998:142-145.
} 
instrucción y no de enseñanza) y por la cual es preciso establecer lo que "debe ser y saber un buen maestro", "los efectos de la enseñanza sobre el individuo", y, como consecuencia, los efectos de esta educación en el pueblo y la nación.

Es en el pasaje del poder religioso o soberano al poder del Estado que el gobierno, disputando el poder de la iglesia, pone en cuestión la verdad religiosa y dogmática para ceder lugar a la ciencia y la razón (no menos religiosa y dogmática que la verdad que cuestionan).

En sus primeros pasos, las sociedades aparecen, en la época primitiva de la humanidad, dominadas por la idea, o mejor dicho, por el sentimiento religiosos. La iglesia, por medio de sus sacerdotes, lo absorbe todo. El hombre vive exclusivamente por la Divinidad y para la Divinidad. Todas las demás tendencias del espíritu están absorbidas y como anuladas por aquella idea dominante. Desde aquel estado de desequilibrio y exclusión, siguen las sociedades, al obedecer a la ley del progreso, desarrollando en su seno nuevas esferas de actividad, mediante las tendencias naturales del espíritu humano, destinado a romper todas las trabas que se opongan a su perfeccionamiento. Los guerreros obligaron a los sacerdotes a compartir con ellos el poder, dice la historia. Así se destruye por primera vez la soberanía absoluta de la iglesia. Empieza a crearse una nueva esfera de actividad para las fuerzas del hombre. Y surge el Estado en lucha con la Iglesia. (La Educación, 1886:33)

Es en este pasaje de la Soberanía al Gobierno que la Educación deja de ser el privilegio de unos pocos para convertirse en un derecho de todos, y será el Estado el encargado de velar por ello, garantizando el acceso "común" a todos los ciudadanos. ${ }^{33}$

Ya se comprende, en la época actual, que el Estado debe tratar de reducir su acción a garantir los derechos de todas las personalidades, individuales y colectivas, para que se realice la libertad en su forma más amplia [...] Después de la Iglesia y el Estado, es la Educación la rama social que más desarrollo e independencia ha adquirido. (La Educación, 1886:34)

Por otra parte, vemos que no se trata de cualquier Educación, sino de una idea de Educación construida en la cosmovisión moderna e inserta en el "umbral biológico de la

${ }^{33}$ En Argentina, la Ley 1420 de Educación Común en la Capital, Colonias y Territorios Nacionales, del 8 de julio de 1884, plantea la obligatoriedad de la Educación para niños de 6 a 14 años. 
modernidad," ${ }^{34}$ e informada por las leyes de la naturaleza según dicta la ciencia. La ciencia por entonces está encarnada en la fisiología.

No es necesario insistir sobre lo que debería ser la educación [...] es evidente que dada la idea luminosa de la función del hombre, ella deberá tener por fin organizar el pensamiento según este supremo punto de vista, de desarrollar las facultades y aptitudes individuales y disponer al hombre en posesión de sí mismo a fin de que pueda querer con energía lo que es conforme a su ley y trabajar libremente para conseguir su realización. Bajo el punto de vista de la salud y de la higiene, la educación debe subordinar las impulsiones de la sensación a la dirección suprema del pensamiento y a desarrollar el principio de voluntad que es el instrumento privilegiado de la doble conservación del ser humano (La Revista Pedagógica, 1883:140),

Al maestro, por su parte, le cabe la responsabilidad de guiar este proceso del mejor modo posible para lograr que sus discípulos logren oír la voz de la naturaleza, educados por el recto camino de la moral y la ilustración conforme a esas mismas leyes:

el poder de oír la voz de nuestra naturaleza es una facultad, que como las demás necesita cultivo, y el maestro que se interese por la salud de sus discípulos debe encaminarles a oír la voz de su naturaleza, cuya principal manifestación es la conciencia, sin cuya ilustración es imposible el mérito ni la libertad moral, y por consiguiente tampoco el bienestar (La Educación, 1886:50).

Así, se funda una nueva razón en las leyes de la naturaleza. La educación, entonces, deberá guiar hacia el buen encauzamiento del hombre, lo que significa a todas luces una educación moral que permitirá fundar sobre estas leyes un pueblo recto y próspero, basado en la razón y el progreso.

A partir de este momento, la escuela tendrá por objeto favorecer y dirigir simultáneamente el desarrollo moral, intelectual y físico de los niños. Así, a partir de la "verdad científica", la enseñanza estará abocada al descubrimiento o desciframiento de símbolos y/o signos secretos que la naturaleza oculta para preservar su esencia; la tarea educativa es, en definitiva, la búsqueda de la ley interior que determina el sentido de la educación.

${ }^{34}$ El umbral biológico de la modernidad se sitúa en el momento en que la especie entra como apuesta del juego en sus propias estrategias políticas. "Uno de los fenómenos fundamentales del XIX fue y es la consideración de la vida por parte del poder, un ejercicio del poder sobre el Hombre en cuanto ser viviente, una especie de estatización de lo biológico" (Foucault, 2007:217). 
Foucault dice que en la modernidad se pasa de la pregunta “¿qué has hecho?”, a la pregunta “¿quién eres?". De esa forma, el poder soberano acciona sobre el "deber ser" y no sobre el derecho. Es un "deber ser" fundamentado y argumentado en la naturaleza: "hablando del ser humano, su primer deber es obedecer la voz de su naturaleza antes que a cualquier otra autoridad, para que así pueda llegar a ser lo que debe ser, y consiga al mismo tiempo su salud física y moral" (La Educación, 1883:49-50).

Se pasa, entonces, del problema de la legitimidad al problema de lo lícito (lo que hay que hacer), y la naturaleza funciona como lugar de verdad (Foucault, 2007:52-53).

El maestro del porvenir será un artista educacional. Debe ser un profundo estudiante de la naturaleza de la niñez, así como también de la idea educacional y de la experiencia de la raza. La actividad propia de la mente del niño, estimulada y dirigida por el maestro se desarrolla para dar pasos inteligentes, el maestro debe comprender el plan del asunto a enseñar, etc., etc., debe entrar en la trama de su economía mental. Sometido a este plan toda la naturaleza del niño -física, moral e intelectual- brotarán flores que se convertirán en botones y luego en exquisitos frutos. La más grande y noble virilidad será el resultado conseguido. Nuestra raza entrará bajo las fases de las probabilidades humanas, predichas por lo poetas y los filántropos". (La Revista Pedagógica, 1883:43)

EI Siglo XIX, entonces, responde a los intentos de implementar un modelo educativo que permita desarrollar aquello considerado "la naturaleza humana", y todo proyecto que se considera "humanista" convierte esta "naturaleza humana" en una tarea pedagógica, a la que también podemos calificar de política. Es a través de una serie de intermediaciones lingüísticas, conceptuales e institucionales que los políticos adoptan los criterios biológicos como rectores de sus acciones y las de aquellos a quienes dirigen. Decir "qué es" (en esencia) el hombre significa decir "qué debe ser", y esto implica necesariamente indicar un camino para la consecución de esa esencia, planteada como un fin de la humanidad.

Entendemos que a partir del análisis de este cuadro de racionalidad política podemos comprender la emergencia de un discurso educativo que permitirá luego pasar a la pregunta acerca de cómo se aprende.

Sobre el suelo originario de una verdad indiscutida respecto de la enseñanza, el Siglo XX, de la mano del discurso del Aprendizaje Motor, ya no se cuestionará más respecto de cómo hay que enseñar; esa pregunta había sido respondida tiempo antes, y la respuesta 
misma ha pasado a ser una "verdad" de Perogrullo: se enseña según dicta la naturaleza. Ese ese es plafón sobre el cual se inaugura la pregunta: ¿cómo se aprende?

\subsection{El modelo organicista: El individuo, la conciencia, LA Unidad y EL Problema de LA GUBERNAMENTALIDAD}

Contrario a lo que se ha creído, el análisis de los discursos modernos nos lleva a afirmar que el nacimiento de la Educación Física moderna no formó parte de una estrategia disciplinaria, sino más bien biopolítica. Reconocemos en ella el brazo armado del biopoder que, a partir del Siglo XIX, hace entrar al cuerpo en la serie población-procesos biológicos-mecanismos reguladores-Estado, no ya como cuerpo individual, sino como cuerpo colectivo y especializante.

Como dice Edgardo Castro,

el biopoder, absolutamente funcional al desarrollo del capitalismo, se ha organizado bajo dos modos principales, articulados entre sí. El primero en formarse fue el poder disciplinario en derredor del cuerpo individual tomado como máquina. El segundo toma el cuerpo-especie en tanto soporte de procesos biológicos como la proliferación, los nacimientos, la mortalidad, la salud, la duración de la vida, etc. El dominio general de intervención, no es ya el individuo y su cuerpo, sino el cuerpo múltiple de la población. Se trata en este caso, de una biopolítica que hace entrar a la vida y sus mecanismo en el domino de los cálculos explícitos y convierte al poder-saber en un agente de transformación de la vida humana (Foucault, 1976:183; citado en Castro, 2007:10).

Michel Foucault nos advierte que el biopoder se ejerce al nivel de la vida pública, como gestión de estado. No se interesa en el adiestramiento del individuo, sino en hacer previsiones, en establecer mecanismos reguladores y en mantener un promedio. Al tomar en cuenta la vida y los procesos biológicos del hombre/especie, asegura en ellos no una disciplina sino una regularización. Se puede decir que, en contraposición con la definición aristotélica tradicional, el hombre moderno es un animal en cuya política está puesta en entredicho su vida de ser viviente. Esta nueva técnica no corrige, sino que previene.

Gracias a que la vida, transformada en objeto político, es entendida como "un conjunto de necesidades fundamentales, esencia concreta del hombre, cumplimiento de sus virtualidades, plenitud de lo posible", ${ }^{35}$ la estrategia del humanismo se extrema y

\footnotetext{
${ }^{35}$ Michel Foucault, La voluntad de saber (p. 175), en Castro, Edgardo (2005). Michel Foucault: La cuestión del Humanismo, inédito.
} 
radicaliza su función prescriptiva y justificatoria. En un contexto de prevención y de intervención biopolítica, el humanismo se funde con el significado mismo de la vida que debe regular. En el avance sobre la vida biológica, el poder recubre al hombre y alcanza sus límites. Interviene sobre lo otro del hombre: lo animal. ${ }^{36}$

La educación encontrará en el discurso higienista los argumentos para conducir al hombre por el recto camino de la naturaleza, evitando "el vicio", "los excesos", y todo aquello que "corrompa", "degenere" o contraríe la "fuerza interna naturaleza" y "desvíe del recto camino" al pueblo y la nación. Encontramos en los documentos del Siglo XIX una serie de registros que comprenden diferentes formas de circulación de saberes relativos a la higiene, que nos remiten a cuatro ideas centrales que el Siglo XX no ha abandonado en absoluto: el Individuo (en tanto que indiviso), por lo tanto la Unidad, también la Conciencia, y por último la Interioridad, que se manifiesta en otros conceptos como instinto, ${ }^{37}$ pulsión (diría luego Freud) o esencia.

La mejor naturaleza del niño debe ser estimulada tan pronto como sea posible para luchar contra el poder creciente del instinto animal, al cual considero como la base de la naturaleza inferior del hombre. La actuación de este instinto animal se hará más patente en los días subsiguientes de la vida del niño. Este instinto, no más contenido ahora que en sus primeros esfuerzos, que fueron necesarios para la propia conservación, crece rápidamente en fuerza. El ardor de estos anhelos del niño forma un fuerte contraste con sus poderes físicos. Se apoderaría de todos los objetos que percibe: no hay nada que despierte su curiosidad que al mismo tiempo no suscite sus deseos; y la inconcebible obstinación de este anhelo aumenta en la misma medida en que se coloca el objeto fuera de su alcance. Todo lo que hay de tosco y poco amable en el niño pequeño se encontrará conexionado de un modo u otro con la acción de este instinto animal. Porque incluso la impaciencia del niño mientras está bajo el influjo de circunstancias que pueden causarle dolor físico, no es más que una reacción de ese instinto. Si consideramos el estado del niño con sus deseos y su impaciencia, veremos que proporciona un paralelo sorprendente con la imagen del hombre que está bajo el influjo de sus pasiones. Es costumbre decir que la pasión debe ser vencida por principio y que nuestros deseos deben ser

\footnotetext{
${ }^{36}$ Castro, Edgardo (2005). Michel Foucault: La cuestión del Humanismo, inédito.

37 “El término instinto significa 'aguijón', 'acicate', 'estímulo' (de instinguere = 'aguijonear', 'estimular'). De ello deriva el sentido de instinto como estímulo natural, como conjunto de acciones y reacciones primarias, 'primitivas' y no conscientes". Ferrater Mora, José, 1964, Diccionario de Filosofía, Tomo I a-K, Sudamericana, Buenos Aires, p. 971.
} 
regulados por la razón (Carta XIII del 12 de diciembre de 1818 - Pestalozzi, 2006:30).

En el discurso del Aprendizaje Motor serán identificables estas ideas, a las que se remite toda vez que se enuncian explicaciones que nombran a lo psicosomático, la unidad psicobiológica, las estructuras en potencia, ${ }^{38}$ los intereses, ${ }^{39}$ la emoción, la motivación, ${ }^{40}$ los estímulos, los incentivos, ${ }^{41}$ las necesidades de los alumnos, etc. En todos los casos, esta interioridad refiere a una "necesidad básica", lisa y llanamente animal.

El individuo se ve activado por diversos motivos, no solamente los que se reconocen comúnmente, tales como los deseos de comida, de agua sino muchos otros [...] Pareciera que tuviera una necesidad básica de expresar sus potencialidades y de reaccionar ante el medio. [...] Estos motivos no solamente son casi universales en la especie humana, sino también característicos de la conducta animal (Lawther, 1983:134).

En referencia a las necesidades y el rol del profesor respecto de esas necesidades, Jean Le Boulch afirma que

es indispensable suscitar la actividad espontánea del alumno, apoyándonos para ello en sus necesidades. Así, el interés motivado por la fijación de una necesidad, parece la base imprescindible para las adquisiciones del niño, puesto que lo impulsará a desplegar todos sus recursos con miras al logro de un objetivo concordante con sus necesidades. [...] Los ejercicios nunca podrán ser impuestos desde afuera. Corresponde al educador, por su experiencia

\footnotetext{
38 "La maduración está representada por el conjunto de las modificaciones que se producen en un organismo en vías de crecimiento y que transforman estructuras potenciales en estructuras funcionales" (Le Boulch, 1991b:232).

${ }^{39}$ El movimiento llamado "Escuela Nueva" o "Nueva Escuela", así como las Pedagogías centradas en el niño o en los centros de interés, dan testimonio de este movimiento iniciado hacia finales del Siglo XIX y principios del XX. Para ello buscaron una nueva educación que fuera activa, que preparara para la vida real y que partiera de los intereses reales que tenía el niño. Autores como Ovidio Decroly, María Montessori, Celestine Freinet, las Hermanas Agazzi o Giner de los Ríos convirtieron en sus máximos exponentes hasta la década de los años 1930, cuando el auge de los totalitarismos y finalmente el temor al comunismo llevaron al olvido estas ideas. Fue en la década de 1990 cuando se retomaron en planes educativos. Este movimiento critica la escuela tradicional: el papel del profesor, la falta de interactividad, el formalismo, la importancia de la memorización.

${ }^{40}$ Para los cognitivistas, la motivación ejerce además un efecto sobre el Sistema Nervioso Central, elevando el nivel de vigilancia (activación), aumentando el nivel general de actividad, elevando el deseo de persistir hasta la consecución de la tarea y aumentando la disponibilidad cognitiva y motriz. cf. Ruiz Pérez, 1997:137-149.

41 "Incentivo es todo objeto material o simbólico, condición o estímulo, que activa al alumno hacia él o a separarse del mismo. Es una promesa de recompensa. Los incentivos incitan al alumno a practicar para obtener satisfacción" (Ruiz Pérez, 1997:144).
} 
pedagógica, relacionar los ejercicios con las necesidades de los alumnos teniendo en cuenta su edad y capacidad de comprensión (Le Boulch, 1981:21).

El otro asunto al que occidente tampoco ha querido renunciar es a la idea de pensar un sujeto de la conciencia. Será por la vía de la instrucción que, desde la llustración en adelante, se podrá impartir normas y preceptos morales a ser incorporados y reproducidos por los pequeños, y generar una "conciencia" que su vez garantice el autocontrol y los cuidados de sí para reducir y encubrir la miseria y las injusticias sociales. "Al educar se trata de poner gradualmente al discípulo en posesión consciente de sus fuerzas, pues así llegará a conocer las tendencias espontáneas de su naturaleza y a distinguirlas de las que no son legítimas" (La Educación, 1883:50).

El Siglo XX no sólo no ha renunciado a pensar en un sujeto de la "conciencia"; más bien ha reforzado ésta idea: ${ }^{42}$

El niño logra sobreponerse a su propia naturaleza, y por ende, acceder a la moralidad, en cuanto adquiere conciencia de sus responsabilidades con respecto al grupo de compañeros al que pertenece. Una parte de la autoridad tradicionalmente investida por el maestro es transferida al grupo, el cual, de esta manera, vive la experiencia de la democracia escolar, tan valiosa para la formación de una personalidad equilibrada (Le Boulch, 1981:24).

Cómo ya hemos visto en los capítulos anteriores, la Psicología ha prestado la palabra al Aprendizaje Motor, que a su vez se ha constituido en buena medida a partir del discurso de esa disciplina que pretende convertirse en ciencia de la subjetividad. Dice Canguilhem que la psicología comienza como psicofísica por dos razones. Primero, porque sólo una física sería tomada en serio por los físicos. Segundo, porque debe buscar en una naturaleza, es decir, en la estructura del cuerpo humano, la razón de existencia de los residuos irreales de la experiencia humana, y convertida en psicología experimental solo puede ser sostenida por la esperanza de hacer aparecer, en las leyes de "los hechos de conciencia”, un determinismo analítico del mismo tipo de aquél que la mecánica y la física permiten esperar para toda ciencia de validez universal. Pero la ciencia de la subjetividad no se reduce a la elaboración de una física del sentido externo: se propone y se presenta como la ciencia de la conciencia de sí, o la ciencia del sentido interno. Pero la conciencia requiere el conflicto de un poder y de una resistencia; el hombre no es entonces una

\footnotetext{
${ }^{42}$ Se sugiere consultar también "El ambiente social, el habla, la conciencia en el aprendizaje motor del ser humano", en Meinel y Schnabel, 1988:189-197.
} 
inteligencia servida por órganos, sino una organización viviente servida por una inteligencia. El alma necesita encarnarse, y por lo tanto no hay psicología sin biología. Podríamos decir, entonces, que hay una cadena de significantes que de algún modo se va articulando, cuya deriva biológica resulta indiscutibles: el alma se encarna en la mente, la mente tiene su localización física en el cerebro y es el cerebro el que secreta los pensamientos. La conciencia es a todas luces una deriva biológica. ${ }^{43}$ Las investigaciones sobre las leyes de la adaptación y del aprendizaje, sobre la relación del aprendizaje con las aptitudes, sobre la detección y la medida de las aptitudes, sobre las condiciones del rendimiento y la productividad (ya se trate de individuos o de grupos) -investigaciones inseparables de sus aplicaciones a la selección o a la orientación-, admiten todas un postulado implícito común: lo propio de la naturaleza del hombre es ser herramienta, su vocación es ser puesto en su lugar, en su tarea (cf. Canguilhem, 1956). Pero, ¿herramienta de qué?, ¿herramienta de quién? El hombre será, desde entonces, una herramienta al servicio de la ideología liberal.

Por otra parte, desde mediados del Siglo XIX, el organicismo fisiologista, encarnado en los principios de la higiene, rige todas las decisiones en torno a la educación, desde la construcción y funcionamiento de los edificios escolares, la elaboración de planes y programas de estudio, la prevención del delito, el diseño y uso de mobiliario escolar, hasta la organización de las clases de gimnástica que permitirán compensar el arrumbamiento del organismo por una educación intelectualizada que entumece al niño y debilita al cuerpo.
El pensamiento, como el cuerpo que se desarrolla y se conserva por el ejercicio, se atrofia por la inhabilidad, vive esencialmente de espontaneidad, de iniciativa y de libertad y, ahogado o comprimido, deja bien pronto el alma sin energía y sin fuerzas, sometida al afligente suplicio de un decaimiento que se ignora y de una voluntad que se abandona, con gran detrimento de la dignidad humana y del organismo. (Revista La Pedagogía, 1884:53)

A partir de las noticias de la época, sabemos que Pierre de Coubertin, luego de recorrer los colegios ingleses, publica para entonces un libro que cuestiona la educación francesa

\footnotetext{
${ }^{43}$ De hecho, para los fisiólogos del siglo XIX, "el cerebro secreta pensamientos como el hígado la bilis"; puede consultarse "Indigestiones intelectuales", en La Educación de 1886, o "Educación Intelectual y Educación Física" en Revista La Pedagogía de 1883. El fisiólogo Lagrange inventó por entonces una balanza que permitía pesar las ideas. El funcionamiento consistía en poner la cabeza del sujeto que se quería investigar, se lo forzaba a pensar mucho y de la ecuación entre el peso inicial y el peso final se deducía (supuestamente) el peso de las ideas.
} 
por su dura disciplina, que no solo limita la libertad de los jóvenes sino que "promueve y fomenta el delito cundo estos son liberados de sus jaulas". En lugar de esto, Coubertin resalta las virtudes del modelo inglés, que compensa el trabajo intelectual con el ejercicio y con juegos reglados por los mismos jóvenes y pone así en acto el ejercicio de su libertad, volviendo proba dicha educación. Para el mismo momento, se difunde también en Argentina otro libro publicado en Francia por Paschal Grousset bajo el seudónimo de Philippe Daryl (1888): "con esta obra ha emprendido Daryl la campaña en pro de la mejora física y moral de sus conciudadanos. Quiere aclimatar muchos juegos que los ingleses han tomado de Francia donde habían caído en desuso, el football que Daryl llama la Barette, el lawn tennis a que da el nombre courte-paume, el rounders, ó grandethèque, la pelota al largo o las regatas. Estos serían solo uno de los medios para regenerar la juventud, el otro tan indispensable como el juego, es el tub, que mantiene la higiene y la limpieza endureciendo la piel y evitando la reabsorción de las substancias excretadas: es decir el baño diario de esponja. La conclusión de Daryl, es que hay que acostumbrar a los niños a estas dos toilletes indispensables, la una externa y la otra interna, que son el baño diario y el ejercicio corporal. La Educación Higienista, permitirá entonces limpiar el organismo, librándolo de la mugre y la inmundicia, sea esta exterior o interior, y la labor de la Educación Física, no es menor: permitirá eliminar la peor de las suciedades del cuerpo humano, limpiará por dentro, quitando toda suciedad que corrompa el cuerpo y sobre todo el espíritu del Hombre.

Son innumerables los escritos en los que se promueve el ejercicio, y con argumentos higienistas se afirma que ejercitarse "prolonga la vida", "hace milagros de la salud" y "posibilita una mejor vejez", evitando la ruina del cerebro y la decadencia de la "raza". No solo se promete larga vida y vejez digna a través de la ejercitación, ${ }^{44}$ sino que se afirma la supremacía de la "raza" amenazando con ejemplos de pueblos cuya "inteligencia es inferior y despreciable". ${ }^{45}$ El discurso educativo (y político) propone entonces no sólo la

\footnotetext{
44 "Los grandes hombres viven bien, y mueren bien; nunca llegan a esa triste ancianidad en que las facultades se debilitan en alto grado, y en que la vida no tiene ya objeto. Los que ejerciten mayor número de facultades vivirán más. El ejercicio metódico de todas las facultades puede hacer milagros en la salud". (La Educación, 1883:51, "La mejor regla de higiene").

45 "La experiencia demuestra con menos evidencia que la energía de la resistencia vital, sea que se comparen naciones o razas entre sí, sea que se comparen los individuos, está siempre en razón directa de la organización intelectual y moral y de la energía de voluntad de cada uno de ellos. ¿Quiénes ignoran que en medio a las mil vicisitudes de la vida o las desgracias que nos amenazan, los espíritus bien templados ofrecen con buen éxito una fuerte resistencia, mientras que los espíritus débiles sucumben? Mil ejemplos, que se aplican a los pueblos o a los individuos,
} 
asepsia de los espacios, sino también de las conductas humanas. Es en el Siglo XIX que la pureza de la raza y su integridad se convirtieron en asunto de estado.

Este pensamiento racista resultará sumamente importante luego, porque creemos que hay allí también una continuidad con el discurso del Aprendizaje Motor que se plasmará no sólo en los métodos y técnicas elegidos para investigar, sino también y de manera más patente en la idea de que existen "talentos deportivos", de los cuáles no sólo habrá que dar cuenta por medio de procedimientos científicos sino que se pondrá en marcha toda una serie de dispositivos e instrumentos que permitan detectarlos (ver, en este mismo capítulo, Del modelo de evolución a la era del genoma).

Decíamos antes que, desde el momento en que el hombre como animal viviente adquiere una existencia política, la vida biológicamente considerada se convierte en el verdadero objeto del gobierno.

\section{Dice Castro:}

En cuanto a la noción foucaultiana de gobierno, ésta tiene, para expresarlo de alguna manera, dos ejes: el gobierno como relación entre sujetos y el gobierno como relación consigo mismo. En el primer sentido, el gobierno es un conjunto de acciones sobre acciones posibles. Trabaja sobre un campo de posibilidad en el que viene a inscribirse el comportamiento de los sujetos que actúan: incita, induce, desvía, facilita o dificulta, extiende o limita, hace más o menos probable, llevado al límite, obliga o impide absolutamente. Pero es siempre una manera de actuar sobre uno o varios sujetos actuantes, y ello en tanto que actúan o son susceptibles de actuar. Una acción sobre acciones. Se trata, en definitiva, de una conducta que tiene por objeto la conducta de otro individuo o de un grupo. Gobernar consiste en conducir conductas. Foucault quiere mantener su noción de gobierno lo más amplia posible. Pero, en el segundo sentido, es también del orden del gobierno la relación que uno puede establecer consigo mismo en la medida en que, por ejemplo, se trata de dominar los placeres o los deseos (2007:11).

Comprender esto es comprender cómo y por qué en el Siglo XIX emerge una disciplina como la Educación Física, que no aparece entonces con valor propio, sino como parte de la estrategia de la racionalidad política liberal y funcional al problema de la gubernamentalidad.

atestiguan en efecto, que la inercia y la pasividad del alma dejan la vida orgánica expuesta sin defensa, a todos los accidentes exteriores de la vida, y que la ausencia de la voluntad y el abandono de sí mismo son las causas infalibles de la degradación física y de la muerte" (La Revista Pedagógica, 1883:52). 
En el Siglo XIX, educar aparece siempre en la trilógica "física-moral-intelectual", y la educación del cuerpo, junto con el ejercitarse, será la forma, el instrumento, para evitar que el cerebro se deteriore. Se encuentra en la Educación Física la manera de "salvar" a la población no solamente de la ruina física e intelectual, sino y sobre todo de la ruina moral que convierte al individuo en un "ser indigno": además del trabajo de los fisiólogos, se sabe por entonces que la falta de ejercitación conducirá a la miseria física, intelectual y moral, y lo que hay que asegurar por entonces es "el porvenir de la Nación".

El "buen sentido", en su acepción más extensa y completa viene a ser el resultado de este "método intelectual", bien como "la buena salud" y la "bondad del corazón" y del carácter son efectos necesarios de la "educación física y moral". Así es como el sistema forma en un todo al hombre. He aquí los motivos por qué he hallado esta educación mejor que la mayor parte de las educaciones modernas, que frecuentemente ofrecen cuerpos lánguidos y débiles, enervados por los estudios prematuros y por una vida demasiado estudiosa y sedentaria, que al mismo tiempo produce almas bajas y degradadas, corazones corrompidos y caracteres ruines e hipócritas, marchitos desde temprano por la opresión de una disciplina dura y humillante, en fin, hombres fatuos, llenos de conocimientos mal digeridos, talento que en su modo de ver los objetos puede compararse con aquellos sujetos a quienes sus nodrizas desde la cuna los han habituado a mirar bizcos, situándolos en una posición falsa en la cual han invertido la dirección natural del órgano de la vista (La Revista Pedagógica, 1883:524).

Contra la tesis que liga a la Educación Física con el militarismo y la disciplina, nos atrevemos a afirmar que nace como contrapartida a la "opresión de una dura y humillante disciplina", ya que se busca en ella el contrapeso necesario que permita el ejercicio de la "libertad individual" que, como parte de la racionalidad política emergente, hará posible la circulación del proyecto liberal burgués.

Pero es también por el mismo trabajo de los fisiólogos que, en la segunda mitad del Siglo XIX, se da este proceso que culmina hacia 1880 y 1890 en la "reforma de la gimnástica" y por el cual se acuñó y consolidó la expresión "Educación Física” para reemplazar definitivamente a la gimnástica en la designación de las prácticas corporales educativas (Crisorio, 2007:69). ${ }^{46}$ Desde entonces cargará consigo esa marca de origen.

\footnotetext{
${ }^{46}$ Para profundizar sobre este tema, recomendamos al lector el trabajo realizado por el Prof. Crisorio en los últimos años, en particular "La Educación del cuerpo entre el Quattrocento italiano y el siglo XIX europeo" y “Educación Física”, en Crisorio y Giles (2009).
} 
El verdadero fin de la educación física podemos resumirlo en las siguientes palabras: fortificar el cuerpo, sujetándolo a las leyes de la higiene y a ejercicios proporcionados a la edad y a la constitución de los individuos, por tanto abarca dos órdenes diferentes de ideas, sin las cuales, no se educa físicamente, sino se enseñará gimnasia y nada más, como mal se comprende y deduce de las escuelas primarias [sic]. La salud es uno de los dos objetivos principales de la educación física y por esto es necesario habituar a los niños a someterse a ciertas reglas, cuya razón de ser deben reconocer, a fin de que puedan conservar su cuerpo en perfecto estado de salud. [...] Las formas del cuerpo, el desarrollo regular de sus miembros, la adquisición de fuerzas es otro de los objetivos de la educación física y tanto la higiene como ésta interesan a la parte material como a la intelectual del individuo (La Revista Pedagógica 1883:106).

Es claro que en la modernidad podemos identificar la consolidación de una forma de discurso del poder que, por la vía de la biología y la fisiología, construye un conjunto de justificaciones por las que sus mecanismos y dispositivos se solapan en procura de una máscara de racionalidad científica.

Hemos visto cómo la Educación Física primero y el Aprendizaje Motor después han sido atravesados por ese discurso del poder que no se reduce a las prohibiciones prescriptas por la ley ni por sus ordenanzas sino precisamente a la constitución de un conjunto de prácticas (técnicas, tácticas, estrategias y discursos) que de manera sutil otorgan eficacia a ese pensamiento.

En el Siglo XIX se constituye un discurso en el que se despliega un conjunto de procesos y procedimientos de instrucción, conforme una serie de reglas estrictas de trasmisión de la instrucción.

La escuela se configura como el espacio de una Educación Física que con argumentos científicos traza verdades políticas que impactan en el cuerpo de los alumnos. El trabajo de la Educación Física estará centrado en el mejoramiento de los "órganos del cuerpo humano", que se traducirán en mejoras de la "forma del cuerpo" y en la "adquisición de la fuerza". Es a partir de la idea de individuo que acuña la modernidad que la educación abrazará, en pos de la "unidad", tres esferas del desarrollo sin las cuales "el ser humano no es completo": el intelecto (por el trabajo intelectual sobre el cerebro), el físico (por el 
desarrollo de las potencias físicas del organismo), y la moral (por un trabajo combinado de las dos anteriores).

Diría muchos años después Le Boulch: "nosotros consideramos al organismo como una estructura indivisible de comportamientos cuyas reacciones están unificadas y ordenadas" (Le Boulch, 1991b:20); "el reconocimiento de la lenta evolución de la motricidad, desde las reacciones expresivas espontáneas hasta la disponibilidad conciente, pone de manifiesto la continuidad de los aspectos afectivo motor, perceptivo y conceptual. La manifestación de las estructuras supone, inicialmente, una maduración inducida por factores intrínsecos: los organizadores embrionarios" (269). Entonces, el discurso del Aprendizaje Motor recupera aquello que ha sido dicho a la sombra de la biopolítica. No es un discurso ingenuo; por el contrario, es un discurso que legitima y hace posible la circulación del proyecto del liberalismo burgués.

Así, en nuestro estudio hemos ido determinando distintos "regímenes de veridicción" que se han articulados entre el Siglo XIX y el Siglo XX. Ello nos ayuda a pensar el alcance de las políticas educativas como estrategias de una biopolítica muy precisa que, haciendo entrar a la vida como parte de una relación entre el Poder y el Saber, establecerá una relación de sujeción y encauzamiento de las conductas de la población, cuyo mayor anhelo es el "gobierno de sí" para que sea posible "el gobierno de los otros". La pregunta que cabría hacerse entonces es por qué el Siglo XX ocultó, enmascaró y maquilló ese discurso. Algo queda claro: para los educadores del Siglo XIX no había eufemismo ni pudor en desnudar su pensamiento, que de hecho puede leerse literalmente en sus dichos. Al ocultar las verdades de aquel discurso, la pesada herencia sobre el pensamiento contemporáneo opera con la fuerza de aquello que susurra por lo bajo, de un decir "políticamente correcto" que esconde sus verdaderas intenciones.

\subsection{Del maestro al Docente: de la asimetría del Siglo XiX al falso EMPODERAMIENTO DEL ALUMNO EN EL S.XX}

En tanto que lo importante de la biopolítica moderna es la especie, el cuerpo hace "carne" la apuesta por la vida fusionando de un modo particular política y naturaleza. Educar es seguir las leyes de la naturaleza y salvar al pueblo y la raza de la ruina moral, espiritual y física, lo que supone en lo relativo a la enseñanza instalar la pregunta por el método y por cómo enseñar respetando ese código natural. El maestro tendrá entonces el desafío de saber decodificar los "signos naturales" para no equivocar el camino. Sin embargo, esta preocupación por el método ni siquiera les pertenece: es probable que, a partir de las 
ideas de Descartes por un lado y de Comenio por el otro, esta preocupación ya estuviese desde mucho antes instalada en la educación.

Descartes (1637) ya planteaba cuatro principios a tomar en cuenta en cuestión de método: el primero consistía en no admitir jamás nada por verdadero que no reconociera que evidentemente era tal, evitando la precipitación y la prevención, y sin abarcar en los juicios nada más que lo que se presente tan clara y distintamente al espíritu que no pudiera ponerse en duda; el segundo, en dividir cada una de las dificultades en tantas partes como fuera posible y necesario para resolverlas mejor; el tercero, en conducir por orden los pensamientos, comenzando por los objetos más simples y más fáciles de conocer para subir poco a poco, como por grados, hasta el conocimiento de los más compuestos, y aun suponiendo un orden entre aquellos elementos que no se preceden naturalmente unos a otros; por último, hacer en todo enumeraciones tan completas y revisiones tan generales que se tuviese la seguridad de no omitir nada.

La búsqueda del método objetivo que permita enseñar todo a todos (de la misma forma y en el mismo acto) fue muy difundida y desveló a los educadores modernos:

el propósito de la enseñanza objetiva es llevar claridad a las ideas de los niños, en parte aumentar su caudal de ideas, acostumbrar los sentidos al uso atento y cultivar el lenguaje. Cumpliendo con esto viene a ser la base de toda enseñanza [sic], y de ella brotarán los diversos conocimientos que se adquieren en la escuela, como las ramas brotan del tronco de un árbol. ("La enseñanza objetiva”, en $L a$ Educación, 1886:83-84).

Entonces, la apuesta moderna es tener buenos maestros: ellos serán los garantes del proyecto liberal burgués. Un educador burro, ruin, o poco preparado solo puede formar burros ruines y poco inteligentes. El maestro es la vedette del XIX; por eso, cuando el aprendizaje motor (informado por el mismo pensamiento) ponga en el centro al alumno, y lo convierta en un supuesto soberano absoluto del proceso educativo, provocará una irrupción en el orden del discurso.

Para la llustración la educación era la vía por la cual acceder al anhelo de "orden y progreso", y para el establecimiento de este sistema político la cuestión de los métodos de enseñanza resultaba de gran importancia. Es "el método" el que garantiza, por la vía de la razón, enseñar "todo a todos" y según las leyes que dicta la naturaleza. En palabras de Ernesto Bavio (1886:93), "los mejores y más racionales métodos, no pueden ser otros 
sino aquellos que interpretan la naturaleza en su gradual y sabio desarrollo", y "un buen maestro" será aquel que tenga la habilidad para aplicarlos.

El método "universalmente aceptado como norma" para la enseñanza debía respetar ciertos principios que garantizarían seguir los designios de la naturaleza. Por ejemplo, debe proceder de lo conocido a lo desconocido -"todos los conocimientos que debemos al alumno [sic] deben estar apoyados en otros que ya poseen para que sus ideas estén en orden lógico y no conforme un conjunto sin correspondencia ni armonía [sic]" (“Indigestiones intelectuales", en La Educación,1884:23)-, de lo "fácil a lo difícil" y de lo "natural a lo artificial", con el objeto de no oponerse a las indicaciones de la naturaleza, sino ayudarla, tratando de realizar sus designios.

El maestro, además

poseerá un conocimiento general del cuerpo, de sus órganos y funciones de estos [sic], para no violar las leyes naturales en tan interesante parte del ser humano, para robustecerlo con saludables ejercicios y para alejar las causas de enfermedad; estudiará el alma humana con el objeto de deducir de sus múltiples y distintas manifestaciones y las circunstancias que las motivan, las diversas facultades, y poder así darle una acertada dirección, que consistirá en seguir la marcha de la naturaleza (Bavio, 1886:5).

El problema que reconocemos aquí es que ese método se funda en dos cuestiones: una epistemo-metodológica, que supone la naturaleza o la existencia de esencias que otorgan un "sentido real", "acabado y universal" a los objetos y a las prácticas -habría una "ley interior" que dictamina lo que es y lo que no es, lo que se puede hacer y no hacer a la luz del ser. La otra cuestión es política, en tanto sostiene una única forma de enseñar a todos según lo pautado por la naturaleza, olvidando y replegando las particularidades estructurales de los sujetos a individuos singulares.

En lo que a la enseñanza se refiere, el método deberá ser gradual y progresivo si se quiere contribuir al éxito;

tratándose de la gimnasia, la graduación debe ser tal que desarrollando cada una de las partes del cuerpo se desarrolle por completo el cuerpo entero. Princípiese por dar flexibilidad a los músculos de los miembros inferiores y superiores con ejercicios bien calculados, procédase luego con otros ejercicios cuyo fin principal sea el desarrollo de las fuerzas en tal o cual región del cuerpo humano y se tendrá una buena enseñanza de la gimnasia (La Revista Pedagógica, 1883:21). 
De los escritos de la época, también recogemos que la instrucción pública estará muy influenciada por las enseñanzas de Pestalozzi, ${ }^{47}$ quien, basándose en las ideas de Rousseau, propone poner especial atención en un método que articule "la educación intelectual" con la "buena salud" y la "bondad del corazón y del carácter", que serán efecto de la educación física y moral de un "sistema que forma en un todo al hombre". Pestalozzi fue el primero en apoyar los procedimientos de enseñanza en las leyes de la naturaleza humana para no contrariarlas al desarrollar las facultades; rechazó por completo todas las prácticas antiguas, que convertían a la escuela en un lugar de sufrimiento para el niño, y estableció el principio contrario -que la escuela debe ser por todos conceptos agradable para el niño.

Fröebel, su discípulo, elabora los principios que deberán regir la enseñanza en los jardines de infantes. Considera muy importante que sea la pelota el primer objeto que se entregue al niño, porque su forma redonda es un símbolo de la integralidad y unidad de la existencia. La gran movilidad de la pelota, que la hace tan especialmente adecuada para las escasas fuerzas de los niños pequeños, no constituye para él una razón suficiente. Por la misma causa, los primeros juegos deberán realizarse en un círculo con el niño en el medio, haciendo evidente el centro alrededor del cual todo se congrega. Después de la pelota se dirigirá el pensamiento necesariamente hacia el cubo apoyado, que será combinado con la pelota en el cilindro. El trabajo deberá ser acompañado siempre por palabras, pues el niño debe tener una clara comprensión de lo que está haciendo. Así, cuando en todo este trabajo la impresión e conjunto precede a la impresión de las partes por separado, se está siguiendo simplemente una indicación de la Naturaleza (cf. La Educación, 1886:193-194).

Nuevamente encontramos una continuidad: la naturaleza "orienta y prescribe" las prácticas del maestro. Seguir sus principios garantizará una buena educación que aleje del vicio y la miseria humana que corrompe al ser humano y lo conduce a la ruina. $Y$ en el Siglo XX, si bien toda la atención estará puesta en el que aprende, será también la naturaleza la que organice, a partir de las Leyes del Aprendizaje y del Desarrollo, qué es lo que puede aprender el alumno, qué es lo que necesita de acuerdo a la edad, y por lo tanto cómo debe aprenderlo. También aquí, como allá, el método será gradual: de lo

\footnotetext{
47 "Enrique Pestalozzi nació en Zurich el 12 de octubre de 1746, se dedicó primero a las leyes y luego a la educación. Sostenía que el bienestar de los individuos y todo verdadero progreso social dependían de la Educación". La Educación, periódico quincenal, Año I, Número 11, Buenos Aires, Julio de 1886.
} 
conocido a lo desconocido, de lo natural a lo artificial, de lo fácil a lo difícil, de lo simple a lo complejo, etc.

Así como plantean Grosser y Neumaier, "el método principal para conseguir un progreso en el desarrollo de la técnica es siempre la práctica bien planificada y sistemáticamente progresiva" (1986:120).

Por otra parte, el maestro, en quien la Modernidad delega el éxito de la enseñanza en tanto responsable de elegir el método apropiado para impartir la instrucción, será una correa de paso, un aplicador pero al que aun así se le supone un saber, que en este caso no es del orden del contenido a trasmitir, sino del de conocer las leyes que rigen la naturaleza; de todos modos, se mantiene la asimetría necesaria entre maestro y alumno de todo acto educativo. En tanto el discurso del Aprendizaje ha sido en desmedro del acto mismo de enseñar, en el Siglo XX al Maestro ya no se le "supone" ningún saber, el maestro queda absolutamente desplazado y desautorizado y por lo tanto se fractura esta relación desigual que hace posible la enseñanza. Este hecho podría hacernos pensar que se da lugar a un empoderamiento del alumno, pero esto no es más que una fantasía. Se nos ha hecho creer que el alumno es el dueño del acto de enseñanza y, aunque parecería haber sido "puesto entre algodones", como aquel a quién hay que cuidar y respetar, en verdad el poder estaría en manos de "la ciencia", que entonces domina el acto educativo. En síntesis, la ciencia ha logrado desplazar todos los elementos y ocupar el trono: ya no importa ni el maestro, ni el contenido, ni el alumno; es la verdad de la ciencia la que dicta, ordena, estipula, normaliza, dirige, incluye, excluye, legitima, deslegitima, etc.

\subsection{DEL MODELO EVOLUTIVO A LA ERA DEL GENOMA}

El aprendizaje Motor lleva consigo el supuesto soterrado de la evolución darwiniana; es más, podríamos decir que Darwin ha sido el gran triunfador. Filogénesis, ontogénesis, habilidades básicas o fundamentales, etapas, ${ }^{48}$ estadios, fases, series, progresiones, enseñanza graduada, líneas de sangre, herencia, capacidades genéticas o epigenéticas, talentosos, habilidosos y torpes, ${ }^{49}$ períodos críticos, ${ }^{50}$ períodos sensibles, ${ }^{51}$ etc., son

\footnotetext{
${ }^{48}$ En los capítulos 1 y 2 hemos desarrollado detalladamente la cuestión de las etapas, estadios y fases en el interior del discurso del Aprendizaje Motor.

${ }^{49}$ Oseretsky ideo el test de evaluación motriz a los efectos de identificar a los niños de menor aptitud física de una población normal, a los que denominó "idiotas motores". Bryant Cratty, por su parte, destina un capítulo entero a "El niño torpe". Cf. el capítulo 12 de Cratty, 1982.

${ }^{50}$ Períodos críticos: momentos del desarrollo en los que si el aprendizaje no se lleva a cabo no se manifestará nunca. Cf. Ruiz Pérez, 1987:22.
} 
conceptos que atraviesan el discurso del aprendizaje y que presuponen una invariable secuencia que va del hombre al animal. Si en estos casos se presupone la existencia de un desarrollo lineal es porque se está operando con una concepción de tiempo de tipo evolutiva. Este carácter evolutivo funda así la existencia de desarrollos organizados a partir del logro de objetivos, y estructura de igual modo una gran cantidad de aspectos de la enseñanza. Por ejemplo, las conocidas progresiones metodológicas que descomponen, en tantos pasos como sea posible, un gesto, para ir poco a poco incorporando elementos hasta llegar al gesto global. Piénsese en la enseñanza de la natación: la progresión no sólo estaría dada por la enseñanza de los diferentes estilos de acuerdo a lo que se supone que es un grado de dificultad universal, desde el crawl, pasando por espalda y pecho hasta el estilo mariposa; además, en el interior de cada estilo de nado se establece una progresiva y analítica aproximación que descompone la brazada, la patada y la respiración, que a su vez requieren de progresiones particulares y ejercitaciones específicas para cada uno de esos elementos. Una vez que se ha logrado adquirir cada gesto, recién podrán fusionarse y articularse en el nado completo (se juntará en un mismo ejercicio patada, brazada y respiración). Este esquema de descomposición analítica por una parte, y gradualidad en la enseñanza por la otra, adquiere a su vez particularidades para cada deporte, y todo lo que deba hacerse está detalladamente estipulado. Este discurso ordena también el currículum escolar, ofreciendo indicaciones respecto de los contenidos, los objetivos y las actividades o tareas; también precisa cuál será la metodología a emplear, es decir cuál será el método que permita más rápidamente lograr esos objetivos, estableciendo que se procederá de un modo analítico integrando objetivos y destrezas particulares que permitan secuenciar los aprendizajes, teniendo como fin último el logro de aquel o aquellos que resultan más generales e integradores.

Podremos encontrar así progresiones metodológicas en la enseñanza del voleibol, la gimnasia artística, el básquetbol, el atletismo, etc. Esto supone universalizar al sujeto y

${ }^{51}$ Períodos sensibles: momentos del desarrollo en que el organismo es especialmente susceptible a las influencias del ambiente. En relación al aprendizaje se hace referencia a los momentos de mayor facilidad para la adquisición de nuevas conductas. Cf. Ruiz Pérez, 1987:22. En el campo del Aprendizaje Motor, este concepto ha sido determinante en cuanto a la planificación de la enseñanza. Se trataría de enseñar ni más ni menos (haciendo hincapié en el "ni más") que lo que se considera que el niño puede y debe aprender a esa edad. Por ejemplo, es conocida la máxima que establece que los niños no deberían iniciar la práctica deportiva antes de los 7 u 8 años. El argumento científico de esta indicación es "que la participación y la coordinación se consiguen más rápidamente cuando el sistema nervioso y los órganos motores se encuentran cercanos al tamaño adulto. Desde un punto de vista del desarrollo del electroencefalograma, el desarrollo cerebral no se completa hasta la edad de 7-8 años" (Ruiz Pérez, 1987:222). 
particularizar al contenido, es decir, pensar que para todo ser humano se trata de las mismas dificultades o idéntica complejidad en la tarea, lo cual no solo es un error evidente, sino que además arrastra a otro equivoco: suponer que, en aras de respetar al "sujeto", hay que realizar adecuaciones sobre el contenido, que deja de ser un "saber culturalmente valioso a ser aprendido por todos" para terminar siendo cualquier cosa. Tanto se adecua el contenido a quién aprende que finalmente deja de ser el contenido que se suponía enseñar.

Por otra parte, esta secuenciación gradual de los aprendizajes supone que tanto hay que adecuarse a la naturaleza que sólo podrá pasarse a la siguiente etapa cuándo la primera haya sido alcanzada en su totalidad. Esto supone entre otras cosas una restricción para el alumno, que se ve privado de la posibilidad de encontrarse con otros saberes (porque no se lo supone maduro para ello), así como una restricción sobre el profesor, que queda atrapado al "deber ser" que la teoría le impone.

La interpretación exacta de los procesos biológicos y fisiológicos que dirigen la formación y crecimiento del ser humano es la única norma que debe guiarnos en la dirección de la crianza del organismo infantil. La misma ley del origen de las especies, según la cual todo ser vivo reproduce, durante su desarrollo embrionario, todas las etapas del desarrollo de su especie, nos enseña que también en el desarrollo extrauterino se deberán seguir todas las etapas progresivas por las que ha pasado la especie humana a lo largo de miles de años, desde aquellos remotos tiempos de ensueño en que coloca Häequel el origen de la especie humana (Spitzy, 1917:32).

En el campo del Aprendizaje Motor, las ideas evolucionistas y esencialistas se manifiestan en otro fenómeno muy difundido: el de la selección de talentos deportivos. De la misma forma que el sentido común adjudica a Dios o a la naturaleza ("Lo que natura no da, Salamanca no presta") la atribución de "dones" y "capacidades especiales", el Aprendizaje Motor, en el afán de encontrar una explicación científica que pruebe las diferencias, ha basado gran parte de sus investigaciones en estudios que encuentran en la genética su justificación. La impronta cientificista de la que ya hemos hablado ha reforzando la idea de que existen individuos genéticamente diferenciados y con una disposición al aprendizaje diferente a la de otros; sin embargo, a pesar de todos los avances en el campo del "genoma humano" se sigue apelando a la naturaleza por falta de otra causa comprobable que justifique "científicamente" la distribución desigual de aquellos dones. 
El concepto de talento a menudo se expresa como "capacidad", "aptitud", "competencia" o "inteligencia". Inteligencia es un término compuesto de intus (entre) y legere (escoger); por lo tanto, refiere a la capacidad de relacionar conocimientos que poseemos para resolver una determinada situación, o más bien a la capacidad para saber elegir la mejor opción para resolver un problema. Sin embargo, tanto ha procurado la ciencia dar cuenta de ello que ha ideado en vano instrumentos para reforzar el argumento de la diferencia, midiendo, clasificando, etiquetando y seleccionando a los sujetos. Surgen una serie de interrogantes: ¿cómo se enmascara la teoría de la herencia en el Siglo XX? ¿cómo se construye este discurso en torno al talento deportivo? ¿cuáles son los procedimientos para su detección y selección? ¿cómo se materializa en las teorías del aprendizaje y cuáles son sus consecuencias en la enseñanza? Todas estas preguntas no podrán ser desarrolladas aquí, ya que son en sí mismas objeto de una tesis. Sin embargo, adelantaremos algunas cuestiones.

Domingo Blázquez Sánchez define como talento deportivo a "la disposición por encima de la norma de poder y querer realizar unos rendimientos elevados en el campo del deporte" (1995:57), y se refiere la selección de talentos como una "operación responsable de predicción a corto plazo en cuanto a las posibilidades de que un sujeto dado en el seno de un grupo de atletas posea atributos, el nivel de aprendizaje, el entrenamiento y la madurez necesarias para realizar una mejor performance que el resto de los miembros del grupo en un futuro inmediato" (1995:57). Entonces el "poder" y "querer", una vez más, se plasman como “atributos” naturales. Continúa diciendo Blázquez Sánchez:

a pesar de la influencia de la familia, la escuela, el entrenamiento, etc., son necesarias determinadas particularidades genotípicas que condicionan la elección de una determinada especialidad, entonces, la selección deportiva no es otra cosa que el proceso a través del cual se individualizan personas dotadas de talento y de actitudes favorables para el deporte, con la ayuda de métodos y de test científicamente válidos (1995:223; las cursivas son nuestras).

Del mismo modo, para Jean Le Boulch "la ontogénesis nos enseña que en su desarrollo los dones hereditarios y la influencia del medio se entrelazan de modo constante habida cuenta de ese poder del organismo de estructurarse por medio del contacto práctico con el mundo exterior" (1991a:271). Por su parte, Ruiz Pérez (1991:25) siguiendo a Ausubel y Sullivan expresa que: a) los factores genéticos limitan el crecimiento potencial absoluto de un individuo, pero los factores ambientales limitan la expresión de la potencialidad genética; b) los factores genéticos hacen a los sujetos más sensibles al efecto de 
determinados factores ambientales; c) en definitiva, el ser humano es el resultado de una compleja interacción, de una recíproca interacción entre lo genético y lo ambiental. Nótese que en estos dos últimos además de la genética se incluyen determinantes externos también del orden de lo natural, un entorno ambiental y no cultural. De la misma forma, Ruiz Pérez, luego de dedicar un largo apartado a explicar los estudios experimentales que demuestran la impronta genética, concluye que "parece ser que los hijos naturales poseen una correlación más alta con los padres que los hijos adoptados; que existe una correlación más alta entre los gemelos monocigóticos que entre los dicigóticos, y que el aspecto más favorecido en este tipo de estudios es la inteligencia”, y culmina llamando la atención sobre los casos de familias de deportistas, los cuales "parecen indicar una predisposición genética para la práctica de ciertas actividades motrices pero ciertamente también podríamos añadir que el medio como tal podría ser el causante de dichas situaciones" (223).

En el campo del Aprendizaje Motor, la aplicación de pruebas estandarizadas tiene como efecto no solo normalizar los comportamientos utilizando parámetros únicos y universales, sino también docilitar y predestinar a cada uno de los sujetos clasificados como torpes, habilidosos, faltos de gracia, etc., para terminar aceptando como inevitable su naturaleza $\mathrm{y}$, consiguientemente, su trayectoria trazada con anterioridad por el docente y por "la ciencia". Así, quien supuestamente "es" no talentoso, termina haciendo suyo el fracaso; por lo tanto, el destino no es otra cosa que la anticipación y concreción de una marca de origen. Continuar alimentando el mito del talento natural, desconociendo las condiciones sociales de producción de los talentos, impone quizás una anulación del rol docente como impulsor de progresos y logros personales de sus alumnos (cfr. Kaplan y Kaplan, 1996). Nada de inocente hay en la apelación a la "ideología de los dones", y lograr desempeños por encima de la "norma" no encuentra explicación en condiciones naturales, filogenéticas u ontogenéticas que expliquen las diferencias en el aprendizaje. Del mismo modo, y con la misma fuerza, que nos negamos a aceptar la idea de una "naturaleza humana" o algo así como "el hombre", nos negamos a ser funcionales a la biopolítica y las políticas liberales y meritocráticas que desde el Siglo XIX se esfuerzan por argumentar a favor de la elección de los elegidos, justificando no solo la selección y clasificación de los sujetos en el plano de lo corporal, sino también un orden social marcado por la desigualdad y la exclusión. 
Si dejáramos a un lado esta idea de "talentos", y de una naturaleza que dota de capacidades especiales para el buen desempeño, en este caso en el orden de lo motor, lo que nos queda es reflexionar acerca de la posibilidad de enseñar esas habilidades.

En síntesis, todo el campo del Aprendizaje Motor se ha organizado a partir de la idea de que existe una Naturaleza Humana que orienta y determina nuestros comportamientos y posibilidades de aprendizaje. Como ya hemos visto, esta concepción de la naturaleza ha sido pensada mucho antes de poder pensar el Aprendizaje Motor mismo. Si pensamos que "eso piensa", de lo que se trata es de problematizar ese pensamiento y poder liberarlo de lo que se piensa en silencio. Continuar alimentando la fantasía de encontrar en las teorías del Aprendizaje Motor respuestas que garanticen la predicción del fenómeno y por lo tanto posibiliten anticipar el comportamiento humano, supone, además de universalizar el sujeto y el modo en que se aprende, desconocer las condiciones culturales y políticas de dichos aprendizajes. Esto implica además una anulación del rol del maestro como trasmisor de saberes relevantes en nuestra sociedad y cultura, y vuelve ficticio el acto educativo mismo, que se convierte en una puesta en escena a la espera de que la naturaleza haga lo suyo.

Por el contrario, si problematizamos estas y otras cuestiones, será posible dejar de pensar a partir de la idea de una naturaleza que determina o un medio que dispone, facilita 0 entorpece el buen desempeño.

Lo que nos queda entonces es reflexionar acerca de la posibilidad de elaborar una teoría de la enseñanza diferente. 


\section{Capítulo V Reflexiones para la elaboración de una Teoría de la Enseñanza. Hacia una biopolítica positiva}

[...] tenemos para hacernos cargo, para realizar una tarea -pero eso equivale a decir 'para vivir' y 'para ser' el con- -o el entre- en el que tenemos nuestra existencia, es decir, a la vez nuestro lugar o nuestro medio y aquello a lo que y por lo que existimos en sentido fuerte, es decir, estamos expuestos.

(Jean-Luc Nancy)

\subsection{EL APRENDIZAJE MOTOR COMO DISPOSITIVO BIOPOLÍTICO}

Ya hemos dicho que estos discursos que hemos seguido a lo largo de la tesis comparten un mismo modo de pensar, hacer y decir, y por lo que tienen de regular podríamos decir que conforman un mismo Dispositivo biopolítico en torno a la educación del cuerpo desde la perspectiva del Aprendizaje y del Desarrollo. Ya hemos hablado de la biopolítica en el capítulo anterior, ahora trataremos de definir qué se entiende por Dispositivo en el marco de esta tesis

El término Dispositivo aparece en Foucault en los años '70. Edgardo Castro (2006:102), en el apartado dedicado al concepto, detalla:

1) El dispositivo es la red de relaciones que se pueden establecer entre elementos heterogéneos: discursos, instituciones, arquitectura, reglamentos, leyes, medidas administrativas, enunciados científicos, proposiciones filosóficas, morales, filantrópicas, lo dicho y lo no dicho. 2) El dispositivo establece la naturaleza del nexo que puede existir entre estos elementos heterogéneos [...] 3) Se trata de una formación que en un momento dado ha tenido por función responder a una urgencia. El dispositivo tiene así una función estratégica [...] 4) Además de definirse por la estructura de elementos heterogéneos, un dispositivo se define por su génesis. Foucault distingue al respecto dos momentos esenciales: un primer momento del predominio del objetivo estratégico; un segundo momento de la constitución del dispositivo propiamente dicho. 5) El dispositivo, una vez constituido, permanece tal en la medida en que tiene lugar un proceso de sobredeterminación funcional: cada efecto, positivo o negativo, querido o no querido, entra en resonancia o contradicción con los otros y exige un reajuste.

Giorgio Agamben va más allá: 
llamaré dispositivos a cualquier cosa que tenga de algún modo la capacidad de capturar, orientar, determinar, interceptar, modelar, controlar y asegurar los gestos, las conductas, las opiniones y los discursos de los seres vivientes. No solamente, por lo tanto, las prisiones, los manicomios, el panóptico, las escuelas, la confesión, las fábricas, las disciplinas, las medidas jurídicas, etc., cuya conexión con el poder es en cierto sentido evidente, sino también la lapicera, la escritura, la literatura, la filosofía, la agricultura, el cigarrillo, la navegación, las computadoras, los celulares y -por qué no- el lenguaje mismo, que es quizás el mas antiguo de los dispositivos, en el que millares y millares de años un primate -probablemente sin darse cuenta de las consecuencias que se seguirían- tuvo la inconsciencia de dejarse capturar (2011b:257).

La función de los dispositivos será entonces, por ese mecanismo de captura, dar lugar a distintos procesos de subjetivación. En este sentido, consideramos al Aprendizaje Motor como un dispositivo de la educación del cuerpo

La nueva relación que podemos y debemos establecer con los dispositivos no consiste en suprimirlos, ni en imaginarse ingenuamente un buen uso, sino en profanarlos y volverlos inoperantes:

es posible que lo improfanable, sobre lo cual se funda la religión capitalista, no sea verdaderamente tal, que se den todavía hoy formas eficaces de profanación. Para esto es preciso recordar que la profanación no restaura simplemente algo así como un uso natural, que preexistía a su separación en la esfera religiosa, económica o jurídica. Su operación [...] es más astuta y compleja, y no se limita a abolir la forma de la separación, para reencontrar, más acá o más allá de ella, un uso incontaminado. Ya que profanar no significa simplemente abolir y eliminar las separaciones, sino aprender a hacer de ellas un nuevo uso [...], desactivar los dispositivos para hacer posible un nuevo uso (Agamben, 2005:111-113).

Lo que intentaremos, pues, es desplegar sintéticamente el Dispositivo Aprendizaje Motor, para introducir en este discurso una inter-versión ${ }^{52}$ que nos permita pensar otros términos

\footnotetext{
${ }^{52}$ Es decir, una versión intercalada que desde luego modifica la relación con el relato. En la medida que esta tesis ha problematizado el discurso del Aprendizaje Motor, lo que buscamos es ejercer una acción transformadora. Dice Grünner que "la acción transformadora es la condición misma de la interpretación. Toda la riqueza de la noción de praxis está contenida en esta idea de que la interpretación puede ser una herramienta de crítica, de 'puesta en crisis' de las estructuras materiales y simbólicas de una sociedad, en polémica con otras interpretaciones que buscan consolidarlas en su inercia". Eduardo Grüner, 1995, "Michel Foucault: una política de la interpretación", en Foucault, Michel, Freud, Nietsche y Marx, El cielo por asalto, Buenos Aires, p.12.
} 
que podrán "entrar en juego" y armar así un nuevo Dispositivo articulado en torno a la cuestión de la Enseñanza.

\subsection{EL ESQUEMA DEL UNO}

Por lo que ya hemos desplegado hasta aquí (y por lo que hemos enunciado aunque no lo hayamos desplegado), podríamos decir que tanto el Siglo XIX como el Siglo XX podrían sintetizarse en el modelo del Uno. Por la vía de la fisiología primero, y de la Psicología y las neurociencias después, la educación del cuerpo ha quedado reducida a la figura del Maestro (en el Siglo XIX), en tanto instruye y conoce las leyes que rigen los fenómenos de la naturaleza, y las aplica así a la enseñanza de la educación física; o a la figura del Alumno (en el Siglo XX), en tanto supuesto soberano del proceso educativo al que hay que conocer (siempre a priori) para planificar la enseñanza. En ambos caso, la Educación queda reducida a Uno de los "actores", o, en el mejor de los casos, a Uno y Uno que se interrelacionan (como en el caso de la concepción acuñada bajo el signo de la "intersubjetividad", o sea, una situación compuesta por dos personas que inter-actúan); de todos modos, siempre queda reducida al Uno (Uno que enseña y Uno que aprende). Sostener que hay una naturaleza humana que organiza el aprendizaje y prescribe por ende la enseñanza, implica la idea de que el individuo (el hombre o la persona) es Uno -fijo, universal, conciente y auto-contenido-, ${ }^{53}$ es Uno con su cuerpo y es Uno con la naturaleza. El cuerpo, reducido al organismo y por lo tanto a su dimensión natural, es Uno con la mente. Nótese además la fuerza del es como reducción ontológica que acompaña un deber ser.

Consideramos que esta idea del Uno no es casual, ni siquiera inocente; más bien, se sostiene solapadas como parte de la estrategia biopolítica que ha hecho entrar a la educación en las coordenadas inmunitarias del liberalismo moderno, primero, y del neoliberalismo y la globalización después:

precisamente contra la amenaza de la comunidad indiferenciada la Modernidad ha creado, en sus dinámicas reales y en su autointerpretación, un enorme aparato de inmunización. [...] interpreto el concepto inmunitas en contraste directo con el de communitas. Ambos remiten al término munus, del que etimológicamente proceden, pero el uno en sentido afirmativo y el otro en sentido negativo. Si la

\footnotetext{
53 "El hombre natural es todo para sí, es la unidad numérica, el entero absoluto que sólo tiene relación consigo mismo o con su semejante. [...] Aspiro al momento en que, liberado de los estorbos del cuerpo, seré yo, sin contradicción, sin división, y sólo tendré necesidad de mí mismo para ser feliz". J.J. Rousseau, Emilio, en Esposito, 2009:98.
} 
communitas se caracteriza por la libre circulación del munus -en su doble aspecto de don y veneno, de contacto y de contagio-, la inmunitas es aquello que lo desactiva, aquello que lo deroga reconstruyendo nuevos confines hacia el exterior del grupo y entre sus propios miembros (Esposito, 2009:6).

Sigamos el razonamiento para ver los dobleces y la pregnancia del discurso inmunitario a partir de la modernidad: si para Esposito el munus que caracteriza a la comunidad es el don que se da porque se debe dar y no se puede no dar, indica entonces solo el don que se da y no el que se recibe. Se proyecta por completo en el acto transitivo de dar y no implica de ningún modo la estabilidad de una posesión -y mucho menos la dinámica adquisitiva de una ganancia- sino pérdida, sustracción, cesión: es una "prenda" o un "tributo" que se paga obligatoriamente. En suma, el munus es la obligación que se ha contraído con el otro y por la cual, en agradecimiento, prevalece la reciprocidad o "mutualidad" (munus-mutuus) del dar, que determina entre el uno y el otro un compromiso. Por lo tanto, communitas es el conjunto de personas a las que las une, no una propiedad, sino justamente un deber o una deuda; es un conjunto de personas unidas no por un "más" sino por un "menos", una falta, un límite que se configura como un gravamen, o incluso una modalidad carencial para quien está "afectado", a diferencia de aquel que está "exento" o "eximido". En el reverso del paradigma comunitario, conviene seguir ahora lo inmunitario.

Dice Esposito que el "inmune" no es simplemente distinto del "común"; es su contrario, y lo vacía hasta la extinción completa no solo de sus efectos, sino de su presupuesto mismo. El individuo moderno, que asigna un precio específico a cada prestación, ya no puede sostener la gratuidad que requiere el don. Los individuos modernos llegan a ser verdaderamente tales, es decir in-dividuos, individuos "absolutos", rodeados por unos límites que a la vez los aíslan y en apariencia los protegen, sólo habiéndose liberado preventivamente de la "deuda que los vincula mutuamente. En cuanto exentos, exonerados, dispensados de ese contacto que amenaza su identidad exponiéndolos al posible conflicto con su vecino. Por temor al contagio de la relación que lleva implícita la política moderna, el individuo sacrifica el cum, la relación entre los hombres, y vive desde entonces en y de la renuncia a convivir. La vida entonces es sacrificada a su conservación. En esta coincidencia de conservación y sacrificabilidad de la vida, la inmunización moderna alcanza el ápice de su propia potencia destructora (cf. Esposito, 2003:30-31). 
Cabe recordar lo que ya hemos mencionado antes: la modernidad ha hecho una apuesta por la vida, pero no cualquier vida, y no de cualquier modo, sino fundiendo la vida con la política y replegando lo que los griegos llamaban bios, la vida calificada, la vida de relación, sobre la zoê, la vida animal de puro mantenimiento biológico: en este repliegue, ambas se funden en un único sentido de la vida. De lo que se van a ocupar las disciplinas nacidas al amparo de los Estado-Nación -y ya vimos que el discurso de la Educación Física sobre el Aprendizaje Motor, en tanto discurso biopolítico, no es ajeno a ellas-es precisamente de aquella vida que compartimos con los animales, de la vida zoê en tanto que vida biológica reducida a los procesos vitales (respiración, nutrición, etc.).

Dice Hannah Arendt que la razón de que la vida se afirmara como fundamental punto de referencia en la Época Moderna, y de que siga siendo el supremo bien de la sociedad moderna, radica en que el cambio moderno, que trajo aparejado una secularización y una general decadencia de la fe cristiana, no modificó, sin embargo, su creencia principal: el carácter sagrado de la vida. Dicho con otras palabras, la modernidad no puso nunca en tela de juicio la más importante inversión con la que irrumpió el cristianismo en el mundo antiguo, transformación que políticamente fue de mucho mayor alcance -históricamente, desde luego- y más duradera que cualquier creencia o contenido dogmático específico. Porque la "buena nueva" cristiana sobre la inmortalidad de la vida humana individual invirtió la antigua relación entre el hombre y el mundo, y elevó la cosa más mortal, la vida humana. Fue precisamente la vida individual la que paso a ocupar el puesto que tenía en otro tiempo la "vida" del cuerpo político. Es como si los primeros cristianos amoldaran conscientemente su concepto de inmortalidad según el modelo romano, sustituyendo la vida individual por la vida política del cuerpo político (cf. Arendt, 2009:339).

En el momento en que la política asume como objeto directo de las propias dinámicas la vida biológica, el paradigma inmunitario experimenta un salto cualitativo que lo lleva al centro de todos los lenguajes de la existencia individual y colectiva. La importancia creciente que, ya a finales del Siglo XVIII, adquieren las políticas sanitarias, demográficas y urbanas en el gobierno de la sociedad pone de manifiesto un incremento significativo de los procesos de inmunización. Desde aquel momento, es la vida humana -el cuerpo de los individuos y de las poblaciones- lo que se pone en juego en todos los conflictos políticos decisivos. Lo que importa, por encima de cualquier otra preocupación, es mantener la vida a salvo de cualquier forma de contaminación capaz de amenazar la identidad biológica. Llegados a ese punto, no solo la medicina adquiere un papel cada vez 
más político, sino que la política misma termina por hablar un lenguaje médico o incluso quirúrgico: cualquier posible degeneración del cuerpo debe ser evitada de forma preventiva mediante la eliminación de sus partes infectadas. El discurso del Aprendizaje Motor, siendo hablada por la Fisiología y la Psicología, no ha sido ajeno a ello; más bien lo ha reforzado, a veces de manera más literal y otras a partir de eufemismos. Recordemos por ejemplo algunos pasajes del discurso de la Educación Física analizados en el capítulo 4.

Todos los defectos orgánicos se van aumentando de generación en generación, cuando en el transcurso de la vida individual no se hace algo para combatirlos. Los padres degenerados o depauperados engendrarán casi seguramente hijos también degenerados. [...] El desarrollo ontogenético del hombre se encuentra reproducido a grandes rasgos, según las leyes bien conocidas en el desarrollo filogenético del individuo, y aún desde aquí hasta el período de la pubertad, viniendo a marcar una serie de normas bien precisas para el desarrollo individual del organismo. (Spitzy, 1917:19 las cursivas son nuestras).

El problema de mayor gravedad del paradigma inmunitario se refleja en el paroxismo de los nacionalismos y totalitarismos del Siglo XX, de los que el Nazismo constituye la mayor expresión tanatopolítica. Una vez encarnado en los dispositivos, el paradigma inmunitario, que había nacido para proteger la vida de su deriva comunitaria, se convierte en aquello que prescribe la destrucción de lo que había de preservar. Una vez que la vida de un único pueblo ha sido concebida como el valor último y absoluto que debe defenderse y potenciarse, resultó natural que a dicha vida le fuese sacrificada la de cualquier otro pueblo, o raza, que parecería contaminarla desde su interior.

Es necesario, entonces, balizar un camino que nos conduzca en otra dirección. Ya hemos visto en los capítulos 1 y 2 que, lejos de separarse del sentido inmunitario, el Aprendizaje motor, en su explicación emergente de los sistemas dinámicos al igual que en la ya conocida teoría de los talentos deportivos, redobla la apuesta hacia las ideas que hicieron posibles los peores tormentos del Siglo $\mathrm{XX} .{ }^{54}$ Podrá parecer un tanto apocalíptico o fatalista semejante planteo, pero basta recordar que ya hemos dicho (y estamos convencidos) que "porque se piensa como se piensa, se hace lo que se hace", planteo que nos obliga a advertir y revisar lo que pensamos para hacer algo distinto con lo que hicieron de nosotros.

\footnotetext{
${ }^{54}$ Se puede consultar también Arendt, 1998.
} 
Para habilitar una reflexión en torno a la enseñanza, nos interesa entonces dejar planteado que toda educación que se articule a partir de las ideas de naturaleza e individuo plantea a su vez una relación con el conocimiento establemente representado, a la que habrá que oponerle una teoría de sujeto.

\subsection{LA EDUCACIÓN CORPORAL: HACIA UNA BIOPOLÍTICA POSITIVA}

La recuperación de prácticas de aprendizaje que hemos hecho en investigaciones anteriores, en una perspectiva que integra la red de significaciones que otorga sentido a las acciones tanto sociales como individuales, nos permite suponer la preeminencia de los factores epigenéticos sobre los genéticos. Por otra parte, la casi invariable apelación de los estudios tradicionales a las "influencias" del medio social o a las diferencias biográficas para explicar las variaciones que no pueden explicar, nos autorizan a pensar que su estudio puede contribuir al conocimiento del aprendizaje motor y, sobre todo, a la enseñanza de las habilidades motrices.

Ya aclaramos que esta Tesis se reconoce subsidiaría del trabajo que hemos realizado bajo la dirección de Ricardo Crisorio en el proyecto de Investigación "El aprendizaje motor: un problema epigenético". ${ }^{55}$ Dicho estudio pretendió, a través de entrevistas en profundidad a deportistas de nivel internacional, examinar el papel de los factores culturales $^{56}$ y subjetivos en las prácticas de aprendizaje de las habilidades motoras, registrando los eventuales correlatos que guardaron, en la biografía particular de los distintos deportistas entrevistados, los aprendizajes propiamente deportivos y otros aprendizajes motores y no motores; de esta manera, se analizaron los aspectos particularmente significados por los deportistas en sus procesos de aprendizaje, con el objeto de establecer correlatos con las significaciones expresadas por alumnos de escolaridad primaria y media, o de clubes deportivos, registrados con anterioridad. Fue nuestra intención establecer principios que hicieran lugar a la pluralidad y diversidad propias de las prácticas y de los sujetos en la enseñanza de las habilidades motoras, y

\footnotetext{
${ }^{55}$ Proyecto de investigación que el grupo de Estudios en Educación Corporal ha desarrollado en el marco del Programa de Incentivos a la Investigación del Ministerio de Cultura y Educación de la Nación (Argentina) desde el 2003 al 2006.

${ }^{56}$ Por aquel entonces apelamos al concepto de epigénesis por falta de un concepto que nos permitiera dejar de pensar al Aprendizaje Motor en los términos que ha utilizado la investigación tradicional, intentando despegarnos de cuestiones genéticas y sin apelar a la naturaleza como explicación. Sin embargo, hoy nos atrevemos a poner en cuestión el concepto de epigénesis, ya que, aun habiendo podido lograr el desplazamiento que buscábamos, el término sigue remitiendo a procesos biológicos (supone la relación entre naturaleza y cultura).
} 
comparar las variables que los deportistas significaron como valiosas en su aprendizaje deportivo con las que considera la investigación tradicional del aprendizaje motor.

En una primera etapa de la investigación se analizó toda la bibliografía existente sobre el aprendizaje motor, y los datos arrojados por aquellas investigaciones se contrastaron con los aportes de investigaciones anteriores del equipo.

El tratamiento innovador que supuso aquel estudio, abordando los elementos epigenéticos (culturales) de ese aprendizaje y procurando establecer los correlatos existentes entre los modos de aprendizaje de aquellos que se han destacado en distintos deportes, su biografía particular y las influencias recibidas del medio cultural y social en que han aprendido, a partir del análisis de los elementos subjetivamente significados por cada uno de ellos, aportó (así lo creemos) al conocimiento de los procesos reales de aprendizaje deportivo y de sus relaciones con otros aprendizajes motores y no motores en situaciones concretas, tal como se presentan en las prácticas de Educación Física.

El trabajo que realizamos se basó en tres tipos centrales de información: a) entrevistas en profundidad realizadas a un conjunto de deportistas y ex-deportistas destacados en distintas especialidades (Roberto De Vicenzo, Golf; Héctor Campana, Básquetbol; Vanina Onetto, Hockey femenino; Waldo Kantor y Hugo Conte, Voleibol; Héctor Silva, Rugby; Francisco Varallo, Fútbol), todos ellos de nivel internacional e integrantes en su momento de los respectivos seleccionados nacionales en los casos en que los hubiera; b) reportajes a deportistas en prensa y publicaciones especializadas, autobiografías como las de Diego Maradona, Earvin "Magic" Johnson, Emanuel Ginóbili, etc.; c) nuestras experiencias personales como aprendices y deportistas en distintas disciplinas y distintos niveles de rendimiento. Las entrevistas fueron semiestructuradas y duraron un promedio de dos horas, generando más de 200 páginas de transcripciones. ${ }^{57}$

\footnotetext{
${ }^{57}$ Fueron preparadas sobre la base de una estructura común, cuya pregunta central era “¿cómo aprendió usted a jugar al... (deporte en el que se destacó o destaca)?”, y de la cual se desprendían otras vinculadas con el problema del aprendizaje motor: cuáles eran sus juegos; qué relación encuentra entre ellos y el aprendizaje del deporte en que se destacó o destaca; cuándo y cómo jugó por primera vez al deporte en que se destacó o destaca; cómo continuó ese proceso; qué papeles jugaron los elementos del entorno social y natural en él (espacios, tiempos, familia, amigos, compañeros, instituciones, etc.); cómo era su percepción de este aprendizaje; cómo era la percepción de su cuerpo y sus habilidades; cómo era la relación con su cuerpo y con los otros (pares y adultos); cómo influía su habilidad en ellas; si tuvo ídolos, deportistas a quienes admirara o tratara de parecerse; qué le pasaba cuando jugaba al deporte en el que se destacó o destaca; si cuando jugaba otros juegos había diferencias significativas, etc. Además, cada entrevistado recibió un cuestionario que debía llenar con su lugar y fecha de nacimiento, nombre y apellido de sus padres, composición familiar (hermanos, hermanas, orden de nacimientos), etc.
} 
El trabajo fundamental, una vez realizadas y textualizadas las entrevistas -el primero de estos pasos fue particularmente gravoso por la dificultad que implica llegar a personas que gozan de (bien ganada) fama, muchas de los cuales estaban aún en actividad-, recopilado y elaborado el material periodístico, las biografías, etc., consistió en encontrar las categorías analíticas (teóricas) que permitieran formalizar las significaciones que los distintos deportistas vertían en las entrevistas, en los reportajes, en sus autobiografías, en relación con las cuestiones inherentes a cómo aprendieron la especialidad deportiva en que tanto se destacaron.

Las categorías que encontramos útiles para analizar y referir la información recogida fueron cuatro: los "otros", el "deseo", la "agresividad" y las "condiciones externas u objetivas", en tanto generadoras de límites y posibilidades.

\section{$>$ LOS OTROS}

En todos los casos, las referencias a los "otros" aparecen inexorablemente; en general ya desde los primeros comentarios, pero si no más tarde. No solamente, como suelen aceptar la investigación tradicional y el sentido común disciplinar, los otros primordiales -madre, padre, familia directa- sino también "otros" mucho más generales y diversos -entrenadores, ídolos, compañeros, amigos, público, etc.-, que ejercen una influencia tan indiscutible como heterogénea. En efecto, determinados "otros" que en unos deportistas ejercen una influencia decisiva no son significativos para otros; apoyan logísticamente el aprendizaje, lo acompañan o lo comparten, otorgan sentido al esfuerzo o son modelos a imitar, testimonian la habilidad, la inteligencia o la perspectiva de éxito en el deporte elegido, enseñan técnicas, tácticas, valores, pasión, etc.

En general, el apoyo familiar es considerado decisivo, pero asume distintos modos: desde el aliento hasta la disposición para llevar, traer, acompañar, en fin, para incluir las prácticas deportivas de los hijos en la organización familiar. Ese "estar" tampoco estuvo siempre ni implicó a toda la familia: a veces sólo a la madre, a veces sólo al padre, a veces a ambos y a veces a hermanos. Para algunos, la presencia familiar en la competencia fue significativa, esperada; para otros no. Decididamente, no puede hablarse de "líneas de sangre": algunos padres y hermanos practicaron deportes, o se interesaron en ellos, pero otros no, y en cualquier caso ninguno fue un deportista destacado; ${ }^{58}$ hay quienes triunfaron en el deporte que practicaba su padre, su madre o sus hermanos y hay

\footnotetext{
${ }^{58}$ No obstante, hay casos en que sí, por ejemplo, Verón, Simeone, Higuaín, Ludueña, etc.
} 
los que lo hicieron en otros. Todos, prácticamente, acentuaron el papel decisivo de uno o de varios entrenadores, pero no significaron particularmente la enseñanza de cuestiones técnicas o tácticas -aunque, por supuesto, las consideraran cruciales para el éxito- sino, antes bien, su saber del deporte que enseñaban, la pasión que transmitían, la amplitud de la formación, su extensión al ámbito de la vida, la transmisión de códigos, de pautas para encarar el deporte, los entrenamientos, la competencia y la vida misma. 59 "Otros" significativos son también los modelos: que llaman la atención, provocan la observación y la imitación, motivan la repetición de gestos técnicos, de comportamientos tácticos; los ídolos: que producen identificaciones y que a veces pertenecen al propio deporte y a veces a otros; los pares: a veces hermanos, pero también los amigos, los compañeros de colegio, o de barrio, que jugaban en ese club o a ese deporte.

De modo que no es tan importante determinar qué "otros" son decisivos en el aprendizaje como destacar y considerar la importancia decisiva de los "otros", su presencia necesaria y constitutiva en el aprendizaje. Constitutiva en tanto que sin "otros" significativos, cualesquiera sean, no se puede aprender un deporte, y mucho menos aprenderlo verdaderamente. Siempre hay "otros", aunque no sean más que "los ojos de la gente. Los ojos de la gente son los que más te ayudan, son los que te alientan o te desalientan" (De Vicenzo). Esta categoría obliga por sí sola a replantear toda la investigación que toma como unidad de análisis el individuo, el aprendizaje individual, y también la que incluye la interacción en términos apenas sociales, casi físicos, sin considerar la subjetividad y la significación en el texto de un orden simbólico.

$>$ ELDESEO

Utilizamos el concepto "deseo" para dar cuenta de ese anhelo, afán, ansia, hambre, como se enuncia sencillamente en el ámbito deportivo, ${ }^{60}$ que nunca se sacia y que todos los deportistas expresan, de un modo $u$ otro, con uno o varios nombres, tanto en las entrevistas que realizamos como en tantos reportajes y biografías, etc. Esta apetencia,

\footnotetext{
${ }^{59}$ Kareem Abdul Jabbar, quizás el mejor centro de básquetbol de la historia, ingresó a la academia católica Power cuando tenía 14 años. Medía ya $1.90 \mathrm{mts}$. pero esa era su única cualidad basquetbolística: estaba comenzando a coordinar sus movimientos y no tenía demasiada fortaleza. Jack Donahue, entonces entrenador de la academia y años más tarde seleccionador canadiense, le enseño los fundamentos del básquetbol pero, fundamentalmente, "Jack nos insufló orgullo y voluntad para ganar siempre. Nos decía que lo peor que nos podía pasar en la cancha era que diésemos la impresión de ser malos jugadores" (Declaraciones a la revista española SuperBasket, № 26, abril de 1988).

60 Galeano, Eduardo (1995). "El talento es hijo del hambre", en El fútbol a sol y sombra, Montevideo, Ediciones del Chanchito.
} 
ambición, aspiración, pasión, se manifiesta en la perseverancia, la paciencia, la voluntad, el empeño, el cuidado, la atención, la contracción, la exclusividad, el sacrificio de unas cosas para conseguir otras. Esa exigencia de destacarse, de "ser protagonista", que hace que alguien se fabrique "una motivación el lunes, el martes, el miércoles, el jueves, para que explote el sábado", juegue "en quinta y en sexta el mismo día" y le encante, le guste "jugar con los más grandes" para que sea más parejo y le bajen "un poquito los humos" (Silva); se pase "10 ó 12 horas dentro de una cancha de Golf, todos los días salvo los lunes" y busque en "los ojos de la gente" la repercusión de lo que ha hecho; vaya a "patearla todos los días"; lance 500 tiros cada mañana; ${ }^{61}$ "llegue al club a las 5, 6 de la tarde" y se quede "hasta la hora en que terminaba la última categoría", juegue en cadetes, en juveniles y en mayores, busque "referentes en las primeras divisiones, en los jugadores importantes" de su época (Kantor); considere importante que su familia sintiera el deporte como una responsabilidad y no como un entretenimiento (Onetto); se apasione descifrando a un entrenador coreano que no dominaba el español (Conte); mire mucho y aprenda mucho mirando, entrene aparte, antes y/o después del entrenamiento con todos. ${ }^{62}$

Estas referencias bastan, creemos, para hacer ver que no se trata aquí de una instancia del orden de la necesidad, de la demanda o de la representación. No hay, en los dichos de los entrevistados, ni en las declaraciones periodísticas ni en los relatos biográficos, nada que pueda relacionarse con la apropiación de algo que pueda ser poseído o detentado, con algo que sea requerido, reclamado, exigido, o con la idea o la representación de algo que pueda ser proyectado. ${ }^{63}$ Recurrimos a la categoría "deseo", no obviamente en tanto deseo objetivo que desea un objeto, una persona o lo que sea, como suele ser pensado por el sentido común, sino en tanto categoría teórica, que ha sido pensada, por ejemplo, por Alexandre Kojève en su lectura de Hegel (Kojève, 1999), o por Lacan en su "reformulación de la estructura tradicional del deseo freudiano", la cual, no obstante, "tiene como condición de existencia la formulación freudiana del deseo

\footnotetext{
${ }^{61}$ Como Michael Jordan, Drazen Petrovic, el propio Héctor Campana y tantos otros.

${ }^{62}$ Todos. En el receso anterior a su octava temporada como basquetbolista profesional en la NBA, James Worthy, ya millonario, famoso y varias veces campeón de esa Liga, entrenó su lanzamiento desde 4 metros porque lo consideraba un aspecto deficitario de su juego (Revista SuperBasket, № 26, abril de 1988).

63 "Yo no me proponía, por ejemplo, llegar a la selección argentina; ese podía ser un objetivo más general, digamos, para otro tiempo. Yo me ponía siempre objetivos mas inmediatos y me quedaba siempre después del entrenamiento; quería estar siempre jugando." Héctor Campana.
} 
inconsciente" (Rabinovich, 1993). No nos internaremos aquí en la discusión, conocida, de Lacan con Hegel y con la lectura que de él hace Kojève. No nos sentimos autorizados a decidir ni a discutir el mérito de las respectivas posiciones. ${ }^{64}$ Sin embargo, ciertamente no encontramos en nuestra investigación nada que nos autorice a suponer que el deseo se ejerza en función del "deseo de reconocimiento" (los deportistas no buscan ser "reconocidos"), ni que genere "autoconciencia" (los deportistas no son conscientes de su deseo y la conciencia de su valía no está en relación con él sino con los otros) o sea "autónomo" (en el sentido de que se mueva por sí mismo, o se origine endógenamente, o tenga "su propia norma, su propia medida, su propio fundamento). Por el contrario, el deseo parece ser efectivamente inconsciente y permanecer desconocido. El análisis de los datos agrupados en esta categoría muestra, nuevamente, que no hay en el aprendizaje motor nada del orden de la naturaleza ni de lo individual, más allá de la necesaria posesión de una "buena salud", como subraya y repite Roberto De Vicenzo.

\section{$>$ LA AGRESIVIDAD}

La "agresividad" tampoco debe entenderse aquí en su sentido corriente, que la relaciona con la violencia, la exasperación o la fiereza, con cierta disposición casi constante para el ataque o el enfrentamiento, sino en tanto "constitutiva de la primera individuación subjetiva" (que el sujeto trasciende sólo a posteriori), "significativa de un desarrollo del yo" (Lacan, 1985:113). El sentido común tiende a creer que la agresividad es la agresión; sin embargo, "Sólo en su límite, virtualmente, la agresividad se resuelve en agresión" (Lacan 1990:176). Nos parece que, a partir de los dichos y declaraciones recogidos y de los hechos observados, podemos suscribir que "lo que es del orden de la agresividad llega a ser simbolizado, tomado en el mecanismo de lo que es represión, de lo que es inconsciente, analizable, de lo que es general e interpretable", mientras que la violencia, que es lo esencial en la agresión, "es algo que en su esencia se distancia de la palabra" (cfr. Lacan, 1999).

Por ejemplo, un deportista que "de chico tenía una cosa bastante autoritaria, de imponerme físicamente, de liderar", al punto que "si no ganaba, los partidos de fútbol no terminaban", que "si perdía un juego en un recreo no podía hacer la clase siguiente" y que se "peleaba con todos", obviamente pudo en algún momento aceptar las reglas y el ethos de su deporte porque, de lo contrario, no hubiera llegado donde llegó. No obstante, refiere

\footnotetext{
${ }^{64}$ Lacan entiende el deseo como "deseo del Otro" y Kojève como "deseo de otro deseo".
} 
haber tenido, en lo deportivo, "una agresividad muy especial" que sostuvo durante toda su carrera, "una exigencia, una autoexigencia desmedida para el deporte" que hacía que se "bancara" mejor la derrota que sus propios errores. Él mismo define esa exigencia como "obsesiva y, a veces, patológica”. En varios pasajes de su obra, Lacan vincula la agresividad a la obsesión. 65 "Ganar -dice Kantor- creo que la primera cosa que me gustaba de un partido era ganar. No sé, la competencia llevada a su máxima expresión, confrontarse con otro y ganar, ser mejor". Lacan sostiene que "la agresividad es subtendida por una identificación con el otro, objeto de la violencia" (Lacan, 1977:92) y, en otro lado, que "la agresividad en cuestión es del tipo de las que entran en juego en la relación especular, cuyo mecanismo fundamental es siempre o yo o el otro" (Lacan, 1994:182). Expresadas con igual o menor vehemencia, la ambición y la exigencia de ganar aparece en todas las declaraciones, tanto en las entrevistas realizadas por nosotros como en los reportajes de prensa y, por supuesto, en los hechos.

Siempre fui muy competitivo, muy de entrenar, de esforzarme y de ponerme metas todos los días: por ejemplo, salía a correr y, si se me ocurría llegar primero, podía dejar la vida para llegar primero; por más que he logrado muchas cosas, todos los años me pongo objetivos, y en cada entrenamiento, en cada partido; cuando fui a la selección había jugadores mejores que yo y trataba de ser mejor que ellos; mi carrera fue un constante desafío, una constante competencia, siempre, siempre; si nos ponemos a tirar al aro compito, porque te quiero ganar, y si te gano quiere decir que estoy haciendo las cosas bien; yo creo que compitiendo estoy mas cerca de la realidad del juego, de las presiones que el juego tiene, que si me diera lo mismo si las cosas salen bien o mal (Campana).

Podríamos agregar, obviamente, más y más dichos y citas. Hugo Conte destaca la exigencia de su primer entrenador, Héctor Silva la del "coach" sudafricano, Gregg Popovich elogia "la actitud ganadora" de Emanuel Ginóbili: "Manu es el jugador más competitivo que dirigí en 30 años, porque, más allá de su talento, siempre tiene enormes ganas de ganar y un ímpetu especial que lo hace diferente a todos". ${ }^{6}$ Una cosa distinta parece decir Roberto De Vicenzo cuando plantea: "el deporte de golf no es, cómo te podría decir, conflictivo: uno admira al que juega bien porque más que con el contrario se compite contra la cancha, y la cancha no habla, la cancha está ahí; el que le saca mejor provecho a la cancha gana, y al perdedor no le queda más que felicitarlo porque no le

\footnotetext{
${ }^{65}$ Por ejemplo, en (Lacan, 1985; Lacan 1977; Lacan:2011).

${ }^{66}$ La Nación Deportiva, Domingo 19 de junio de 2005.
} 
ganó a él sino a la cancha y él perdió porque no le ganó a la cancha". Sin embargo, en otro lugar dice:

a medida que vas compitiendo con jugadores de primera línea ya no jugás con la soltura y la tranquilidad con que podés jugar con jugadores de segunda línea. Cuando jugás con jugadores de primera línea tenés que poner el pie en el acelerador y controlarte, y manejar la pelota a una posición un poco más controlada que cuando jugás con jugadores de segunda línea. Cuando jugás con jugadores de segunda línea tirás la pelota, pero cuando jugás con jugadores de primera la presionás; es como cuando viajás en un auto: a 80 kilómetros por hora vas conversando con el copiloto, pero a 160 ni lo mirás, mirás el camino.

De todas maneras, más allá de las características de cada deporte y de cada deportista, nos parece evidente que la agresividad, en el sentido en que la hemos incluido, es un requisito principal del éxito en el aprendizaje deportivo. Muchas de las declaraciones recogidas en este apartado se relacionan, también, con la categoría "deseo". Lacan relaciona también agresividad y deseo en muchos pasajes de su obra (cf. Lacan, 2011). Además, el hecho de que los deportistas se sometan a reglas y códigos estrictos remarca el atravesamiento simbólico que es propio de la práctica deportiva, el cual deberíamos considerar detenidamente de cara a la enseñanza del deporte, entendiéndolo como lo que es, una figuración compleja que no puede reducirse a un conjunto de técnicas y tácticas.

\section{$>$ LAS CONDICIONES EXTERNAS U OBJETIVAS}

Resta considerar brevemente el papel de las condiciones externas u objetivas. No constituyen una categoría menor aunque tienen una índole naturalmente azarosa con la que no simpatizan, obviamente, los "científicos" dedicados al estudio clásico del aprendizaje motor. Sin embargo, Roberto De Vicenzo se inició en el golf

por circunstancias de la vida. Mis padres fueron a vivir cerca del campo de golf: mis hermanos, mayores que yo, comenzaron como caddies, luego lo hice yo también [...] y empecé a practicar el juego, a la criolla, como bien se dice. [En ese entonces] no pasaba por mi imaginación lo que iba a ser mi vida deportiva, simplemente creí que iba a poder hacer un trabajo y que con él iba a poder salir de la pobreza en que vivíamos. 
En cambio, Waldo Kantor y Vanina Onetto destacan la importancia del club familiar. ${ }^{67}$ También Hugo Conte subraya lo que "proponía GEBA", el hecho de que allí había "cancha para todo", agrega la libertad y la seguridad de que dispuso en su juventud para andar por la calle, y valora, igual que Héctor Campana y Héctor Silva, los clubes de barrio, y la posibilidad que todo esto ofrecía de contar con otros, pares y mayores, para jugar a todo, todo el día. Sin embargo, al lado del juego, de la libertad y la diversión, todos incluyen la enseñanza, la exigencia y, sobre todo, la competición, es decir, la disposición de instancias en las que competir.

Por muy azarosas que parezcan o sean, todas estas condiciones aisladas como categorías de análisis pueden reproducirse, ya mediante políticas, ya en la enseñanza. Se objetará que las condiciones de libertad y seguridad, tan estrechas (estrechadas) en la sociedad actual, difícilmente volverán, y que los clubes de barrio prácticamente han desaparecido. Ello no obsta para que la educación física incluya en sus prácticas la de denunciar estas situaciones que constriñen, como tantas otras, la educación corporal de las generaciones jóvenes, tanto como la de imaginar situaciones nuevas que devuelvan a las prácticas corporales sus posibilidades de producir emociones placenteras, para lo cual es urgente poder pensar de nuevo la enseñanza, la competición, el rendimiento, la agresividad, las estructuras y las condiciones del aprendizaje, en fin, todo aquello que la educación y la educación física, la pedagogía y la didáctica, han excluido o rebajado en aras de sus pretensiones cientificistas.

La Educación Corporal, entonces, en tanto logre huir de las esencias y desustancializar y desbiologizar al cuerpo y al sujeto, podrá re-interpretar las relaciones entre aprendices y maestros, abandonando una perspectiva de enseñanza sesgada por las ideas de naturaleza, designios, dones, continuidades, universales, leyes, representaciones, etc. La Educación Corporal no buscará establecer generalidades o periodos de edades óptimos, sino que pretenderá dar lugar a la diversidad de las prácticas y a la particularidad del sujeto.

Todo esto supone un cambio radical en tres ejes: el del saber, el del poder y el de la ética. Proponemos entonces, a la manera de Foucault, que hay que establecer los problemas en tres dimensiones: en relación con el saber -¿qué práctica enseñar?, ¿por qué?, ¿cuándo?, ¿para qué?-; en relación con el poder, es decir con los otros -¿cómo

\footnotetext{
${ }^{67}$ Igual que Kantor en el voleibol, Emanuel Ginóbili se inició en el básquetbol en el club fundado por su abuelo y del cual su padre fue jugador, entrenador y presidente.
} 
vincularse con otros por medio del saber?, ¿cómo se enseña a los otros?, ¿cómo hacer para que los aprendices se relacionen con el contenido?-; y por último en relación con uno mismo, es decir la ética, que supone un análisis de lo que cada uno hace con el saber y con los otros.

Nuestra apuesta, entonces, es desbiologizar la Educación Física en pos de una posible des-inmunización de la educación y, si se quiere, de la sociedad. Este cambio supone a todas luces re-signar el concepto de vida, restituyendo el bios por sobre la zoê. Se trataría de replegar la vida de puro mantenimiento orgánico a la vida política, lo que supondría intervenir no sobre el organismo sino sobre el modo de vida.

\subsection{EL ESQUEMA DEL “AL MENOS TRES”}

Para poder repensar esta educación subsumida al Uno, será necesario proponer otras articulaciones posibles. El nuevo dispositivo de Enseñanza que proponemos supone al menos Dos (maestro y aprendiz) y una tercera posición que media esta relación: el saber. Esto supone el imperativo de abandonar la relación causal entre Enseñanza y Aprendizaje que ha supuesto que se aprende porque se enseña. Maestro y Aprendiz no podrían referirse uno al otro si no hubiera una tercera instancia (un Otro, un Orden simbólico) que sanciona este encuentro, haciéndolo posible (Voltolini, 2008:184).

Pensar estas nuevas relaciones supone abandonar Educación Física poder pensar en una Educación Corporal que de un tiempo a esta parte ha comenzado problematizar algunas cuestiones (que nosotros enunciamos como tensiones): Conocimiento/Saber Enseñanza/Transmisión - Individuo/Sujeto. Estas primeras cuestiones, desde luego, abrirán infinitas posibilidades de seguir tensionando, problematizando y articulando: Maestro/Profesor - Alumno/Aprendiz - Teoría/Práctica, etc. De lo que se trata entonces es de hacer tajos en "la verdad", puesto que, como dice Lacan, "la dimensión de la verdad no está en ningún lugar mientras solo se trata de la lucha biológica" (2007:44).

Pretendemos que estas cuestiones que hemos introducido cumplan una función de fractura. Pensemos, a propósito de la Enseñanza, con Lacan:

No es inútil percatarse de que el profesor se define entonces como aquel que enseña sobre las enseñanzas. Dicho de otra manera, hace un recorte en las enseñanzas. Si esta verdad fuese mejor conocida -que se trata de algo análogo al collage-, ello permitiría a los profesores poner un poco más arte en el asunto, del que el collage, con el sentido que ha adquirido en la obra de arte, nos muestra la 
vía. Si hicieran su collage preocupándose menos de que todo encajara, de un modo menos temperado, tendrían alguna oportunidad de alcanzar el mismo resultado al que apunta el collage, o sea, evocar la falta que constituye todo el valor de la propia obra figurativa, por supuesto cuando es una obra lograda. Y por esta vía llegarían a alcanzar el efecto propio de lo que es precisamente una enseñanza (Lacan, 2011:187-188).

Tomar en cuenta este enunciado nos invita a pensar que quizás no sea necesario que todo encaje a la perfección, que la transmisión puede darse en los términos de una "falta", de lo incompleto, de lo que "no se sabe", de "saber que no se sabe", porque en todo caso "todo lo que pueda forjarse como saber propio corre el riesgo de constituirse como una defensa contra la verdad" (cfr. Lacan, 2007:140).

Si estamos de acuerdo en que los contenidos son el conjunto de saberes o formas culturales cuya asimilación y apropiación por parte de los alumnos se considera esencial para su socialización, y que en el caso de la Educación Física son los juegos, los deportes, la gimnasia, y la vida en la naturaleza y al aire libre; si estos contenidos son formas culturales, saberes relevantes para una cultura que por ello deben trasmitirse a las nuevas generaciones, y no lo que la genética determina, no pueden entonces ser "naturales", ni pueden ser patrimonio del individuo, ni nada que provenga del "interior". No son por lo tanto las capacidades condicionales, tampoco el movimiento, ni el hombre integral, ni nada que ponga a la supuesta "naturaleza" humana en el lugar del saber.

El contenido permanece entonces significativo para la sociedad y la cultura, y su adecuación a cada uno, imposible a priori, se realiza (nunca totalmente) en el dialogo particular de cada maestro con cada aprendiz y/o en las relaciones interpares que ellos autorizan. El diálogo acentúa no el cerramiento del individuo sobre un supuesto sí mismo sino su sujeción a reglas que, situando a dos personas desde una tercera posición, hacen que haya un campo común entre los involucrados (Crisorio, 2012:5)

Como sostiene Crisorio,

la Educación Corporal no identifica al sujeto con la persona, el individuo, el ciudadano, el psiquismo o cualquier entidad que se presente como unidad en sí misma. Más bien no identifica al sujeto sino que apunta a reconocerlo como la marca misma de la falta de identidad de alguien o algo consigo mismo. Se trata de un sujeto producto del discurso y no de un individuo con un aparato psíquico propio, separado del otro, cuya representación remite siempre a un dentro del 
cuerpo. El sujeto embraga en el cuerpo, se articula a un cuerpo, no está dentro de él ni determinado por él (Crisorio, 2012:4).

El sujeto que nos interesa es sujeto no en la medida en que hace el discurso, sino en que está hecho por el discurso, e incluso está atrapado en él; es el sujeto de la enunciación, es lo que representa un significante para otro significante (cf. Lacan, 2007:53). Entonces,

pensar el cuerpo humano y el sujeto constituidos en el orden simbólico y no en la naturaleza, pensarlos como lo que resulta de la desconexión en el hombre de lo humano y lo animal, y no de su articulación o conjunción, lleva a pensar también de otro modo el problema de la educación, tanto en sus puntos centrales como en sus detalles. Destituir la naturaleza y cualquier función que se le quiera atribuir en el terreno de lo humano implica destituir también por ejemplo, cualquier explicación atribuida a la psicología contemporánea (Crisorio, 2012:2).

Por último, y a modo de cierre, intentaremos responder a la pregunta que en algún momento dejamos en suspenso: ¿qué es lo que podemos hacer con lo que hicieron de nosotros?

En primer lugar, se trataría de establecer investigaciones que nos permitieran indagar sobre las relaciones de nosotros mismos con el saber, el poder y la ética; es decir, trabajos histórico-críticos que nos permitan indagar los puntos de emergencia de las relaciones que hemos establecido con el saber, los otros y nosotros mismos en esas relaciones de saber y poder. Este tipo de investigaciones nos pondrían frente a la necesidad de desplazar el territorio tradicional de la Educación Física como educación de la naturaleza o del organismo (y por ende desplazar también sus técnicas y sus métodos de investigación) hacia una educación del cuerpo textualizado por la cultura. El "origen" de la Educación Física también será puesto en cuestión, ya no más como "origen" sino a partir de cierto contexto de surgimiento, de cierto "Ethos" en el que esas prácticas pudieron ser pensadas y hechas de determinada manera. Pero también es necesario que esta Educación Física asuma una "actitud" reflexiva y crítica respecto de los saberes que trasmite -"los contenidos" en tanto recortes de la cultura-, como del "curriculum", ya no de un modo prescriptivo y funcional a las teorías y poderes que lo informan sino como "conjunto de prácticas" a partir del cual quien imparta la educación corporal, asumirá un nuevo rol que ya no es el de intentar aplicar ciegamente aquello que le es "impuesto", sino el de convertirse en un "interprete". Y es este último punto el que nos interesa desplegar. 
Este intérprete de la cultura, de las prácticas corporales, intentará deducir de la contingencia histórica que nos ha hecho ser lo que somos la posibilidad de no ser, hacer o pensar lo que somos, hacemos o pensamos, e intentará establecer: 1) Principios para la selección de contenidos, qué es lo que debe enseñarse; 2) Principios para la enseñanza, cuál es la estrategia que permita enseñar de un modo crítico a todos, no a partir de la universalización del sujeto y la particularización del contenido sino a la inversa, de la universalización del contenido y la particularización del sujeto; 3) Principios sobre los cuáles analizar el marco político contextual, a quién y dónde se va a enseñar. Todo contenido debe ser trasmitido críticamente, porque solo la función crítica sirve a la transformación de la práctica.

Podríamos definir esta actitud crítica, con Foucault, no como un comportamiento que nos obligue a optar por la alternativa del adentro y del afuera, sino más bien como una actitud que nos permite permanecer en los límites. La crítica reside justamente en el análisis de los límites y de su reflexión. Pensar en el límite, en la frontera, ni adentro ni afuera, supone por ejemplo repensar la relación con la vida; de hecho, es posible, y diría que hasta necesario, establecer que la discusión por la vida deberá estar en el centro de la escena. Claro está que semejante afirmación no podría hacerse si no cuestionáramos a qué nos referimos con vida, qué vida es la que hay que poner en el centro; pero una vez que lo hagamos, la pregunta misma nos pondrá entonces de cara al problema de la biopolítica, ya no en los términos que estableciera la modernidad, eso ya no será posible para nosotros.

Este trabajo en los límites nos permitirá pensar otra relación con la biopolítica que no suponga ni el rechazo absoluto que nos coloca afuera (tarea imposible), ni la adhesión resignada de lo que nos es legado, y que por eso mismo nos colocaría definitivamente adentro y aceptando su mandato; más bien se trata de tomar una actitud que nos permita pensarnos en la frontera, en el límite entre el afuera y el adentro, que nos permita pensar y actuar en los términos de una biopolítica positiva. Es decir, una actitud teórica y al mismo tiempo práctica que recomponga la relación política-vida pero no ya en el sentido biológico de puro mantenimiento orgánico, sino en el de una vida calificada y de relación que obviamente incluye a otros: en síntesis, esto nos pone de cara a una "vida" que no se limita a prologar indefinidamente las funciones de respiración, nutrición, etc., sino que nos corre de lo orgánico para pensar en tiempo presente, en fin, una vida "que merezca ser vivida". Al mismo tiempo, se invita a cuestionarnos respecto de la educación del cuerpo, 
que ya no puede reducirse al conjunto de huesos, articulaciones y músculos, o a un sistema nervioso que organiza nuestras percepciones y acciones y que por ende hay que mantener o estimular para que logre su "natural" desarrollo; por el contrario, debe pensarse un cuerpo de las prácticas, un cuerpo en "uso" que no está destinado a agotarse como consecuencia del "consumo", sino que puede ser educado "para ser usado" y "disfrutado" con la alegría y el placer que sólo es posible pensar y experimentar en los límites del sistema, de las modas y hasta de las teorías mismas. Reflexionar sobre estas cuestiones nos hace escapar de la pura "repetición", nos hace "pensar" haciendo un mejor ejercicio de nuestra libertad. 


\section{CONCLUSIONES}

Toda conclusión es forzosamente provisoria. Las que extraemos de esta tesis no son una excepción. Sin embargo, creemos necesario advertir, antes de reseñarlas, que ellas resultan de un trabajo de desplazamiento del territorio tradicional y de los métodos con que la Educación Física delimita los ámbitos que procura dominar o investigar, de la forma mediante la cual el saber científico se utiliza en ella, del proceso de formación de sus objetos de conocimiento y creación de sus conceptos, para el caso particular del Aprendizaje Motor.

La teoría tradicionalmente elaborada en torno del Aprendizaje Motor, adherida al esquema de la ciencia positiva moderna, ve en la experiencia un punto de partida para la elaboración teórica y, suponiendo que este aprendizaje existe como dato de la realidad, accede a estudiarlo empíricamente para desarrollar una teoría. Nosotros, en cambio, encontramos que es la teoría la que permite el encuentro con el aprendizaje motor; dicho de otro modo, es porque los teóricos de la Educación Física piensan al ser humano como lo piensan (del hombre al individuo) que se encuentran con el aprendizaje motor y lo hacen entrar en pulsación con la naturaleza. Nuestra posición, entonces, nos ha puesto de cara a un objeto distinto, con otras formas, otros bordes, otra epistemología que lo soporta y, por lo tanto, otros efectos de verdad. Entendemos que el Aprendizaje Motor no está, no es, sino que lo hemos construido a partir de interpretaciones teóricas.

$\mathrm{Si}$, por otra parte, la materialidad del sujeto que nos interesa es discursiva, y el sujeto que concebimos habita el lenguaje, nuestro punto de partida no podrá ser la experiencia sino el lenguaje, ordenado en el discurso que se articula para hacerlo aparecer en las prácticas. Esto supone una ruptura. Para estudiar al aprendizaje motor no recurrimos al experimento en el laboratorio ni a la observación de prácticas de enseñanza, sino que lo inscribimos en un sistema simbólico. Y ese solo movimiento nos llevó a desnaturalizar en el Aprendizaje Motor lo que la Educación Física, sirvienta de varios amos, había recubierto. Al suponer en el hombre un animal agazapado nos había negado, por la vía de un discurso naturalista, nuestra propia condición humana de pensar y darle forma a nuestra humanidad. Pensar el Aprendizaje Motor en los términos de un discurso nos permitió adueñarnos tanto de nuestra potencia como de nuestra impotencia. El discurso de la Educación Física intenta cegarnos por la vía de una naturaleza que cristaliza nuestras posibilidades de aprender. Nuestro objeto, en cambio, habilita otros marcos de libertad, otras posibilidades de resistir a ese poder que engañosamente nos convence de 
que "hay quienes pueden" aprender mientras que otros "no". Pensar que el hombre no es un animal que sólo puede su propia potencia sino que, precisamente por su capacidad simbólica, puede tanto ser como no ser, hacer como no hacer, y puede justamente aquello que puede no, abre nuevos horizontes tanto para el que aprende como para el que enseña.

Si el Aprendizaje Motor es una categoría, un concepto, una abstracción, y nunca una representación de algo que existe, que se puede medir, observar o cuantificar, podemos sostener la mirada fija en él sin que por ello sus luces nos cieguen y, hundiéndonos en sus tinieblas, buscar aquello que había quedado velado, cubierto e invisibilizado por un discurso que hemos vuelto inoperante al revelarlo e interpretarlo. Ya no es posible entonces pensar "lo que Natura non da, Salamanca non presta": hay que enseñar. Pero tornarlo inoperoso supone también otras subversiones, afrontar el desafío de efectuar otros desplazamientos (siempre teóricos) que consideramos necesario puntualizar.

En primer lugar, escapar de la idea de que somos individuos, organismos individuales dotados de un interior, que vivimos en un medio exterior, para pensar que lo interior y lo exterior están conectados, como en la cinta de Moebius, y que el lenguaje permite articularse con la cultura. Pensar el Aprendizaje Motor por fuera de la categoría de individuo, persona y hombre, permite borrar ese límite artificial y ficticio, volver inoperante la oposición interior-exterior, mostrar que no hay uno y otro sino Uno en el Otro y Otro en el Uno, proponer una enseñanza que supone contar en un mismo esquema al maestro, el aprendiz y una tercera posición que media esta relación: el orden simbólico, recortado, en este caso como contenido. Esto supone, a la vez, abandonar la relación causal entre Enseñanza y Aprendizaje, que ha supuesto que se aprende lo que se enseña. Maestro y Aprendiz no podrían referirse uno al otro si no hubiera una tercera instancia, un Otro, un Orden simbólico que hace posible este encuentro.

Dejar de pensar en el individuo supone también abandonar la idea que procura encontrar en lo biológico su identidad. El discurso tradicional del Aprendizaje Motor enclava al individuo en lo biológico individual $\mathrm{y}$, de ese modo, reduce al sujeto a la vida desnuda, pretendiendo construir la identidad sobre datos meramente biológicos, de los que no se tiene ningún tipo de control: medidas antropométricas, órganos y funciones fisiológicas, ADN, sistema nervioso, fibras musculares rápidas o lentas, consumo de oxigeno, etc.

Como en un juego de dominó, cada movimiento teórico provoca un nuevo desmoronamiento/derrumbe/derrumbamiento. Cuestionar el individuo nos obliga a 
repensar esas categorías naturales (naturaleza, designios, dones, continuidades, universales, leyes, generalidades, representaciones, evolución, períodos óptimos), para dar paso a la diversidad de las prácticas y a la particularidad del sujeto a partir de articular en la enseñanza las categorías que nosotros mismos hemos elaborado. Si resulta que es determinante en el aprendizaje de las habilidades y de los deportes la influencia de los otros, del deseo, de la agresividad y de las condiciones externas u objetivas, ya no es posible pensar en un modelo de enseñanza que tienda a invisibilizarlas o anularlas. Del mismo modo, incluir estas cuestiones pone necesariamente en tela de juicio el patrón "inmunitario": no hay modo de abandonar la idea de un aprendizaje individual si no pensamos la vida humana como una vida con otros, es decir, si no pasamos lo "comunitario", que en los términos de una teoría de enseñanza formalizamos como el transitar del esquema del Uno (en las Teorías del Aprendizaje), que establece una simple relación dual entre un emisor y un receptor, entre alguien que enseña y alguien que aprende, al esquema del al menos tres: maestro, alumno y saber (en tanto Orden Simbólico). Este desplazamiento acompaña además la idea de abandonar una Educación Física que toma por objeto al organismo para pensar en una Educación Corporal que toma por objeto al cuerpo (textualizado en la cultura), y que supone además transitar de una biopolítica negativa a una biopolítica positiva -es decir, de la zoe al bíos- para intervenir no sobre el organismo sino sobre el modo de vida. Pensar las prácticas en los términos del organismo pone al cuerpo fuera juego, es decir, de todo uso posible; y ya hemos dicho que el uso nunca puede ser individual y privado sino sólo común. En fin, usar el cuerpo y servirse de él como instrumento para un fin no son la misma cosa (en griego, organon significa, precisamente, instrumento, utensilio, herramienta).

El modelo de cuerpo que sostiene la Educación Física actual es un cuerpo para ser admirado y exhibido, un cuerpo para rendir, un cuerpo utilitario, un cuerpo que reducido a su dimensión biológica y orgánica queda destinado a la espectacularidad. Es un cuerpo que se consume, que se agota, que incluso es empujado a los límites de la vida. El concepto de cuerpo con el que se maneja la Educación Física parece mostrarnos que las promesas de juventud y belleza eterna tienen un alto costo, que nunca es la sola promesa incumplida. Nuestras clases, podemos decir con seguridad, resultan ser el lugar destinado al sacrificio, el templo en el que el culto al cuerpo es consagrado, pero también el museo en el cual los cuerpos son exhibidos, admirados, contemplados -nunca usados. La pregunta entonces resulta ineludible ¿es posible habilitar por vía de la Educación Corporal nuevos usos del cuerpo? La respuesta es sí, pero a condición de volver inoperante la 
categoría de organismo que pone al cuerpo en el lugar del instrumento, biológico, natural y físico, al que hay que mantener o estimular para que logre su "natural" desarrollo; a condición de pensar un cuerpo de las prácticas, un cuerpo que, pensado como elaboración de la cultura, del orden simbólico, pueda ser educado para ser "usado" y "disfrutado" con la alegría y el gozo que sólo es posible pensar y experimentar en los límites del sistema, de las modas y hasta de las teorías mismas.

Cada una de estas cuestiones ha sido analíticamente desplegada. Para no abundar, digamos que todas estas subversiones nos obligan a desplazar la mirada y estudiar los problemas no en los términos en que la Educación Física los ha pensado, sino en los términos de una Educación Corporal que nos permita el encuentro con las prácticas.

Esta tesis no se agota en sus planteos; lejos de cerrar el tema, abre a futuro la posibilidad de seguir preguntando. Nuestra intención no es tener todas las respuestas sino asumir la falta, instalar las preguntas que nos movilicen a seguir pensando. La tarea que queda por delante solo está enunciada. 


\section{BIBLIOGRAFÍA}

- Agamben, Giorgio (2002). Lo abierto, Buenos Aires, Adriana Hidalgo.

- Agamben, Giorgio (2005). Profanaciones, Buenos Aires, Adriana Hidalgo.

- Agamben, Giorgio (2010). El sacramento del lenguaje. Arqueología del juramento, Buenos Aires, Adriana Hidalgo editora.

- Agamben, Giorgio (2010). Signatura Rerum. Sobre el método, Barcelona, Anagrama.

- Agamben, Giorgio (2011a). Desnudez, Buenos Aires, Adriana Hidalgo.

- Agamben, Giorgio (2011b). “¿Qué es un Dispositivo?”, en Revista Sociológica, año 26, número 73, pp. 249-264.

- Andrè Comte-Sponville (2001). Diccionario filosófico, Paris, Paidós.

- Ardila, Rubén (2001). Psicología del Aprendizaje, Madrid, Siglo XXI Editores.

- Arendt, Hannah (1998). Los orígenes del totalitarismo, Madrid, Taurus.

- Arendt, Hannah (2008). La condición Humana, Buenos Aires - Barcelona - México, Editorial Paidós.

- Ball, Stephen (1990). Foucault y la educación. Disciplinas y saber, Madrid, Paideia.

- Bavio, Ernesto (1886). "Lo que debe ser el Maestro. Necesidad de las Escuelas Normales", en La Educación, periódico quincenal, Año I, Número 11, Buenos Aires, Julio de 1886.

- Bayer, Claude (1992). La enseñanza de los juegos deportivos colectivos, Barcelona, Editorial Hispano Europea S.A.

- Behares, Luis Ernesto y Rodríguez Giménez, Raumar comp. (2008). Cuerpo, Lenguaje y Enseñanza, Montevideo, UDELAR.

- Berger, Peter y Luckmann, Thomas (1998). La Construcción Social de la Realidad, Buenos Aires, Amorrortu editores.

- Bernardo de Quirós Aragón, Mónica (2006) Manual de Psicomotricidad, Madrid, Ediciones Pirámide. 
- Blázquez Sánchez, Domingo (1989). Evaluar en Educación Física, Madrid, INDE Publicaciones.

- Blázquez Sánchez, Domingo (1998). La iniciación deportiva y el deporte escolar, Barcelona, INDE Publicaciones.

- Bourdieu, Pierre (1991). El sentido práctico, Madrid, Taurus Editores.

- Bourdieu, Pierre (1994a). Sociología y Cultura, México, Grijalbo.

- Bourdieu, Pierre (1994b). "Lección inaugural", impartida el 23-04-1982 en la cátedra de Sociología del Colegio de Francia, en Sociología y Cultura, México, Grijalbo.

- Bourdieu, Pierre, Chamboredon, J.C., Passeron, J.C. (1999). El oficio de sociólogo, Buenos Aires, Siglo XXI.

- Bourdieu, Pierre, Dunning, Eric, y otros (1993) Materiales de Sociología del Deporte, Madrid, La Piqueta.

- Bourdieu, Pierre, y Wacquant, Löic (1995). Respuestas por una antropología reflexiva, México, Grijalbo.

- Burns, Jimmy (1997). La mano de Dios. La vida de Diego Maradona, Buenos Aires, Editorial Planeta.

- Cagigal, José María (1979). Cultura intelectual y cultura física, Buenos Aires, Editorial Kapelusz.

- Canguilhem, Georges (1956). “¿Qué es la Psicología?”, Conferencia en el Collége Phlosophique, 18 de diciembre de 1956, Publicada en Revue de Metáphisique, (Traducción: María Teresa Poyrazian).

- Canguilhem, Georges (1980). "El cerebro y el pensamiento", Conferencia en la Sorbonne para el M.U.R.S. (diciembre de 1980); primera publicación en Prospective et Santé, $n^{\circ} 14$. Los subtítulos que la revista había añadido se han suprimido. El orden de algunos parágrafos que se habían invertido ha sido restablecido según las indicaciones del G. Canguilhem. (N.d.E. en francés). Traducción al español: Ernesto Hernández B., Abril de 2004.

- Caraballo, Ana María y Rodríguez Giménez, Raumar org. (2011). Evocar la falta. La angustia y el deseo del enseñante, Montevideo, Edit. Psicolibros - Waslala. 
- Carretero, Mario (2005). Constructivismo y educación, Zaragoza, Editorial Luis Vives.

- Caruso, Marcelo (2005). La biopolítica en las aulas. Prácticas de conducción en las escuelas elementales del Reino de Baviera, Alemania (1869-1919), Buenos Aires, Prometeo Libros.

- Castro, Edgardo (2005). Michel Foucault: La cuestión del Humanismo, inédito.

- Castro, Edgardo (2006). El vocabulario de Michel Foucault: un recorrido alfabético por sus temas, conceptos y autores, Buenos Aires, Prometeo.

- Castro, Edgardo (2007). "Biopolítica y Gubernamentalidad", en Revista Temas \& Matizes, Dossiê Biopolítica, número 11, primeiro semestre de 2007, Unioeste, Brasil. pp. 8 a 18.

- Castro, Edgardo (2008). Giorgio Agamben. Una arqueología de la potencia, Buenos Aires, UNSAM Edita.

- Coll, César coord. (1998). Psicología de la Educación, Barcelona, EDHASA.

- Coll, César (1988). Conocimiento psicológico y práctica educativa. Introducción a las relaciones entre psicología y educación, Barcelona, Edit. Barcanova.

- Corraze, Jacques (1988). Las bases neuropsicológicas del movimiento, Barcelona, Editorial Paidotribo.

- Cratty, Bryant (1982). El desarrollo perceptual y motor de los niños, Barcelona, Paidós.

- Crisorio, Ricardo (1995). "Enfoques para el abordaje de los CBC desde la Educación Física", Serie Pedagógica № 2, FaHCE - UNLP, La Plata, Argentina.

- Crisorio, Ricardo (2003). "Educación física y Epistemología", en La Educación Física en Argentina y en Brasil. Identidad, desafíos y perspectivas, La Plata, Al Margen Editores.

- Crisorio, Ricardo (2003). La Educación Física en Argentina y Brasil. Identidad, desafíos y perspectivas, La Plata, Al Margen Editores. 
- Crisorio, Ricardo (2003). Protocolo de "El aprendizaje motor: un problema epigenético", Programa de Incentivos a la docencia y la investigación, MCyE, UNLP, Argentina.

- Crisorio, Ricardo (2005). Informe final de "El aprendizaje motor: un problema epigenético", Programa de Incentivos a la docencia y la investigación, MCyE, UNLP, Argentina.

- Crisorio, Ricardo (2007). "Educación Física y Biopolítica", en Revista Temas \& Matizes, Dossiê Biopolítica, número 11, primeiro semestre de 2007, Unioeste, Brasil, pp. 67 a 78.

- Crisorio, Ricardo (2012). Educación Corporal, inédito.

- Crisorio, Ricardo y Giles Marcelo dir. (2009). Estudios críticos de Educación Física, La Plata, Al Margen.

- D’Angelo, Rinty; Carabajal, Eduardo y Marchilli, Alberto (2000) Una introducción a Lacan, Buenos Aires, Lugar editorial.

- Daryl, Philippe (1888). Rennaissance physique, 1ํvol, in 16º, París, Hetzel.

- Dreyfus, Hubert (1990). Ser en el mundo. Comentarios a la división I de Ser y Tiempo de M. Heidegger, Santiago de Chile, Cuatro Vientos editorial.

- Eidelsztein, Alfredo (2001). Las estructuras clínicas a partir de Lacan, Vol. I, Buenos Aires, Letra Viva Editorial.

- Elias, Norbert (1993). El Proceso de la Civilización. Investigaciones Sociogenéticas y Psicogenéticas, México, Fondo de Cultura Económica.

- Elias, Norbert, y Dunning, Eric (1996). Deporte y ocio en el proceso de la civilización, México, Fondo de Cultura Económica.

- Esposito, Roberto (2006). Bíos. Biopolítica y filosofía, Buenos Aires - Madrid, Amorrortu editores.

- Esposito, Roberto (2007). Communitas. Origen y destino de la comunidad, Buenos Aires-Madrid, Amorrortu Editores.

- Esposito, Roberto (2009). Comunidad y violencia, Madrid, Circulo de Bellas Artes. 
- Esposito, Roberto (2009). Tercera persona. Política de la vida y filosofía de lo impersonal, Buenos Aires - Madrid, Amorrortu editores.

- Famose, Jean Pierre (1990). Aprendizaje motor y dificultad en la tarea, Barcelona, Editorial Paidotribo.

- Ferrater Mora, José (1964). Diccionario de Filosofía, Buenos Aires, Sudamericana.

- Foucault, Michel (1977). "El nacimiento de la medicina social", en Revista Centroamericana de ciencias de la Salud, № 6, Río de Janeiro, pp. 89-108.

- Foucault, Michel (1966). Las palabras y las cosas: una arqueología de las ciencias humanas, México, Siglo XXI.

- Foucault, Michel (1989). Vigilar y Castigar, Buenos Aires, Siglo XXI editores.

- Foucault, Michel (1991). Saber y Verdad, Madrid, La Piqueta.

- Foucault, Michel (1992). Genealogía del Racismo, Madrid, La Piqueta.

- Foucault, Michel (1992). Microfísica del poder, Madrid, La Piqueta.

- Foucault, Michel (1996a). La vida de los hombres infames, La Plata, Editorial Altamira.

- Foucault, Michel (1996b). ¿Qué es la llustración?, Madrid, La Piqueta.

- Foucault, Michel (2002). La arqueología del saber, Madrid, Siglo XXI Editores.

- Foucault, Michel (2004). Nietzsche, la genealogía, la historia, Valencia, PreTextos.

- Foucault, Michel (2007). Nacimiento de la biopolítica. Curso en el Collège de France (1978-1979), Buenos Aires, Fondo de Cultura Económica.

- Foucault, Michel (2008). Historia de la sexualidad. Tomo 1. La voluntad de saber, Buenos Aires, Siglo XXI editores.

- Foucault, Michel (2008). Tecnologías del yo y otros textos afines, Barcelona Buenos Aires - México, Ediciones Paidós Ibérica s.a.

- Foucault, Michel (2010). Defender la sociedad, México - Argentina - Brasil Colombia - Chile - España - Estados Unidos de América - Perú - Venezuela, Fondo de Cultura Económica. 
- Gallahue, David y Mc. Clenaghan, Bruce (1986). Movimientos fundamentales. Su desarrollo y rehabilitación, Buenos Aires, Editorial Médica Panamericana.

- Giddens, Anthony (2000). En defensa de la sociología, Madrid, Alianza.

- Giorgi, Gabriel y Rodríguez, Fermín comps. (2007) Ensayos sobre biopolítica. Excesos de vida, Buenos Aires - Barcelona - México, Paidós.

- Gómez, Raúl Horacio (2000). El aprendizaje de las habilidades y esquemas motrices en el niño y el joven. Significación, estructura, psicogénesis, Buenos Aires, Editorial Stadium.

- Grosser, Manfred y Neumaier, August (1986). Técnicas de entrenamiento. Teoría y práctica de los deportes, Barcelona, Ediciones Martínez Roca s.a.

- Grüner, Eduardo (1995). "Michel Foucault: una política de la interpretación", en Foucault, Michel, Freud, Nietsche y Marx, Buenos Aires, Editorial El cielo por asalto.

- Hamersley, Martin y Atkinson, Paul (1994). Etnografía: Métodos de investigación, Barcelona, Paidós.

- Hughes, John y Sharrock, Wes (1999). La filosofía de la investigación social, México, Fondo de Cultura Económica.

- Kaplan, Carina y Kaplan, Demián (1996). "Deportes y distinciones de clase, fútbol para las escuelas de los pobres y rugby para las escuelas de los ricos", en Revista Digital EFDeportes.com año 1, ํㅡ․

- Knap, Bárbara (1963). La habilidad en el deporte, Valladolid, Editorial Miñon.

- Kojève, Alexandre (1999). La Dialéctica del amo y el esclavo en Hegel, Buenos Aires, Fausto Ediciones.

- Lacan, Jacques (1953-54). El Seminario. Libro 1. Paidos, Buenos Aires-BarcelonaMéxico, 1990.

- Lacan, Jacques (1956-57). El Seminario. Libro 4. Paidos, Barcelona-Buenos Aires-México, 1994.

- Lacan, Jacques (1957-58). El Seminario. Libro 5. Paidos, Buenos Aires, 1999

- Lacan, Jacques (1977). La Familia (1), El complejo, Buenos Aires, Homo Sapiens. 
- Lacan, Jacques (1985). La agresividad en psicoanálisis, Escritos, México, Siglo XXI.

- Lacan, Jacques (1988). Reseñas de enseñanza, Buenos Aires, Manantial.

- Lacan, Jaques (2005). El triunfo de la religión, Buenos Aires, Paidós.

- Lacan, Jacques (2007). Mi enseñanza, Buenos Aires - Barcelona - México, Paidós.

- Lacan, Jacques (2011). El Seminario de Jaques Lacan. Libro 10. La Angustia, Paidós, Buenos Aires, Barcelona, México.

- Lawther, John (1968). El aprendizaje de las habilidades motrices, Barcelona Paidós.

- Le Blanc, Guillaume (1998). Canguilhem y las normas, Buenos Aires, Ediciones Nueva Visión.

- Le Boulch, Jean (1984). La Educación por el movimiento en la edad escolar, Barcelona - Buenos Aires - México, Paidós.

- Le Boulch, Jean (1991a). El deporte educativo. Psicocinética y aprendizaje motor, Buenos Aires, Paidós.

- Le Boulch, Jean (1991b). Hacia una ciencia del movimiento humano, Buenos Aires, Paidós.

- Le Boulch, Jean (1995). "Psicocinética, Educación Física y 'APS' (Actividad Física Deportiva)", en Actas del Primer Congreso Argentino de Educación Física y Ciencia, La Plata, Facultad de Humanidades y Ciencias de la Educación, Universidad Nacional de La Plata.

- Mangione, Oscar (2002). Gabriel Batistuta, Perfil de un crack que se construyó a sí mismo, Buenos Aires, Editorial Sudamericana.

- Manzo, Silvia (2008). Los usos políticos del cuerpo - los dos cuerpos del rey en la filosofía política de Francis Bacon, Belo Horizonte, Kriterión.

- Marradi, Alberto (2007). Metodología de las Ciencias Sociales, Buenos Aires, EMECE. 
- Maturana, Humberto (1996). El sentido de lo humano, Santiago de Chile, Dolmen Ediciones.

- Mc Clenaghan, Bruce y Gallahue, David (1986). Movimientos fundamentales. Su desarrollo y rehabilitación, Buenos Aires, Editorial Médica Panamericana.

- Meinel, Kurt y Schnabel, Günter (1988). Teoría del Movimiento. Síntesis de una teoría de la motricidad deportiva bajo el aspecto pedagógico, Argentina, Editorial Stadium.

- Parlebas, Pierre (1988). Elementos de sociología del deporte, Málaga, Junta de Andalucía/Universidad Nacional Deportiva de Andalucía.

- Pestalozzi, Johann Heinrich (2006). Cartas sobre Educación infantil, Madrid, Tecnos.

- Pozo, Juan Ignacio (2006). Teorías cognitivas del Aprendizaje, Madrid, Morata.

- Rabinovich, D., 1993, La angustia y el deseo del Otro, Buenos Aires, Manantial.

- Revel, Judith (2008). Diccionario Foucault, Buenos Aires, Ediciones Nueva Visión.

- Revel, Judith (2008). El vocabulario de Foucault, Buenos Aires, Atuel.

- Rigal, Robert (2006). Educación motriz y psicomotriz en preescolar y primaria, Barcelona, INDE Publicaciones.

- Rocha Bidegain, Liliana (2009). "Psicomotricidad y Educación Física", en Crisorio, Ricardo y Giles, Marcelo dir. Estudios críticos de Educación Física, La Plata Al Margen editores.

- Rockwell, Elsie (1987). Reflexiones sobre el proceso etnográfico, Departamento de Investigaciones Educativas, México, Centro de Investigación y Estudios Avanzados de IPN.

- Roudinesco, Élisabeth (2007). Filósofos en la tormenta, Buenos Aires, Fondo de Cultura Económica.

- Roudinesco, Élisabeth (2007). "Georges Canguilhem: una filosofía del heroísmo", en Filósofos en la tormenta, Buenos Aires, Fondo de Cultura Económica.

- Ruiz Pérez, Luís Miguel (1987). Desarrollo Motor y actividades Físicas, Madrid, Gymnos. 
- Ruiz Pérez, Luis Miguel (1997). Deporte y Aprendizaje. Proceso de adquisición y desarrollo de habilidades, Madrid, Visor Dis S.A.

- Sáiz, Milagros (2009). Historia de la psicología, Barcelona, Editorial UOC.

- Sánchez Bañuelos, Fernando (1986). Bases para una didáctica de la educación física y el deporte, Madrid, Gymnos Editorial.

- Santamaría, Carlos (2009). Historia de la Psicología. El nacimiento de una ciencia, Barcelona, Editorial Ariel.

- Silva, Héctor (2001). Pasión y Coraje. Historia personal de los Pumas, Buenos Aires, Editorial Sudamericana.

- Singer, Robert (1986). El aprendizaje de las acciones motrices en el deporte, Barcelona, Editorial hispano europea, s.a.

- Stenhouse, Lawrence (1984). Investigación y desarrollo del curriculum, Madrid, ediciones Morata.

- Sternberg, Robert (1982). Inteligencia humana, I. La naturaleza de la inteligencia y su medición. Cognición y desarrollo humano, Barcelona - Buenos Aires - México, Paidós.

- Suaudeau, René (1960). Los nuevos métodos de la educación física, Buenos Aires, Editorial Paidós.

- Valdés, Teresa (1988). Venid, benditas de mi padre. Las pobladoras, sus rutinas y sus sueños, Chile, FLACSO, Facultad Latinoamericana de Ciencias Sociales.

- Voltolini, Rinaldo (2008). "Enseñanza y Transmisión”, en Behares, Luis y Rodríguez Jiménez, Raumar, Cuerpo, Lenguaje y Enseñanza, Montevideo, Facultad de Humanidades y ciencias de la Educación, UDELAR.

- Willis, Paul (1980). Culture, Media, Language, London, Hutchinson.

- Zevi, Susana (2000). Aprendizaje Motor. Maduración y Desarrollo, Buenos Aires, Edic. del autor. 